\title{
Impact of relative permeability on the outcomes of natural gas production from low permeability reservoir
}

\author{
Melaine Edouard Kolimedje \\ West Virginia University
}

Follow this and additional works at: https://researchrepository.wvu.edu/etd

\section{Recommended Citation}

Kolimedje, Melaine Edouard, "Impact of relative permeability on the outcomes of natural gas production from low permeability reservoir" (2012). Graduate Theses, Dissertations, and Problem Reports. 3359. https://researchrepository.wvu.edu/etd/3359

This Thesis is protected by copyright and/or related rights. It has been brought to you by the The Research Repository @ WVU with permission from the rights-holder(s). You are free to use this Thesis in any way that is permitted by the copyright and related rights legislation that applies to your use. For other uses you must obtain permission from the rights-holder(s) directly, unless additional rights are indicated by a Creative Commons license in the record and/ or on the work itself. This Thesis has been accepted for inclusion in WVU Graduate Theses, Dissertations, and Problem Reports collection by an authorized administrator of The Research Repository @ WVU. For more information, please contact researchrepository@mail.wvu.edu. 
Impact of relative permeability on the outcomes of natural gas production from low permeability reservoir.

\author{
Melaine Edouard KOLIMEDJE
}

Thesis Submitted to

Benjamin M. Statler College of Engineering and Mineral Resources at West Virginia University

In partial fulfillments of the requirements

for the degree of

Master of Science

in Petroleum and Natural Gas Engineering

H. Ilkin Bilgesu PhD., Chair

Khashayar Aminian, PhD.

Samuel Ameri, M.S.

Department of Petroleum and Natural Gas Engineering

Morgantown, West Virginia 2012

Keywords: Relative permeability, modeling, tight gas sand, gas production

Petroleum and Natural Gas Engineering Copyright 2012 Melaine Edouard KOLIMEDJE 


\section{ABSTRACT}

\section{Impact of relative permeability on the outcomes of natural gas production from low permeability reservoir.}

\section{Melaine Edouard. KOLIMEDJE}

Tight Gas Reservoir (TGR) is one of the primary types of unconventional reservoirs now accounting for about $25 \%$ of US gas production. The complexity of the reservoir leads to low productivity issues and thus there is a need to thoroughly understand all the parameters of uncertainty. One of the prime factors affecting productivity is the relative permeability. In this study, the effect of relative permeability on cumulative gas production for gas-water phase was studied in detail using a numerical computer simulation study.

In an effort to comprehend the impact of the relative permeability on gas production over the life of these reservoirs, the effects of the relative permeability curve on cumulative gas produced from different types of wells were evaluated using field data obtained from 11 different relative permeability curves generated by Corey's correlation. Unlike many previous studies that simply assume a linear shape, the relative permeability curves used for our study are quite non-linear. In this study, commercially available software, simulating multi-phase flow is used to determine the impact of relative permeability on gas-water two-phase flow for two different well designs: a horizontal well with and without fracture treatments and a vertical well. Additionally the volume of water production was also varied. The model has been run for 60 years to predict gas production. Finally, results showing the impact of the relative permeability on the predicted gas production have been discussed. 


\section{ACKNOWLEDGEMENTS}

First and foremost, I would like to thank and express my sincere gratitude to my research advisor, Dr. Ilkin Bilgesu, for providing direction and for relentlessly motivating me throughout this research work and my graduate study at West Virginia University. His professionalism and knowledge of the subject of research is splendid. His professional assistance and advice are greatly appreciated.

I would also like to thank the other members of my research committee. I strongly appreciate the constant financial support and advice from Professor Sam Ameri, Department Chair, Petroleum and Natural Gas Engineering department. He has been as a father and as a friend throughout my study at the university. I greatly appreciate the continuous support from Dr. Khashayar Aminian, for his wisdom and excellent communications skills as an educator. He has greatly impacted my academic life. It is my pleasure and honor to have him on my committee.

I would like to thank everyone in the Department of Petroleum and Natural Gas Engineering. My sincere appreciation also goes to my parents for their unconditional love, financial and moral supports, prayers and advice throughout my endeavors in life. I cannot thank you enough. I also thank my brother Florent G. Kolimedje for his understanding, his financial and his moral support.

I also dedicate this work to my brothers, sisters and my friends who are always there for me. My sincere gratitude also goes to my friend Ali Omran Ali Nasar.

Above all, this work is offered to God for his greater glory. 


\section{Table of Contents}

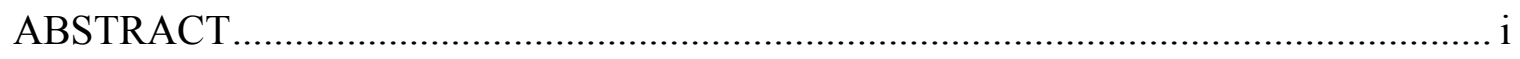

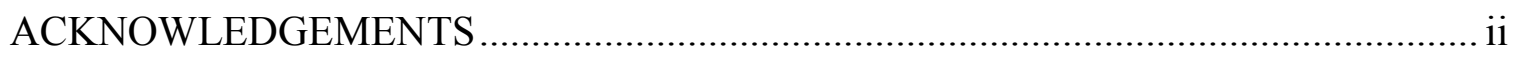

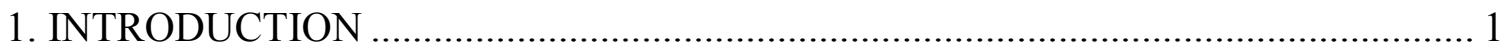

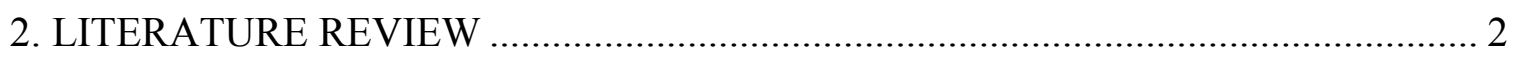

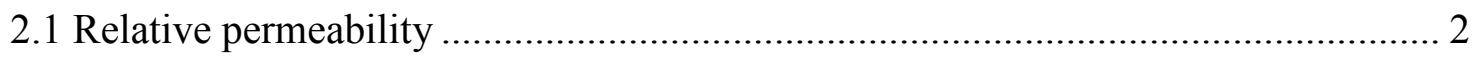

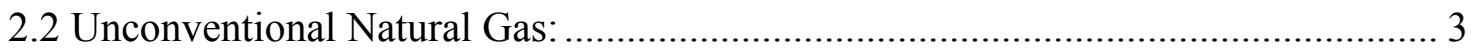

2.3 Tight Gas in the United States............................................................................ 5

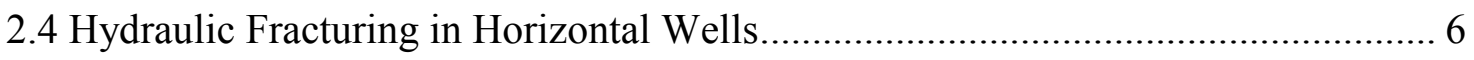

2.5 Relative Permeability measurement for two Phases-Flows ....................................... 7

2.5.1 Case Study of Steady-State Method ........................................................... 8

2.6 Factors Affecting Production Behavior in Tight Gas Reservoirs ........................... 10

2.6.1 Fracture conductivity and Fracture Permeability …………............................ 10

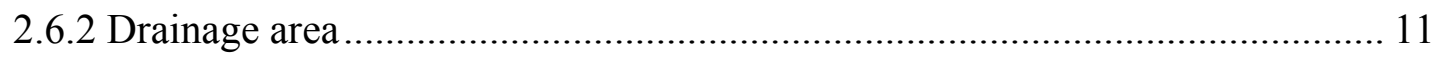

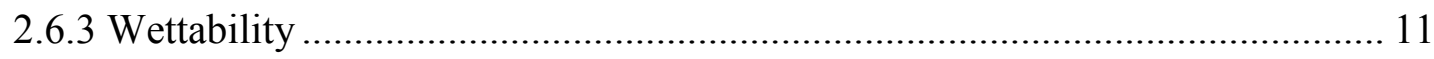

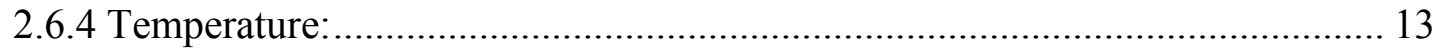

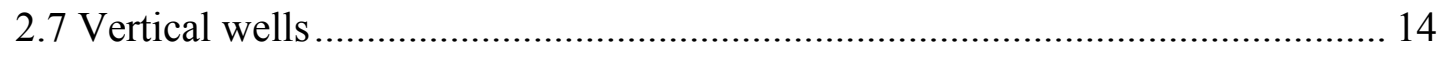

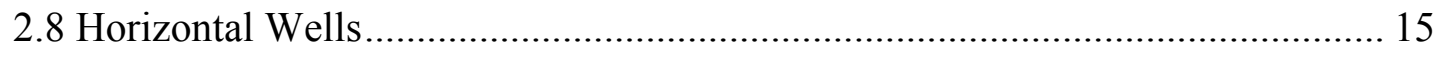


3.1 Overview 19

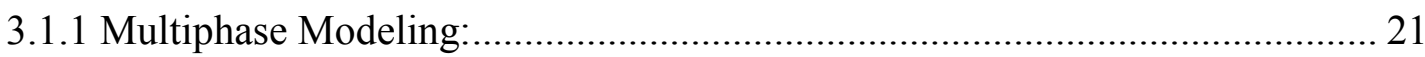

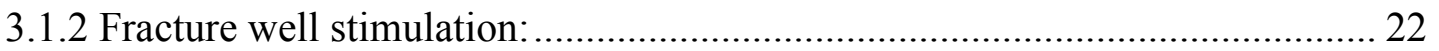

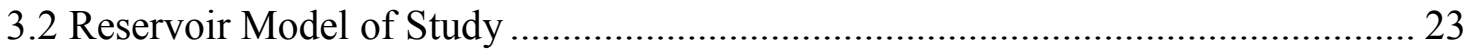

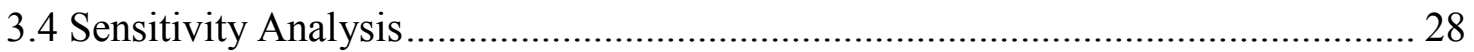

3.4.1 Effect of Relative Permeability on gas-water flow: .................................. 28

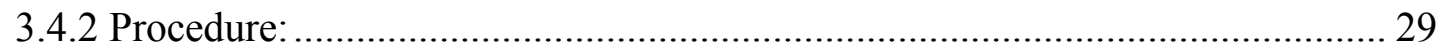

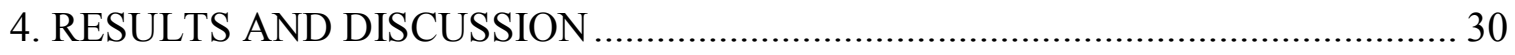

4.1 Tight Gas Reservoir with a vertical Well...................................................... 30

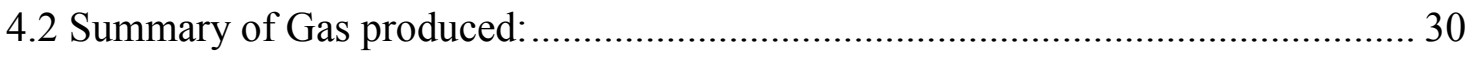

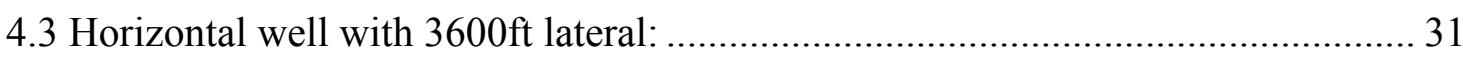

4.4 Horizontal well fracture treatment with $3600 \mathrm{ft}$................................................ 33

4.5 Cumulative gas production from horizontal well of length $2000 \mathrm{ft}$...................... 35

4.6 Horizontal well fracture treatment with $2000 \mathrm{ft}$ lateral ..................................... 37

4.7 Cumulative gas production from Vertical well: ........................................... 39

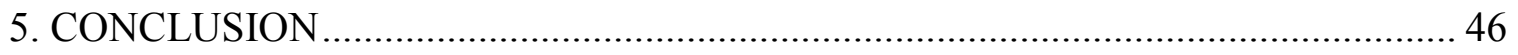

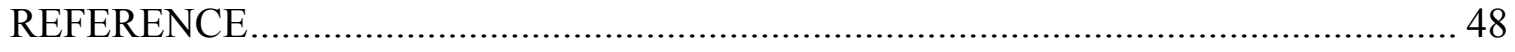

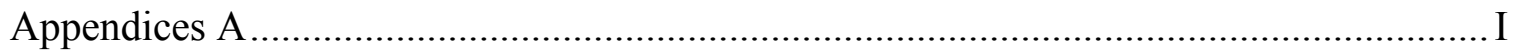


Appendices B. XXII

Appendices C ..............................................................................................

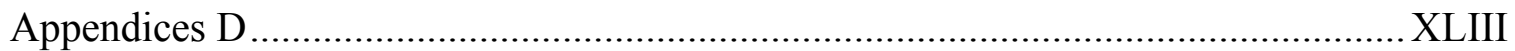




\section{List of Tables}

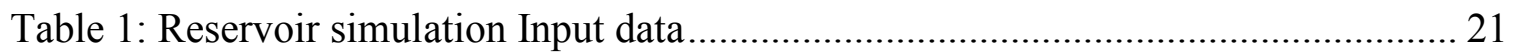

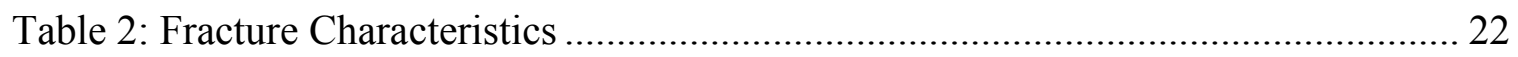

Table 3: Cumulative gas production values at the end of 60 years ............................... 31

Table 5: Cumulative gas produced from horizontal well of $3600 \mathrm{ft}$................................. 32

Table 6: Cumulative gas produced from horizontal fracture well of $3600 \mathrm{ft}$.................. 34

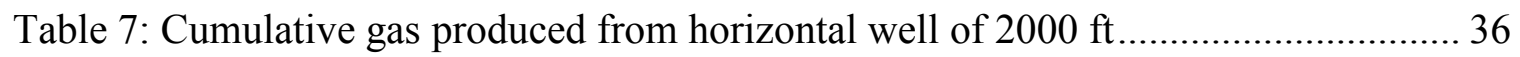

Table 8: Cumulative gas produced from horizontal fracture well of $2000 \mathrm{ft}$................. 38

Table 9: Cumulative gas produced from Vertical well ........................................... 40 


\section{List of Figures}

Figure 1: Unconventional gas sources in the Rocky Mountains (EIA, U.S Crude Oil, Natural Gas liquids Reserves, 2002 Annual Report)...................................................... 3

Figure 2: Resource Triangle (Holditch, SA 2006) .................................................... 4

Figure 3: Tight gas sands production Charts (source: modified from American clean sides, summer 2008) http://emd.aapg.org/technical_areas/tightGasProductionChart.jpg 6

Figure 4: Two phase relative permeability apparatus (Van Spronsen 1982)................... 9

Figure 5: Effect of Wettability on relative permeability curves at reservoir conditions (Ahmed Gawish \& Emad Al-Homadhi) 12

Figure 6: Effect of temperature on relative permeability curves at water conditions (Ahmed Gawish \& Emad Al-Homadhi)

Figure 7: horizontal well configuration (Oilandgasevaluationreport.com) 15

Figure 8: vertical well configuration (Energy Information Administration,Office of Oil and Gas) 16

Figure 9: Dynamic balance of non-Darcy and multiphase gas permeability (Barree \& Associates and M.W Conway, Stim Lab) 18

Figure 10: Reservoir simulation model 24

Figure 11: Modeling well fracture of $2000 \mathrm{ft}$ 25

Figure 12: Reservoir Simulation rectangular area .................................................... 26

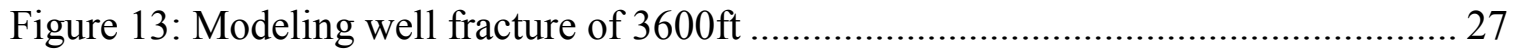

Figure 14: Reservoir simulation rectangular drainage area ....................................... 28

Figure 15: Cumulative gas produced from horizontal well of $3600 \mathrm{ft}$ 32 
Figure 16: Gas produced from horizontal fracture treated well of $3600 \mathrm{ft}$

Figure 17: Cumulative gas produced from horizontal well of $2000 \mathrm{ft}$ 37

Figure 18: Cumulative gas produced from horizontal treated fracture well of $2000 \mathrm{ft}$.... 39

Figure 19: Cumulative gas produced from vertical well 41

Figure 20: Horizontal well of $3600 \mathrm{ft}$ without/with fracture treatment. Xxxviiii

Figure 21: Horizontal well of $2000 \mathrm{ft}$ without and with fracture treatment..........xxxx

Figure 22: Comparison of 2 different lateral lengths of horizontal well without fracture $(2000 \mathrm{ft}$ and $3600 \mathrm{ft})$ $\operatorname{xxxxi}$

Figure 23: Comparison of 2 different lateral lengths of horizontal well with fracture

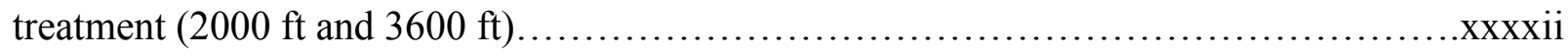




\section{INTRODUCTION}

There are several parameters that affect flow of fluids in a reservoir. This study investigates impact of relative permeability on natural gas production in different types of wells. In fact relative permeability is one of the critical unknowns in multiphase fluid flow through porous and fractured media. In addition it is a direct measure of the ability of the porous medium to conduct one fluid when two or more fluids are present. This flow property is the composite effect of pore geometry, wettability, fluid saturation, reservoir temperature, reservoir pressure, rock types, porosity and permeability values. Therefore; its impact on gas production must be well understood to have confidence in reservoir simulations and other reservoir models of fractured media. In practice relative permeability curves are also very important in reservoir studies. They are used in predicting production rate and recovery from the reservoirs during all stages of recovery.

However fluid flow through porous and permeable medium is a complex transport process. When the porous medium contains more than one fluid, an effective permeability to each phase flow must be defined and the ability of each fluid to flow is reduced by the presence of the other fluids in the system.

This study uses commercial available modeling software (CMG) to determine the impact of relative permeability on gas production from a horizontal well with different lateral lengths and with and without fracture and and from a vertical well. 


\section{LITERATURE REVIEW}

\subsection{Relative permeability}

Several studies (Gawish and Al-Homadhi, 2008) demonstrate that relative permeability is one of the important properties governing multiphase flow through porous media. Moreover it describes quantitatively the simultaneous flow of multi fluid phases through a porous media. The relative permeability is also defined as the ratio of the effective permeability of the porous medium to the specific (absolute) permeability of the material. It depends upon the fluid saturation levels as a result of the pore space in the porous medium is occupied by one fluid of the multiphase fluid system so that flow of another is impeded and reduced.

Relative permeability is not readily available but some methods are used for its determination. In general, two kinds of laboratory measurement techniques are mostly used, namely, steady state method and unsteady state method. But for an accurate determination of relative permeability, one should know what factors affect its measurement. For example, boundary effects, effects of gas expansion, and the rate effect commonly affect the relative permeability measurement. 


\subsection{Unconventional Natural Gas:}

Figure 1 shows the U.S natural gas reserves in different states from 1977 to 2001.

It can be inferred from this graph that there is a huge amount of natural gas reserves in U.S, which remain unexploited, and more is being discovered.

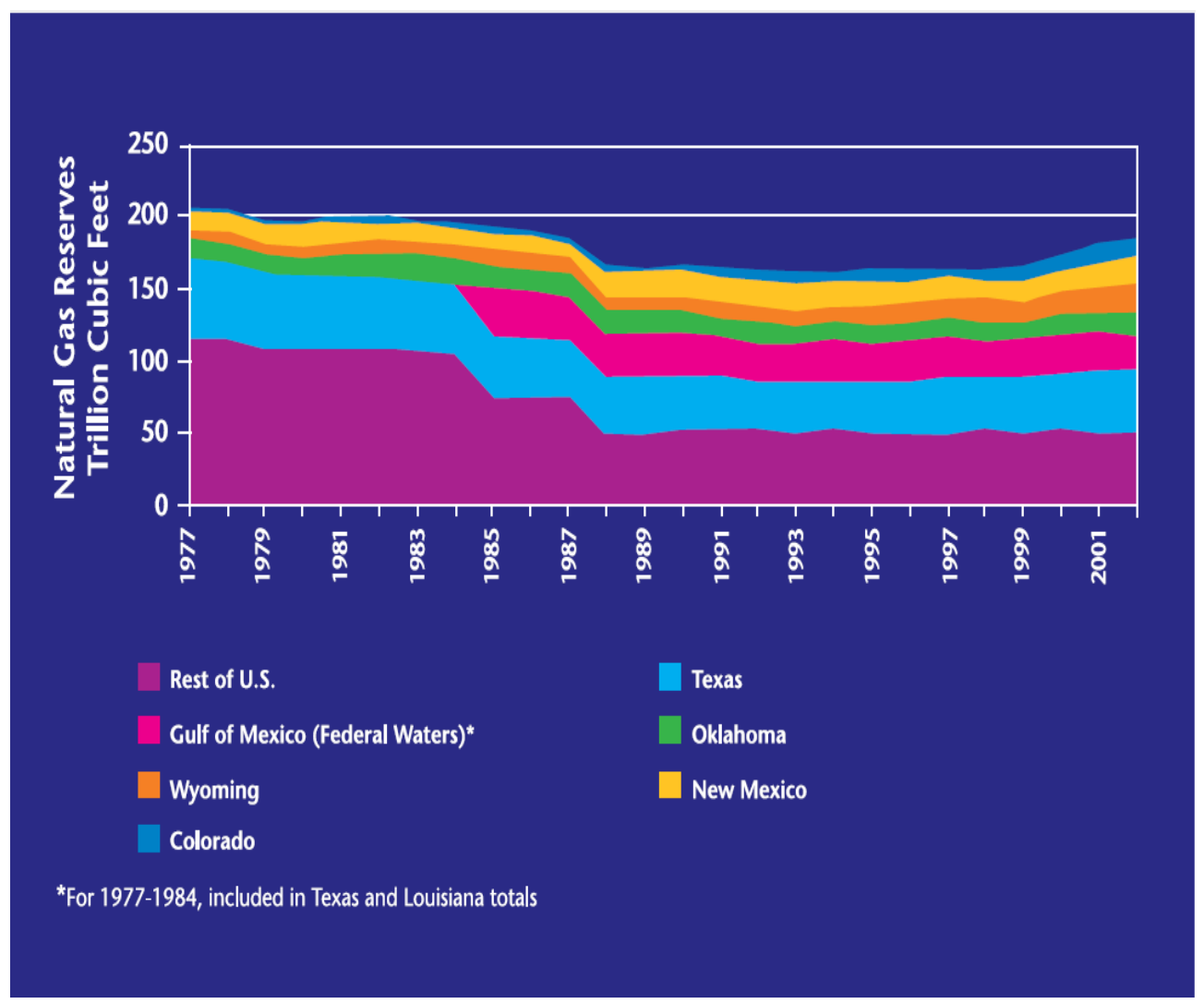

Figure 1: Unconventional gas sources in the Rocky Mountains (EIA, U.S Crude Oil, Natural Gas liquids Reserves, 2002 Annual Report).

Previous studies have shown that unconventional natural gas is more difficult and less economical to extract, usually because the technology to reach it has not been fully developed. Several authors showed prior to 1978 that natural gas in the Anadarko basin 
was virtually untouched because it wasn't economical or possible to extract it. Additionally it has been shown that the economics of extraction plays a role in determining whether or not a particular deposit may be unconventional, or simply too costly to extract. However unconventional reservoirs are larger in volume compared to conventional reservoirs, but difficult to exploit. Figure 2 shows the resource triangle (Holditch, 2006) where it can be seen that when one moves towards unconventional resources, better technology in drilling and development are needed. Unconventional natural gas comprises tight gas reservoirs, deep gas, gas-containing shales, coalbed methane, geopressurized zones, and Arctic and sub-sea hydrates but this study focuses on tight gas formations due to the new interest by industry to exploit these reservoirs.

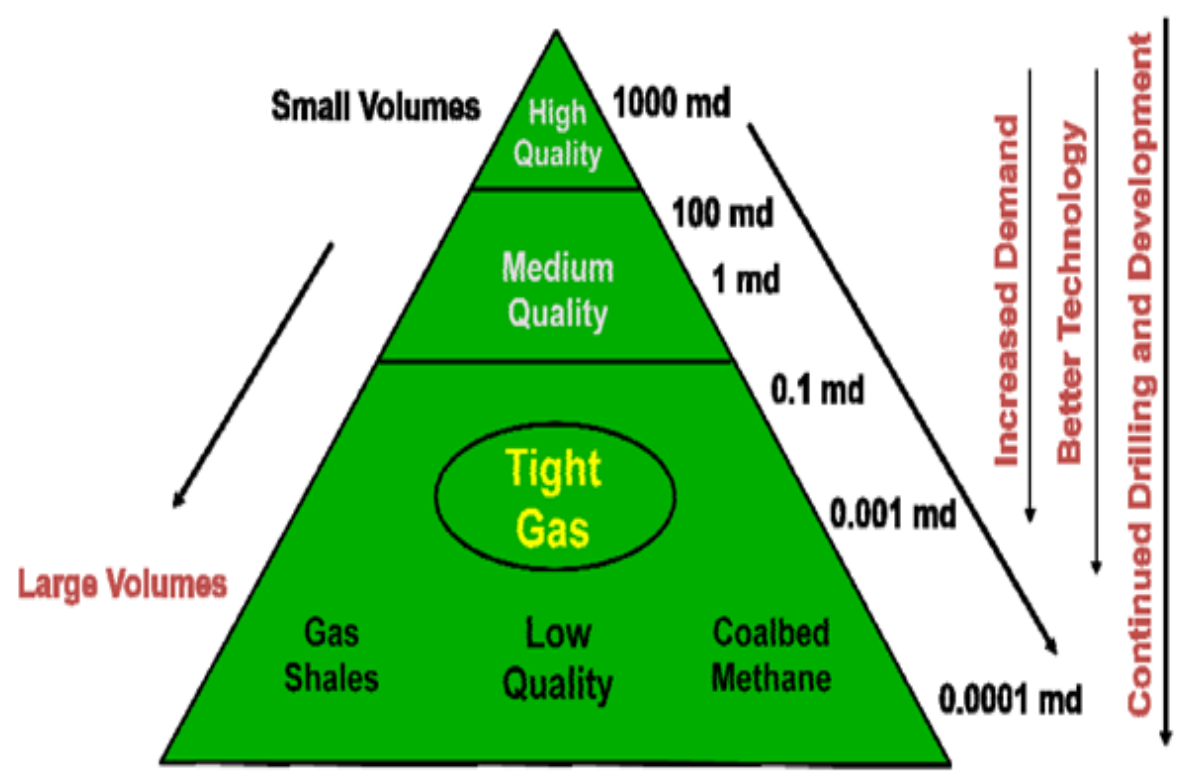

Figure 2: Resource Triangle (Holditch, 2006) 


\subsection{Tight Gas in the United States}

The term tight gas sand refers to low permeability sandstone reservoirs that produce primarily dry natural gas. Several studies have shown that tight gas reservoir is one that cannot be produced at economic flow rates or recover economic volumes of gas unless the well is stimulated by a large hydraulic fracture treatment and/or produced using horizontal wellbores (Holditch, 2006).

In addition, tight gas is usually stored in a very firm formation underground, such as hard rock, or in a sandstone or limestone formation that is unusually impermeable and non-porous (tight sand). Moreover the extraction of gas from tight formation requires more efforts. Various techniques are used to extract the natural gas namely fracturing and acidizing which are very costly. However like all unconventional natural gas, the economic incentive must be there to incite companies to extract this costly gas instead of more easily obtainable, conventional natural gas. A significant portion of the nation's natural gas resource base is made up by tight sand. For instance; many studies have shown that tight sands produce about 6 trillion cubic feet (TCF) of gas per year in the United States which represents $25 \%$ of the total gas produced. As of January, 2009, the U. S. Energy Information Administration (EIA) estimates that 310 TCF of technically recoverable tight gas exists within the U.S, representing over $17 \%$ of the total recoverable gas. Worldwide, more than 7,400 TCF of natural gas is estimated to be contained within tight sands with some estimates as large as 30,000 TCF. The Energy Information Administration (EIA) estimates that 253.83 TCF of technically recoverable deep natural gas exists in the U.S representing over 21 percent of the total recoverable natural gas and it is an extremely important portion of natural gas resources. 
Figure 3 shows that tight gas sands produce about eighteen billion cubic feet of natural gas in U.S per day.

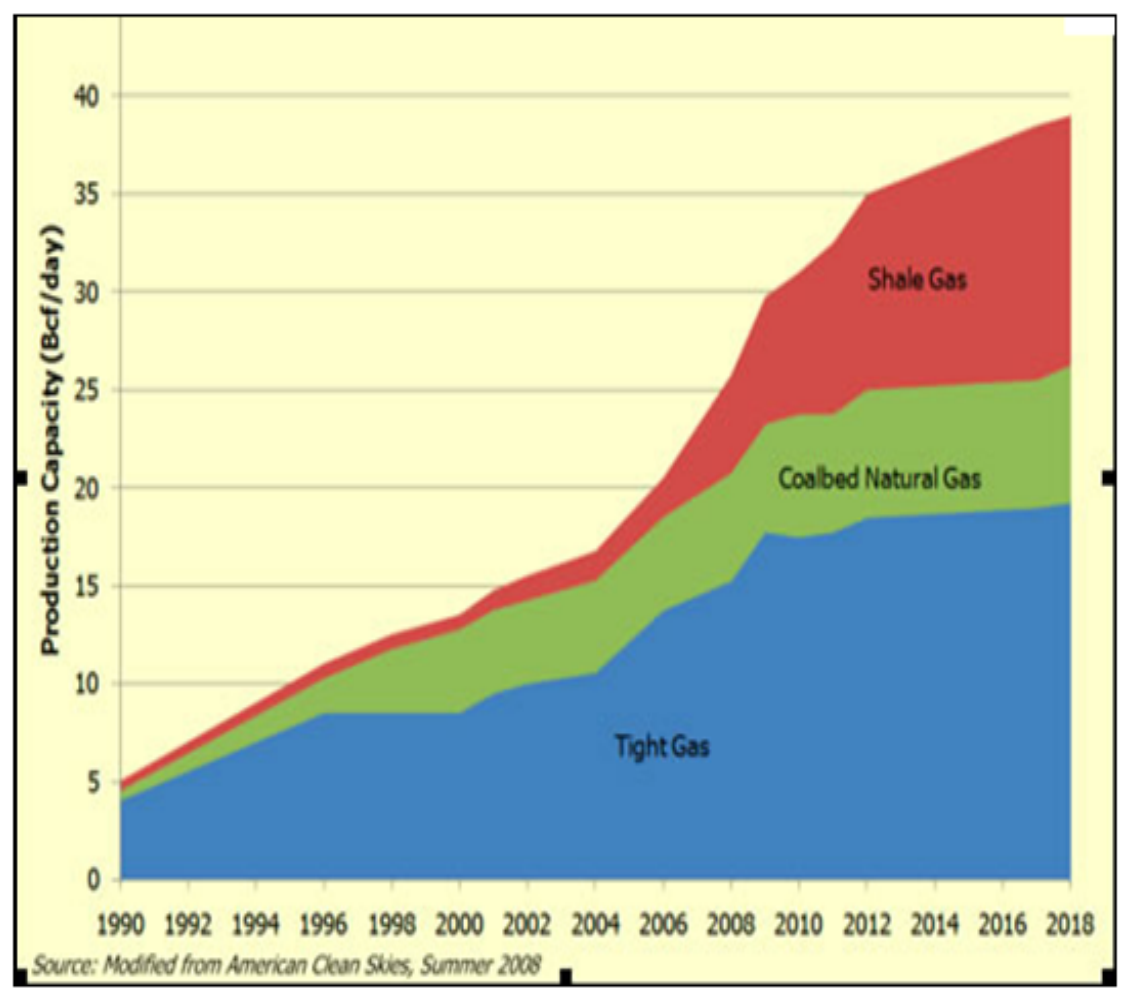

Figure 3: Tight gas sands production charts (http://emd.aapg.org/technical_areas/tightGasProductionChart.jpg)

\subsection{Hydraulic Fracturing in Horizontal Wells}

Hydraulic fracturing in gas reservoirs is a common practice to increase production rate. Multiple fracturing of horizontal wells has been shown to be both a viable and successful approach. In a tight gas naturally fractured reservoir, the productivity of a multi-fractured horizontal well is shown to be several times greater than that achieved by a stimulated vertical well (Yost and Overbey, 1989). Yost and Overbey presented a practical view of the fracturing treatment of a horizontal well in a naturally fractured reservoir. They reported improvement ratios six days after fracture treatments ranging 
from 4 to 35 in different zones along the horizontal wellbore. Multiple hydraulic fracturing is especially beneficial in low permeability gas reservoirs such as tight gas sand reservoir formations to improve productivity. Studies show that tight gas reservoirs (TGR), characterized by permeability lower than $0.1 \mathrm{md}$ is one of the primary types of unconventional reservoirs to be exploited in the search for long-lasting resources.

Researchers have investigated the conditions under which multiple fractures provide significant improvement over a single fracture (Horne et. al., 1995). The study showed that the effectiveness of creating multiple fractures along a horizontal well depends on the relative lengths of the well and number of fractures.

\subsection{Relative Permeability measurement for two Phases-Flows}

Several studies (Honarpour and Mahmood) showed that effective permeability of a permeable medium is a measure of the ability of the material to conduct one fluid phase of a multiphase flow system while the measurement of relative permeability consists of injection at a steady rate of a mixture of gas and liquid into a vertical column of unconsolidated sand.

Various experimental studies showed that despite the multiple methods developed in literature for the determination of relative permeability; only two types of laboratory measurement technique are commonly used to determine relative permeability namely; steady state and unsteady state.

A steady state method which consists of a fixed ratio of two phases is driven simultaneously at constant rate and pressure through the medium until saturation and differential pressure along the sample become constant. This method is in fact; time 
consuming, because the equilibrium attainment may require several hours or days to reach saturation level.

\subsubsection{Case Study of Steady-State Method}

Hassler Method

This is a steady-state method used for relative permeability measurement described by Hassler in 1944. The technique was later studied and modified by Gates and Lietz." Osoba et al., and Josendal et al.. The laboratory apparatus is illustrated in Figure 4 below. Semi permeable membranes are installed at each end of the Hassler test assembly. These membranes keep the two fluid phases separated at the inlet and outlet of the core, but allow both phases to flow simultaneously through the core. The pressure in each fluid phase is measured separately through a semi permeable barrier. By adjusting the flow rate of the non-wetting phase, the pressure gradients in the two phases can be made equal, equalizing the capillary pressures at the inlet and outlet of the core. This procedure is designed to provide a uniform saturation throughout the length of the core, even at low flow rates, and thus eliminate the capillary end effect. The technique works well under conditions where the porous medium is strongly wet by one of the fluids. 


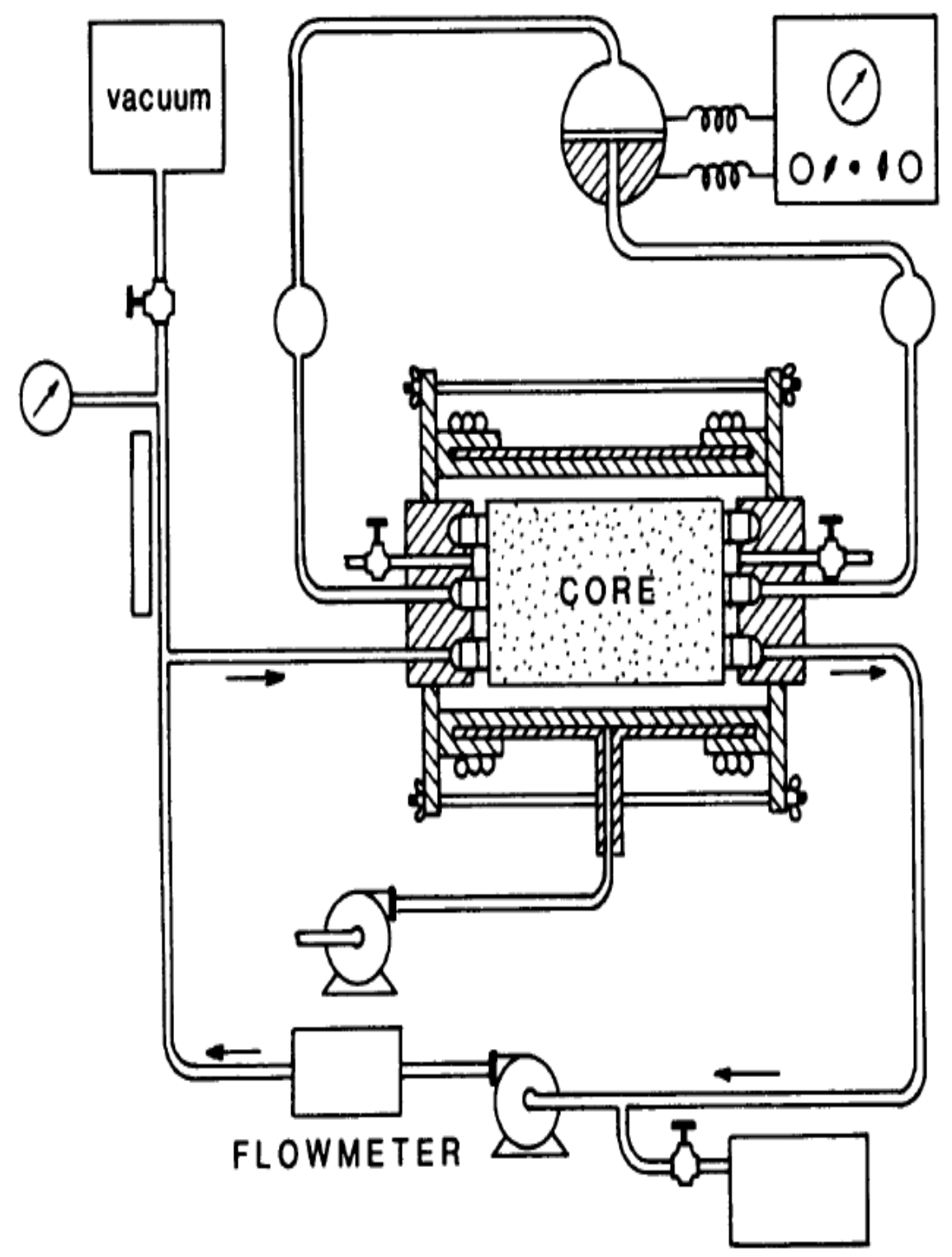

Figure 4: Two phase relative permeability apparatus (Van Spronsen 1982)

Unsteady-state method is the quickest laboratory method in which a gas phase only is injected into the sample and saturation equilibrium is not attained. This technique involves injecting in-situ fluid by injection of the gas phase. The disadvantages of this method are capillary end effect, fingering and scaling effects. 


\subsection{Factors Affecting Production Behavior in Tight Gas Reservoirs}

Different researchers (Waqar Ali Khan \& Shar Abdur Rehman, ) have shown that several factors affect the production behavior of tight gas reservoirs: Drainage area, reservoir permeability, fracture conductivity, porosity, initial water saturation, and net pay are some of the major parameters that affect production from tight gas reservoirs.

Most of the previous studies have shown that reservoir permeability is the primary factor affecting tight gas production forecasts. They have demonstrated that it has a major impact on field development decision and its estimation comes from pressure build up analysis. In many cases, this value is guesstimated from experience or attempt to estimate it from core data.

Transmissibility from Mini Fall-Off analysis is another way of getting accurate value of permeability (Pankaj and Kumar 2010).

\subsubsection{Fracture conductivity and Fracture Permeability}

Previous research works show that fracture conductivity (fc) and fracture permeability are calculated taking into account inertial flow effects causing additional non-Darcy pressure drops which can significantly impact production of a stimulated tight gas well.

They show that fracture conductivity is one of the parameters with a significant effect on production. It depends on many parameters namely fracture geometry, proppant type, fluid-retained permeability, filter cake width, stress on proppant, multiphase flow, and non-Darcy inertial pressure drops. Effective or apparent fc is sensitive to gas rate 
which is an often neglected factor. The increase of effective stress on the proppant causes the fracture conductivity to decrease as the proppant is compressed. It is also dependent on the proppant type.

\subsubsection{Drainage area}

Drainage area has been defined in different ways by different researchers. Based on the study by Ramey et al (1973), drainage area is equivalent to a real sweep for reservoirs under water injection or aquifer drive. In water injection or aquifer drive reservoirs, the drainage area of wells closer to the flood is smaller (Kumar and Anil 1977).

Drainage area in case of a tight gas reservoir may be defined as an isopressure line (Alzate et al 2001). Alzate et al (2001) use 70\% of initial pressure cut-off, and come up with plots of cumulative recovery vs. drainage area.

Cox et al (2005), define drainage area as the area divided between wells, which are spaced for efficiency. They define efficient well spacing as the spacing required to recover $80 \%$ of initial gas in place (GIIP) over a 30 years period.

In tight gas reservoirs, drainage areas are a lot smaller than in permeable reservoirs, and even after long production times the drainage area may be quite limited.

\subsubsection{Wettability}

Several studies (Waqar Ali Khan, Shar Abdur Rehman,Sclumberger) showed that wettability affects relative permeability because it is a major factor in the control of the location, flow, and spatial distributions of the fluids in the core. It determines the relative 
locations of oil and water within the reservoir porous medium. Due to its effect on the oil/water distribution, wettability influences the relative permeability of the flowing fluids.

Figure 5 shows the effect of wettability on relative permeability curves at different reservoir conditions. Four different cases have been studied with oil relative permeability and water relative permeability but all the experiments have been run at the same temperature.

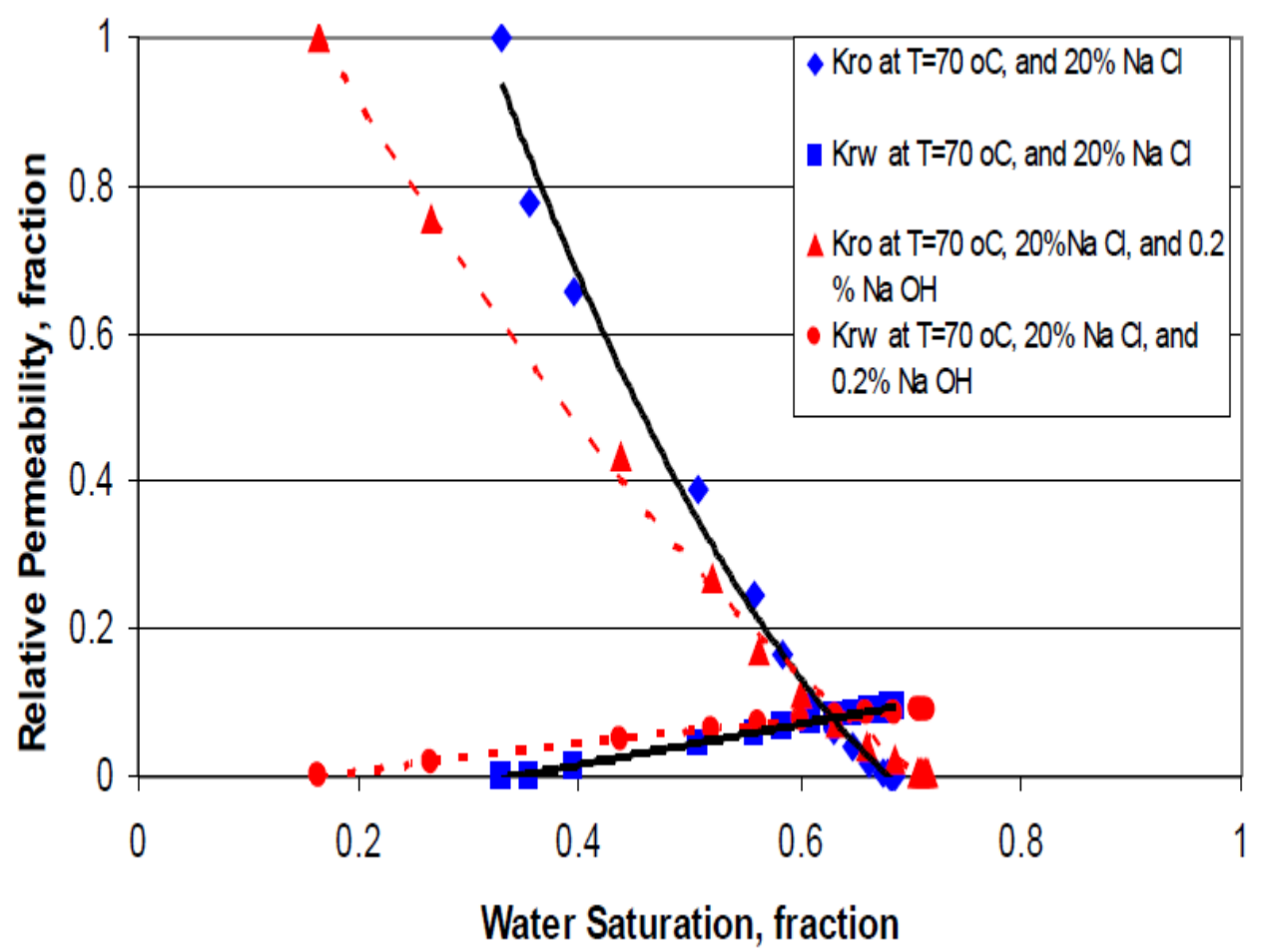

Figure 5: Effect of Wettability on relative permeability curves at reservoir conditions (Ahmed Gawish, Emad Al-Homadi) 


\subsubsection{Temperature:}

Edmondson, Casse and Ramey presented one of the earlier studies on the impact of temperature on relative permeability. Miller M.A. and Ramey H.J. measured dynamicdisplacement relative permeability. The study proves that temperature has no effects. Also [21]-[22] showed consolidated sands water/oil relative permeabilities at temperature ranging from $22^{\circ} \mathrm{C}$ to $175^{\circ} \mathrm{C}$. They found that water/oil relative permeability curves are affected by temperature especially at low interfacial tensions (IFT). The change in wettability of the rock and reduction of the interfacial tension with increasing temperature were important factors in causing the observed changes in the relative permeability curves.

Figure 6 shows the effect of temperature on relative permeability curves at water conditions for different temperatures. 


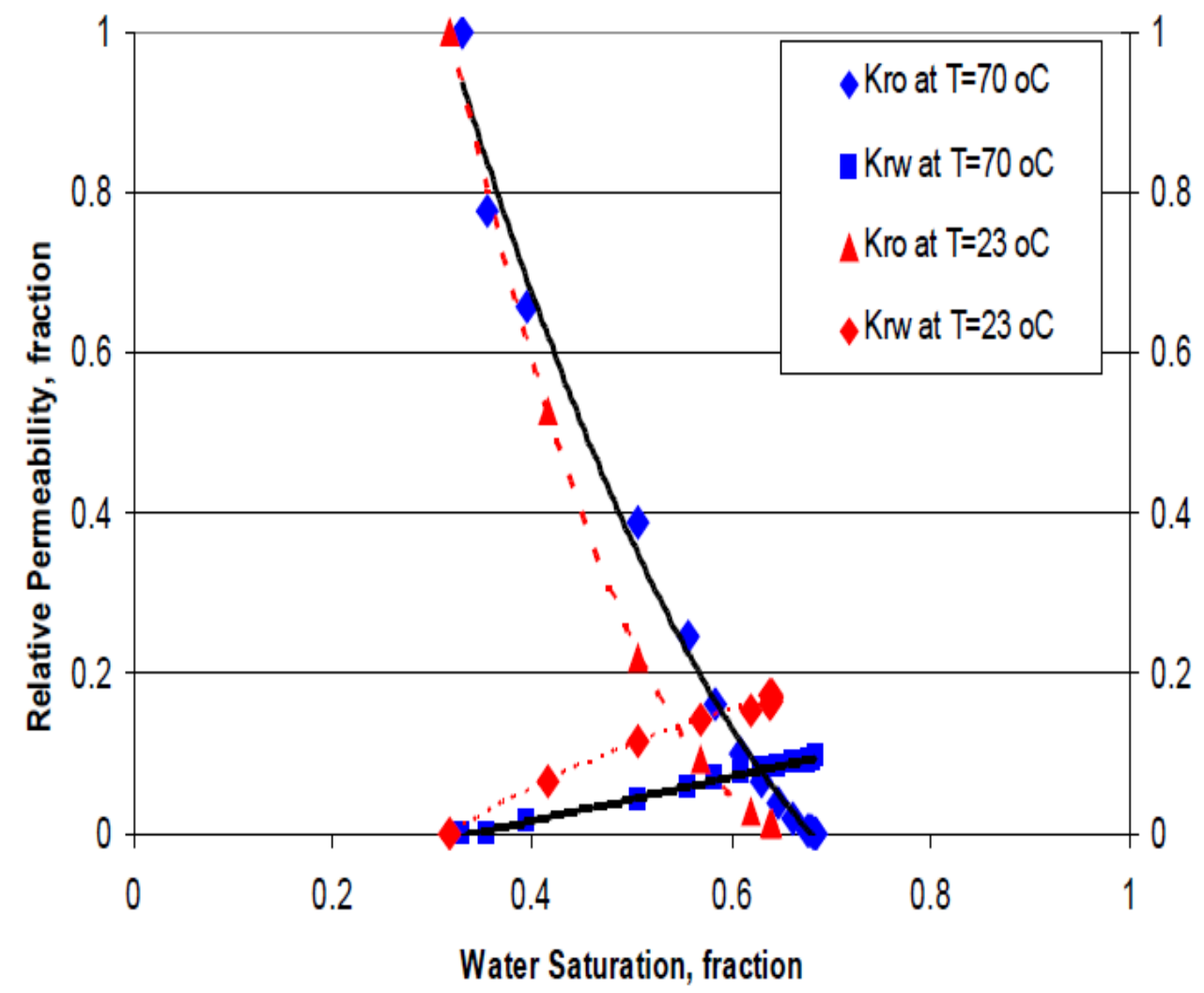

Figure 6: Effect of temperature on relative permeability curves at water conditions (Ahmed Gawish, Emad Al-Homadi)

\subsection{Vertical wells}

Several literature reviews show that in most of the tight gas Sand reservoirs, the wells that have been drilled in the early life of the reservoir are vertical wells. The vertical well drilling technique is used in sandstone reservoirs and can be used in the tight gas sand reservoir. However, there are some differences in drilling methods due to the complexity of the reservoir properties. For vertical wells drilling; the type of formation determines the technique to adopt. The method which is used to drill vertical wells is 
called the rotary drilling technique. This technique works by rotating drill string from surface through formation. Drilling vertical wells in the thick coalbed methane formation has been proven to be more successful than drilling horizontal wells. The thickness ranges from 100 to $200 \mathrm{ft}$ in the thick coal bed methane reservoirs where most vertical wells are drilled. The same observation has been made for tight sand gas reservoirs.

\subsection{Horizontal Wells}

In recent years, horizontal wells have been very successful in increasing productivity, and improving the overall cost-effectiveness of field operations. The horizontal drilling technique is the process of drilling a well from the surface to a subsurface location called the "kickoff point just above the target oil or gas reservoir as shown in Figures $7 \& 8$. After that, the well will deviate toward well bore from the vertical plane around a curve to intersect the reservoir at the "entry point" with a nearhorizontal inclination, and remaining within the reservoir until the desired bottom hole location is reached.

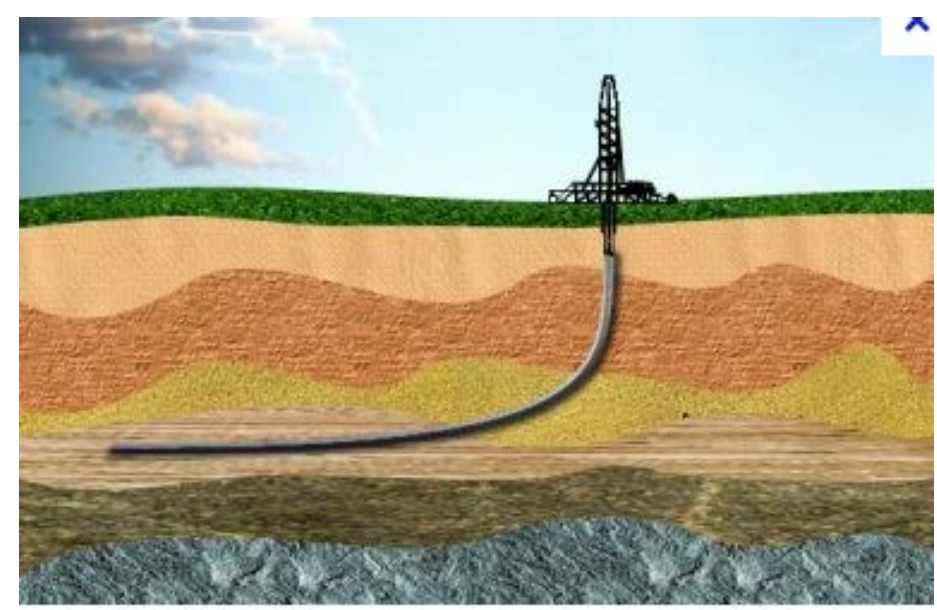

Figure 7: Horizontal well configuration (oilandgasevaluationreport.com) 


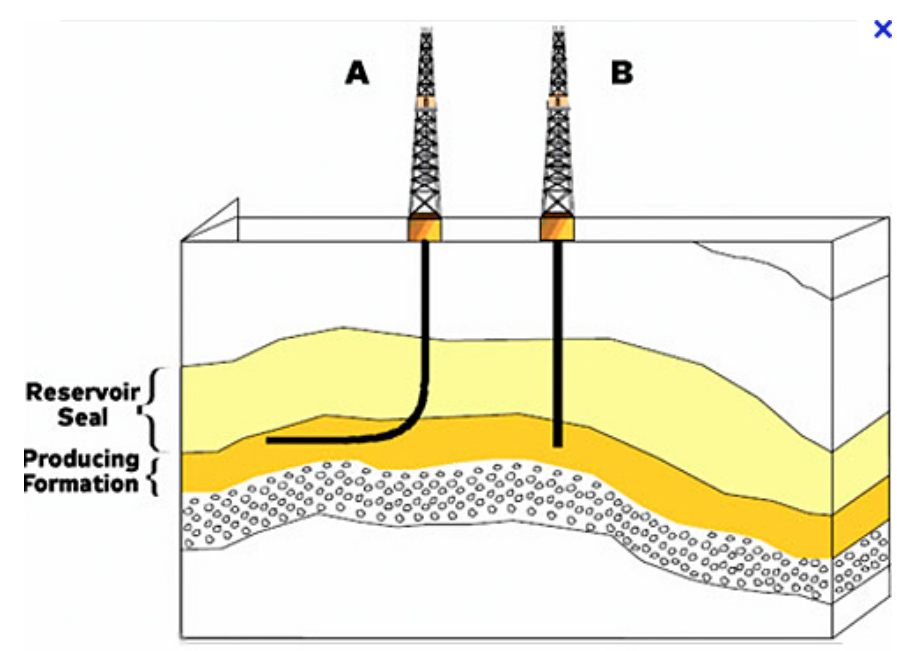

Figure 7: vertical well configuration (Energy Information Administration, office of Oil and Gas).

One of the most important factors to be considered in drilling the horizontal well is the horizontal well length. The length has the most influence on the production rate and the drilling cost of horizontal wells. Basically, the horizontal well length is dependent on the drainage area of the reservoir. In most tight gas reservoirs, the length of the horizontal wells usually ranges between $400 \mathrm{ft}$ to $6000 \mathrm{ft}$. For this reason this study used 3,600 $\mathrm{ft}$ and 2,000 $\mathrm{ft}$ as length of horizontal well.

\subsection{Multiphase Non-Darcy Flow}

In multiphase flow probably the key toward understanding the phenomena is the ability to identify the internal geometry of the flow; i.e., the relative location of interfaces between the phases, how they are affected by pressure, flow, heat flux and channel geometry, and how transitions between the flow patterns occur.

The importance of multiphase non-Darcy flow on well productivity and impairment has been widely recognized. Multiphase and non-Darcy flow effects in hydraulically fracture gas wells increase pressure drop in the fracture and consequently 
reduce effective fracture conductivity of the proppant. Considering multiphase non-Darcy effects in the fracture allows optimization of the fracture treatment.

Previous work by Olson (2004), found that laboratory data for multiphase nonDarcy flow can be fit to a Geertsma (1974), type equation with good accuracy provided that the water saturation is not too high. Olson (2004), also found that at high water saturations, conducting experiments is more difficult, which means that there is a lack of laboratory data to compare to Geertsma's correlation at higher water saturations.

To predict the combined effects of non-Darcy and multiphase flow, either a constant value of the Forchheimer inertial coefficient $(\beta)$ or a combined average Reynolds number has to be assumed but in most cases a modified value of $\beta$ is used.

In case of two phases Non-Darcy Flow, when each flowing phase is affected by its own Reynolds Number mobility ratio depends on the velocity of each phase. This means that the fractional flow under any specified condition is dependent on the Reynolds Number for all flowing phases.

Figure 9 illustrates that the equilibrium between non- Darcy phase permeability and relative permeability, required to maintain a constant mobility ratio. 


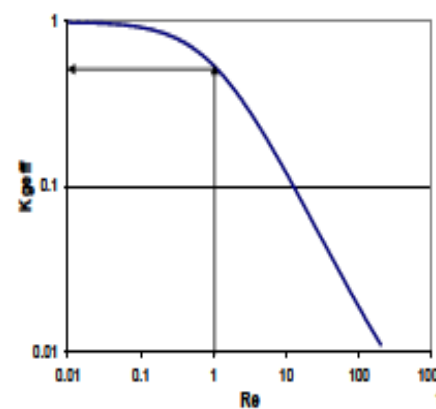

For constant water mobility, fractional flow remains constant at any $\mathrm{R}_{\mathrm{e}}$ only if $\mathrm{S}_{\mathrm{f}}$ and $\mathrm{k}_{\mathrm{rg}}$ change.

At $\mathrm{S}_{\mathrm{g}}=0.47, \mathrm{k}_{\mathrm{rg}} / \mathrm{k}_{\mathrm{rw}}=1.0$ For $R_{e}=0, F_{g}=0.98$ at $\mathrm{S}_{\mathrm{g}}=0.47$

At $\mathrm{S}_{\mathrm{g}}=0.52, \mathrm{k}_{\mathrm{rg}} / \mathrm{k}_{\mathrm{rw}}=2.0$ At $R_{e}=1, k_{g}=0.5 K_{d}$ For $\mathrm{R}_{\mathrm{e}}=1, \mathrm{~F}_{\mathrm{g}}=0.98$ at $\mathrm{S}_{\mathrm{g}}=0.52$

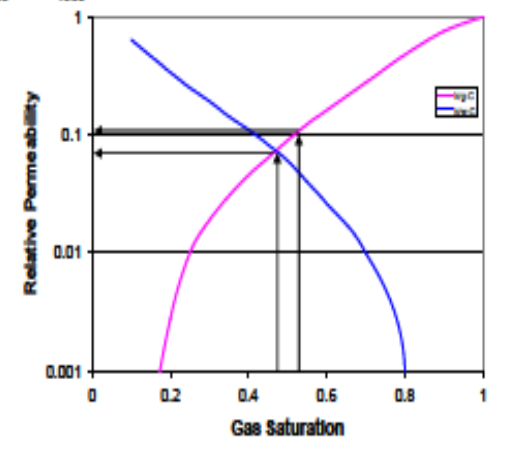

Figure 8: Dynamic balance of non-Darcy and multiphase gas permeability Source (Barree \& Associates and M.W Conway, Stim Lab)

Accurate prediction of multiphase non-Darcy flow requires a complete set of relative permeability curves determined under Darcy-flow conditions and also a description of the change in apparent single-phase permeability with Re is needed. In non-Darcy flow the fractional flow of each flow is no longer a single-valued function of saturation. The mobility of each phase is controlled by its own Reynolds Number and Saturation as well as by its relative permeability. 


\section{METHODOLOGY}

\subsection{Overview}

The objective of this research work is to study the impact of relative permeability on natural gas production where high water saturation exists. The main part of the study uses reservoir simulation to conduct sensitivity analysis with 11 different set of relative permeability curves to determine how they would affect cumulative gas production in tight gas sand reservoirs. The first data set of relative permeability has been obtained by reading the values from the gas-water relative permeability curves typical to the Bossier tight gas sand play in the Dowdy Ranch Field. For each value of water saturation, we read the corresponding value of relative permeability on the y axis until we are done with all the water saturation values. An analogous procedure has been adopted for the gas saturation values. The other sets of relative permeability tables derived from the first set of relative permeability data using either correy's correlation or approximation. Also for some of the tables we alternated the values of water relative permeability and gas relative permeability keeping unchanged water saturation and gas saturation values. The objective of this procedure is to get as many as possible relative permeability data to conduct our study. To ensure the accuracy of our tables we confirm them by importing them to the software to check compatibility. To perform this study, different scenarios have been considered: horizontal well with different lateral lengths with and without fractures, vertical well. In order to understand the impact of the relative permeability, the same relative permeability data was used to make the runs for the different well completion 
scenarios. The reservoir properties used in this study are given in table (1). The initial reservoir pressure is relatively high (9000 psi). These data were derived from several petro physical studies from the Bossier tight gas sand play in the Dowdy Ranch Field located in Freestone Co., TX. This study also incorporates relative permeability data typical for the Bossier Sands. It is also important to mention that some parameters have been assumed based on several literature reviews to ensure the accuracy of data used in the study. 
Table 1: Reservoir simulation Input data

\begin{tabular}{|c|c|}
\hline RESERVOIR PARAMETER & VALUE \\
\hline Reservoir depth, $\mathrm{ft}$ & 15000 \\
\hline Initial pressure, PSI & 9000 \\
\hline Thickness, $\mathrm{ft}$ & 100 \\
\hline Porosity & 0.1 \\
\hline Porosity fracture & 0.08 \\
\hline Permeability I & 0.002 \\
\hline Permeability J & 0.002 \\
\hline Permeability $\mathrm{k}$ & 0.005 \\
\hline Permeability I fracture & 0.01 \\
\hline Permeability J fracture & 0.01 \\
\hline Permeability k fracture & 0.001 \\
\hline Fracture spacing I & 0.02 \\
\hline Fracture spacing $\mathrm{J}$ & 0.02 \\
\hline Fracture spacing $\mathrm{K}$ & 0.02 \\
\hline Reservoir Temperature & 280 \\
\hline Bottom hole pressure & 2000 \\
\hline Water saturation & 0.35 \\
\hline
\end{tabular}

\subsubsection{Multiphase Modeling:}

The results in this section consider multiphase flow. A General correlation for non-Darcy flow effects was used for fractures. It was observed that for two phase gaswater flow particularly for high water saturation this correlation yields realistic pressure drops. For computational efficiencies we modeled our reservoir with dimension 80 by 80 
by 100 covering an area of 14.7 acres a rectangular reservoir with three layers of $100 \mathrm{ft}$ thickness each.

\subsubsection{Fracture well stimulation:}

In this study half of the rectangular drainage area (Figure 10) is modeled. The fracture is assumed to extend an equal distance on both sides and fully penetrates the vertical extent of the formation. The model is two phases (gas and water) and the reservoir is assumed to be horizontal and homogeneous.

The table below shows the fracture characteristics.

Table 2: Fracture Characteristics

\begin{tabular}{|l|l|}
\hline Fracture spacing & $500 \mathrm{ft}$ \\
\hline Fracture half-length & 200 \\
\hline Fracture width & $0.01 \mathrm{ft}$ \\
\hline Horizontal well\#1 & $3600 \mathrm{ft}$ \\
\hline Horizontal well\#2 & $2000 \mathrm{ft}$ \\
\hline Permeability & $50000 \mathrm{md}$ \\
\hline
\end{tabular}

In order to accomplish the objective of this study, the following procedure was followed:

- Build a reservoir model with a typical tight gas sand reservoir properties.

- Perform sensitivity analysis to address the impact of relative permeability on gas production in vertical and horizontal wells. This will help us to identify which well production is more affected by the relative permeability. 
- Perform sensitive analysis when detected relative permeability relationship for two different lateral lengths of horizontal wells with fracture and without fracture.

\subsection{Reservoir Model of Study}

The stipulation for reservoir simulation arises from the necessity for petroleum engineers to find perfect performance predictions for a hydrocarbon reservoir under different operating conditions. As a result of model studied engineers have a better understanding of reservoir behavior and make production forecasts to help engineers in making investment decisions.

In this study, a dual-porosity reservoir simulator is utilized to model and stimulate gas production from tight gas reservoir. For this research (Computer Modeling Group) has commercial software for reservoir simulation capable to determine reservoir capacities in order to maximize potential recovery. In this work BUIDER, IMEX, and RESULTS modules were used with adjustment for tight gas sand reservoir. Two basic reservoir simulation models were developed using builder IMEX. The first model has a vertical well and the second model has a horizontal well. The input data for the two models are the same, and they are shown in Table1. These two models are synthetic models for tight gas sand, which are located at deepest depth. The formation depth is 15000 feet, which consists of three layers of 100 feet thickness.

Figure (10) below represents the simulation model for the vertical well. It can be seen on Figure (10) that the vertical well is located at the center of the drainage area. 


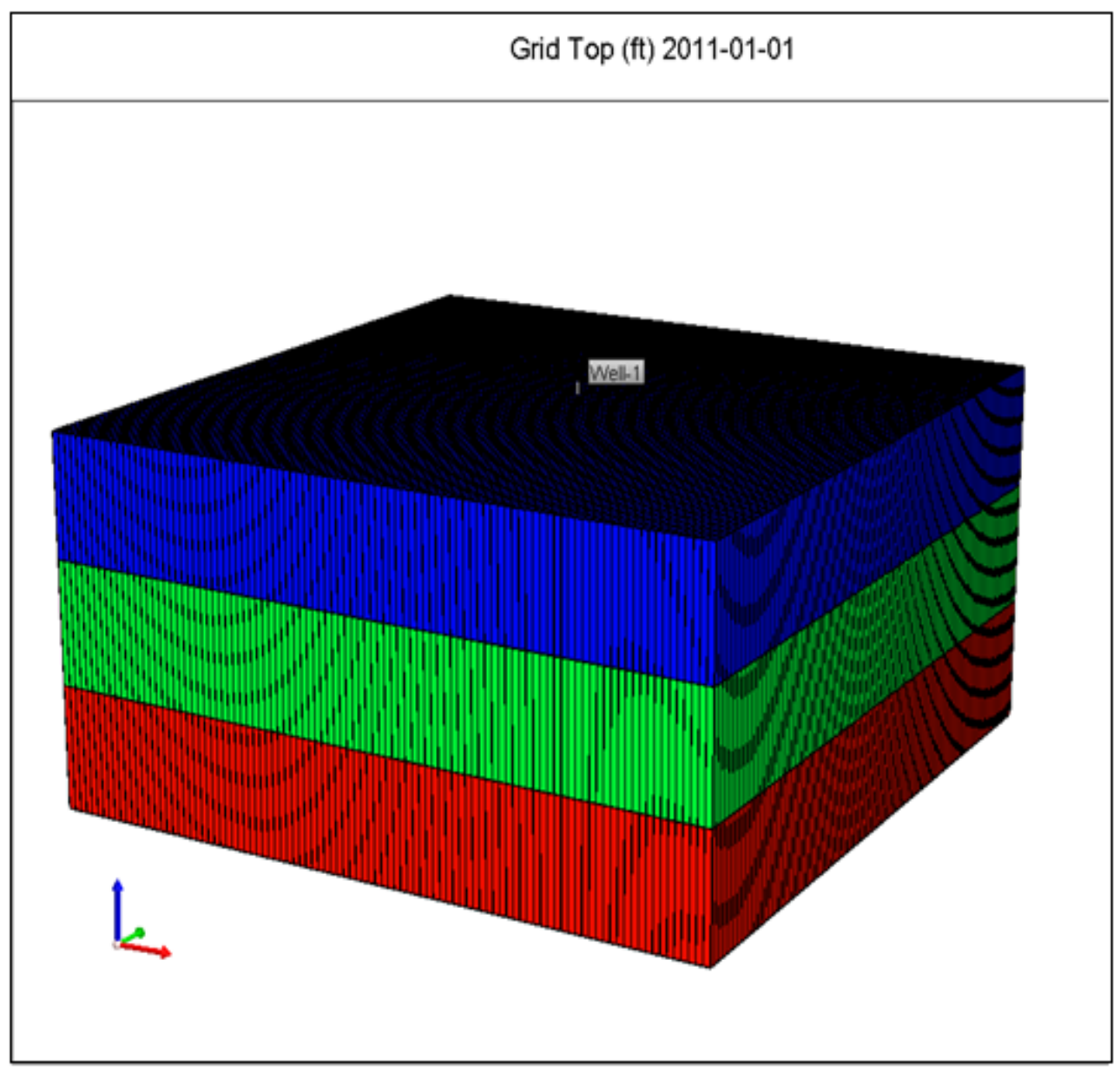

Figure 9: Reservoir simulation model

Figure (11) symbolizes the 3 -D view of the fracture reservoir of 2,000 ft. The 3 different layers are shown on this figure and the well too is seen with its position. 


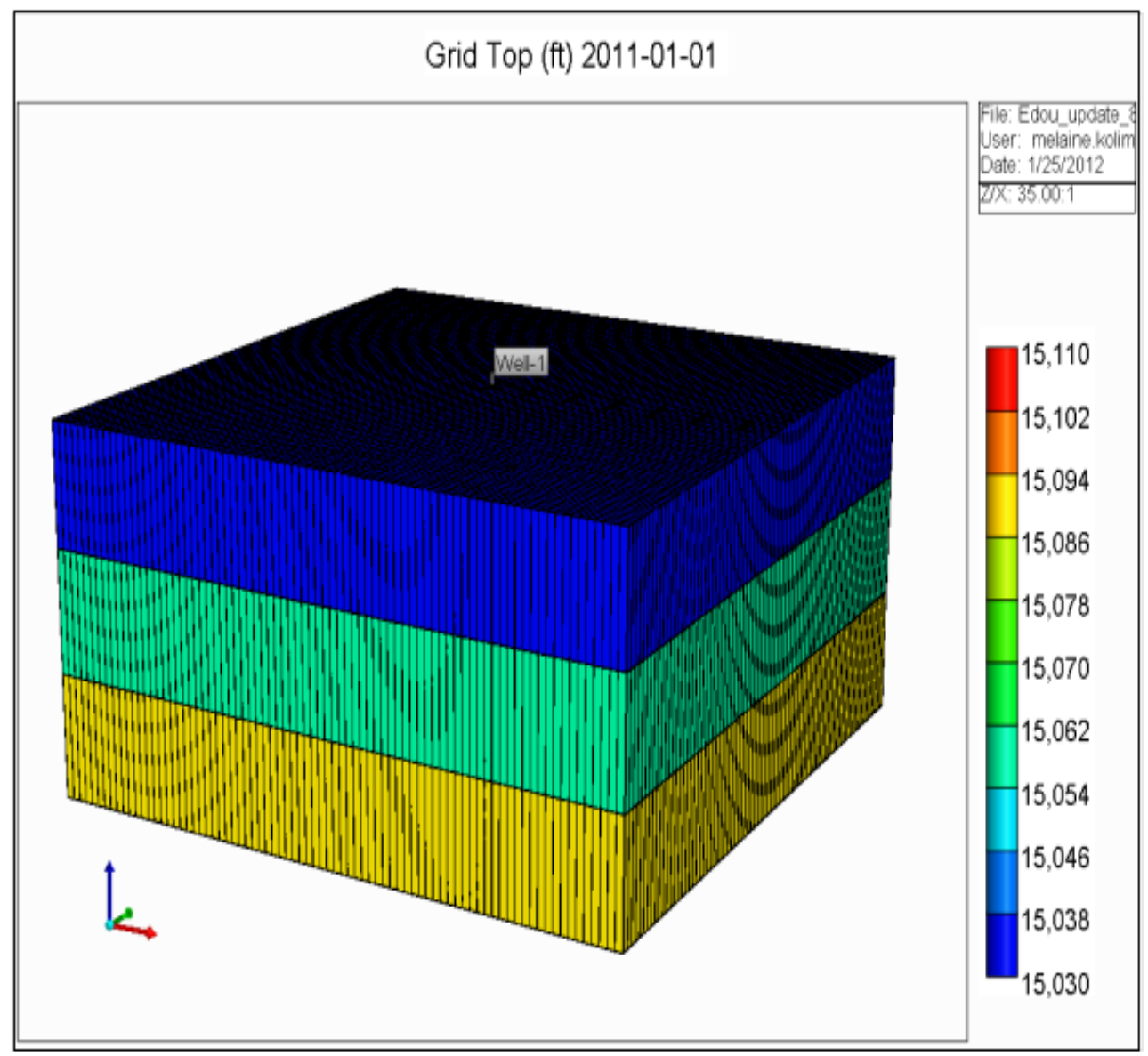

Figure 10: Modeling well fracture of $2000 \mathrm{ft}$

Figure (12) shows the drainage area of the well and the number of fracture treatment for the horizontal well with $2000 \mathrm{ft}$ lateral length. 
Grid Top (ft) 2011-01-01 K layer: 1

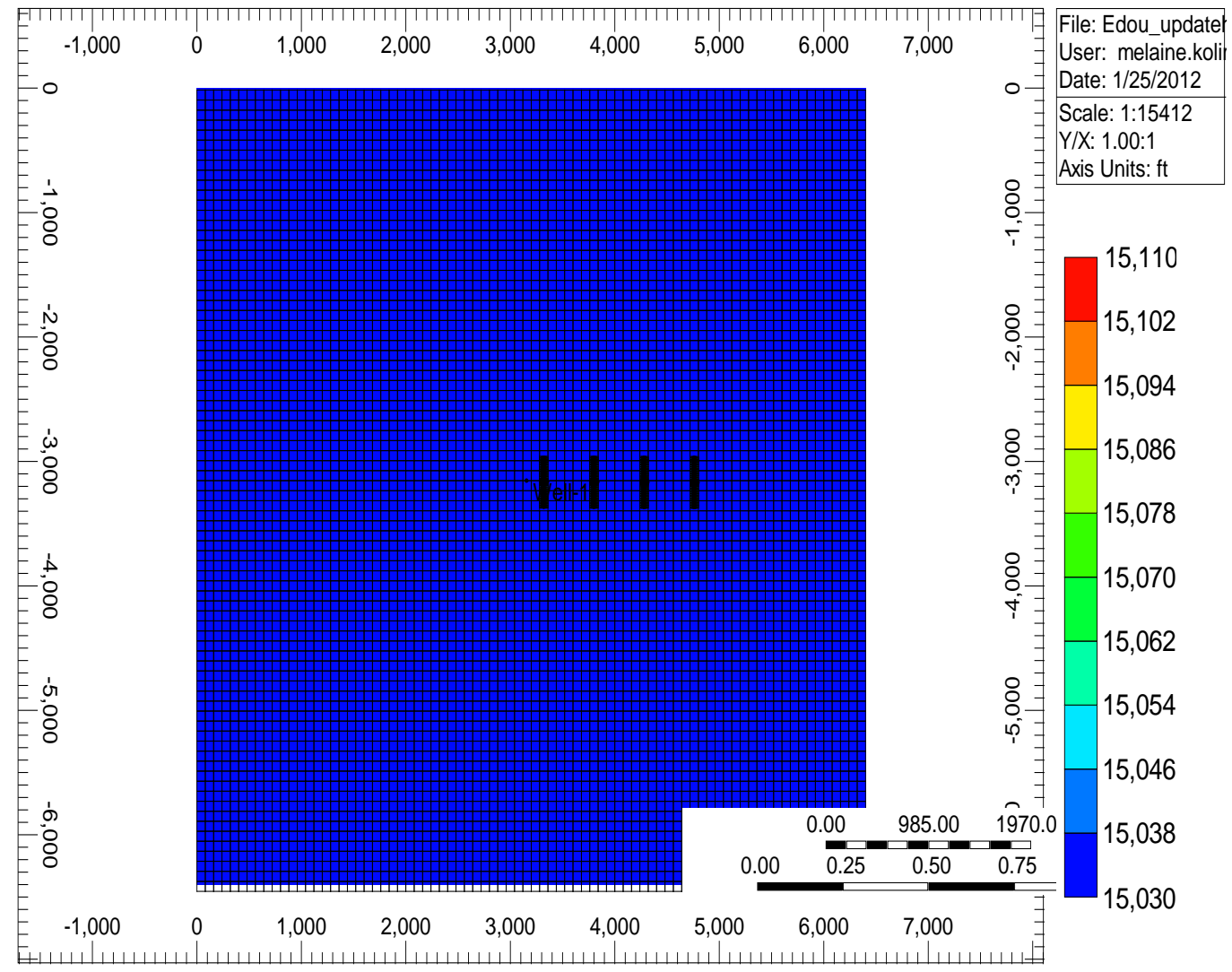

Figure 11: Reservoir Simulation rectangular area

Figure (13) shows the rectangular drainage area of the horizontal fractured treated well with 3,600 ft lateral and seven fractures with $500 \mathrm{ft}$ spacing. 
Grid Top (tt) 2011-01-01 K layer: 1

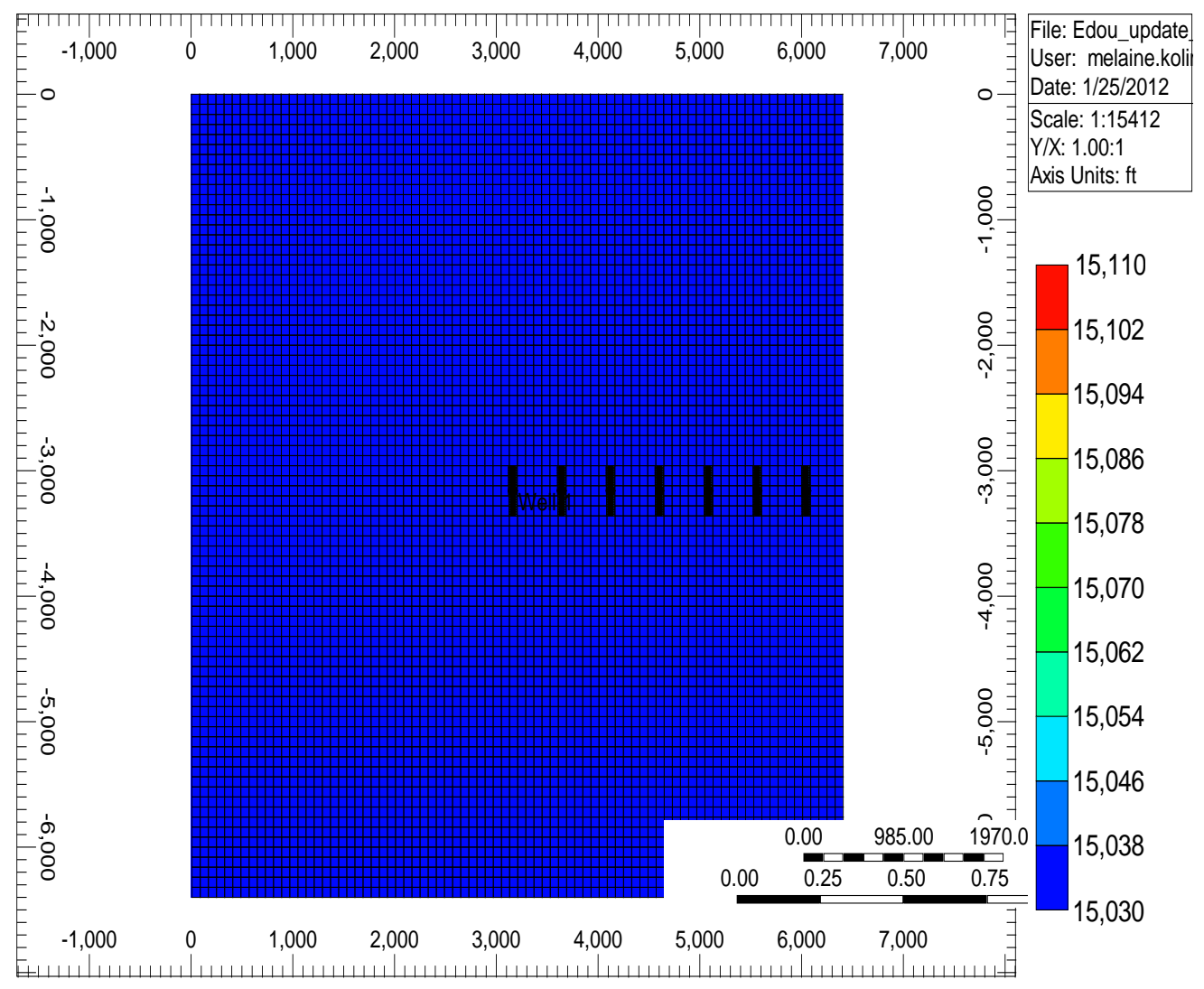

Figure 12: Modeling well fracture of $3600 \mathrm{ft}$

Figure (14) shows the location of the vertical well and the rectangular drainage area. 
Grid Top (ft) 2011-01-01 K layer: 1

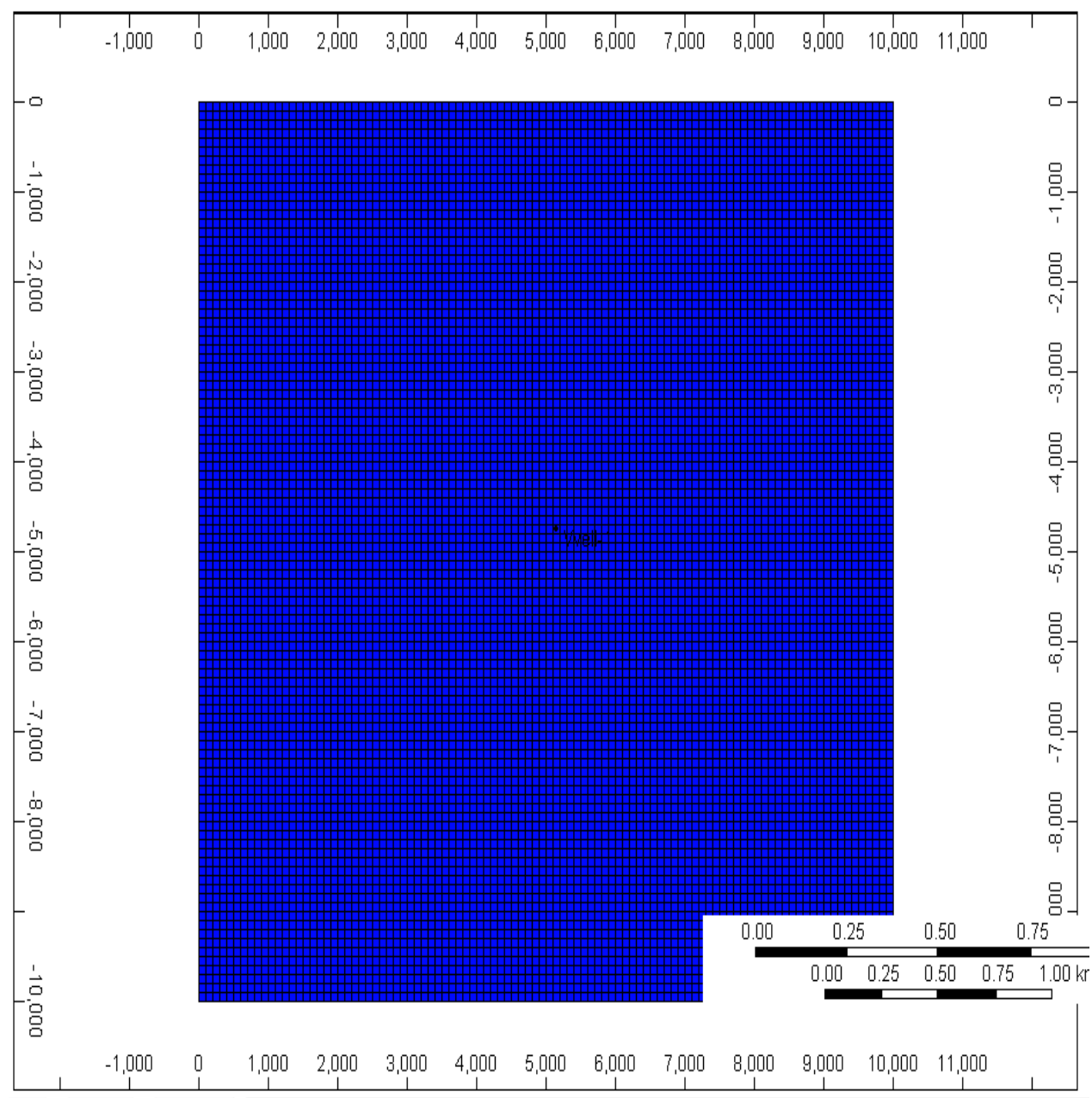

Figure 13: Reservoir simulation rectangular drainage area

\subsection{Sensitivity Analysis}

\subsubsection{Effect of Relative Permeability on gas-water flow:}

The primary objective of the analysis is to understand the effects of the relative permeability on gas-water flow. In this study, a sensitivity analysis was performed for a vertical well and horizontal well. Several reservoir models were built in order to investigate the impact of relative permeability on the cumulative gas production. 
The relative permeability is found to have a great impact on production from gaswater flow. Sensitivity analysis is based on a set of simulation runs in which different relative permeability curves are used and their impacts on the cumulative gas production are determined.

\subsubsection{Procedure:}

To observe the impacts of the relative permeability on the cumulative gas production on gas-water flow, different relative permeability tables were prepared and used to investigate its impact on gas production. For this analysis several simulation runs have been made for both types of wells namely vertical and horizontal. The same type of relative permeability tables are used for both vertical and horizontal wells. Different 11 type's data sets have been used to make several simulations for both well types.

The gas production from all runs is compared to the initial gas in place. The different relative permeability tables and related curves that are used in this study are summarized in Appendices A. The cumulative gas production results are presented in Appendices B while Appendices C illustrates the fracture well cumulative gas production and some screen shots about the base model. 


\section{RESULTS AND DISCUSSION}

The simulation results of different reservoir models are shown and discussed. In this section the study is about the impact of relative permeability on these different designs. The first scenarios illustrate the results of different lateral lengths of horizontal well with and without fracture and in second hand the results from the vertical well that were drilled in the reservoir. To perform the study several reservoir models have been built and run with different relative permeability data.

\subsection{Tight Gas Reservoir with a vertical Well}

The first model has a vertical well, which is located at the center and perforated through the three layers. The well is located in the middle of the reservoir. The net pay thickness consists of three 100-ft layers. The reservoir is homogeneous in terms of reservoir properties. The model has been built in a Cartesian gridding system.

\subsection{Summary of Gas produced}

Table (3) illustrates cumulative gas production values for the different cases used in this study. Further the table compares the gas production values for different relative permeability curves and how different they are from the initial gas in place. The initial gas in place is calculated to be 22,849 MMSCF for all cases studied. 
Table 3: Cumulative gas production values at the end of 60 years

\begin{tabular}{|c|c|c|c|c|c|}
\hline \multirow{3}{*}{ RUNS } & \multicolumn{5}{|c|}{ WELL TYPE } \\
\hline & $\begin{array}{l}\text { Horizontal with } \\
\text { fracture } \\
\text { treatment }\end{array}$ & $\begin{array}{l}\text { Horizontal with } \\
\text { fracture } \\
\text { treatment }\end{array}$ & Horizontal & Horizontal & \multirow[t]{2}{*}{ Vertical } \\
\hline & $\begin{array}{l}\text { Lateral length } \\
3600 \mathrm{ft}\end{array}$ & $\begin{array}{l}\text { Lateral length } \\
2000 \mathrm{ft}\end{array}$ & \begin{tabular}{|l|} 
Lateral \\
length $3600 \mathrm{ft}$
\end{tabular} & \begin{tabular}{|l|} 
Lateral \\
length $2000 \mathrm{ft}$
\end{tabular} & \\
\hline 1 & 26299 & 17637 & 21688 & 14242 & 3001.9 \\
\hline 2 & 22911 & 24538 & 21688 & 14242 & 3001.9 \\
\hline 3 & 23065 & 17708 & 21689 & 14243 & 3003 \\
\hline 4 & 23055 & 14790 & 21867 & 14364 & 3024.2 \\
\hline 5 & 21346 & 13562 & 19576 & 12693 & 2612.9 \\
\hline 6 & 24257 & 22328 & 19575 & 12692 & 2612 \\
\hline 7 & 23066 & 17709 & 21690 & 14244 & 3003.3 \\
\hline 8 & 16224 & 9990.1 & 13301 & 8291.4 & 1568.3 \\
\hline 9 & 17681 & 17816 & 15218 & 9601 & 1867.1 \\
\hline 10 & 16224 & 9990.1 & 15218 & 8291.4 & 1568.3 \\
\hline 11 & 14695 & 10216 & 13301 & 8291.2 & 1568.2 \\
\hline
\end{tabular}

\subsection{Horizontal well with $3600 f t$ lateral:}

Table 4 summarizes the results obtained from the runs for the $3600 \mathrm{ft}$ horizontal well with 11 different sets of relative permeability data. The values in Table 4 range from 21,688 (MMSCF) to 13,301 (MMSCF). Results are also shown in Figure (15). The sets of relative permeability data have then an effect on the cumulative gas production. The difference between the maximum and minimum cumulative gas production was $38.67 \%$. 
Table 4: Cumulative gas produced from horizontal well of $3600 \mathrm{ft}$

\begin{tabular}{|c|c|}
\hline RUNS & Cumulative Gas Production (MMSCF) \\
\hline 1 & 21688 \\
\hline 2 & 21688 \\
\hline 3 & 21689 \\
\hline 4 & 21867 \\
\hline 5 & 19576 \\
\hline 6 & 19575 \\
\hline 8 & 21690 \\
\hline 9 & 13301 \\
\hline 10 & 15218 \\
\hline 11 & 15218 \\
\hline & 13301 \\
\hline
\end{tabular}

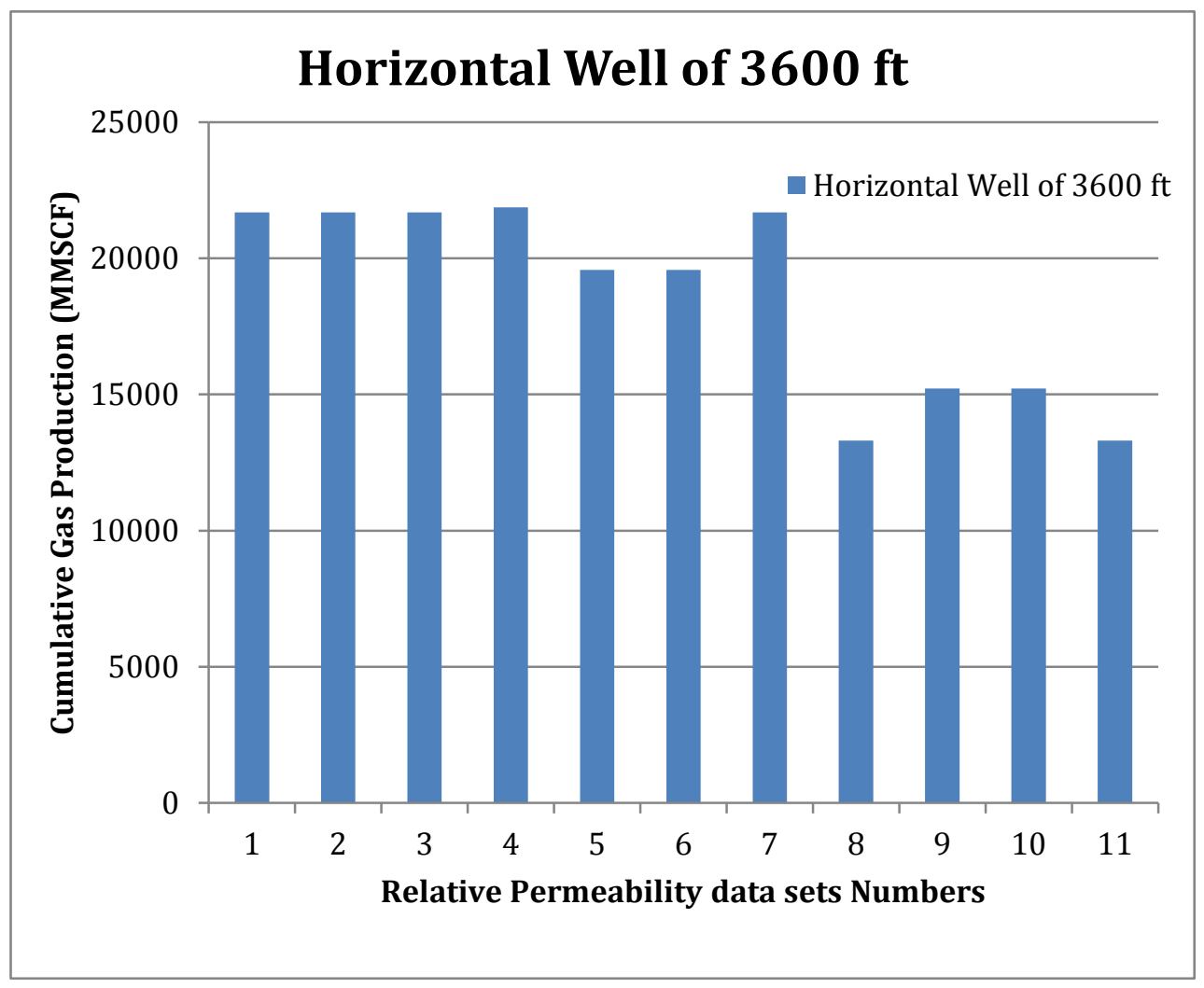

Figure 14: Cumulative gas produced from horizontal well of $3600 \mathrm{ft}$ 
The above plot shows in one hand the difference in gas production values from different data set of relative permeability. The plot shows an insignificant change in the cumulative gas produced for the first 4 different relative permeability data sets. The cumulative gas production remains at an approximate average value of 21690MMSCF.There is a slight decrease in value for the fifth and sixth run and the gas

produced reduces to about $19576 \mathrm{MMSCF}$ with an increase for the seventh run. The $8^{\text {th }}$ to $11^{\text {th }}$ relative permeability data sets shows a greater drop in cumulative gas production. Overall, the relative permeability has an effect on the produced gas volume.

\subsection{Horizontal well fracture treatment with $3600 \mathrm{ft}$}

Table 5 summarizes the results obtained from the simulation of 11 different sets of relative permeability data. The cumulative gas produced ranges from 26,299 (MMSCF) for the first data set to 14,695 (MMSCF) for the eleventh data set. This represents a change of $44.12 \%$. Results are also projected in Figure (16). The relative permeability data sets have a significant impact on the cumulative gas production. 
Table 5: Cumulative gas produced from horizontal fracture well of $3600 \mathrm{ft}$

\begin{tabular}{|c|c|}
\hline \multirow{2}{*}{ RUNS } & Cumulative Gas Production (MMSCF) \\
& \\
\hline 1 & 26299 \\
\hline 2 & 22911 \\
\hline 3 & 23065 \\
\hline 4 & 23055 \\
\hline 5 & 21346 \\
\hline 6 & 24257 \\
\hline 7 & 23066 \\
\hline 8 & 16224 \\
\hline 9 & 17681 \\
\hline 10 & 16224 \\
\hline 11 & 14695 \\
\hline
\end{tabular}

Figure 16 shows the case of the fracture treated horizontal well of lateral length $3600 \mathrm{ft}$. The effect of relative permeability on cumulative gas production can also be seen from the plot. The highest gas production volume of approximately 26,299MMSCF was obtained with the first data set while the lowest cumulative gas production of approximately 14,695MMSCF was obtained with the last data set.

Comparing the impact of relative permeability of the fractured well results with the results from the well without fracture treatment, it can be seen that the relative permeability has more impact on the fracture treated well and generate more gas production. It can be concluded that the fracture treatment in addition to the relative 
permeability created a wider path for the flow of gas. In this study seven fractures are used for this well with a fracture spacing of $500 \mathrm{ft}$.

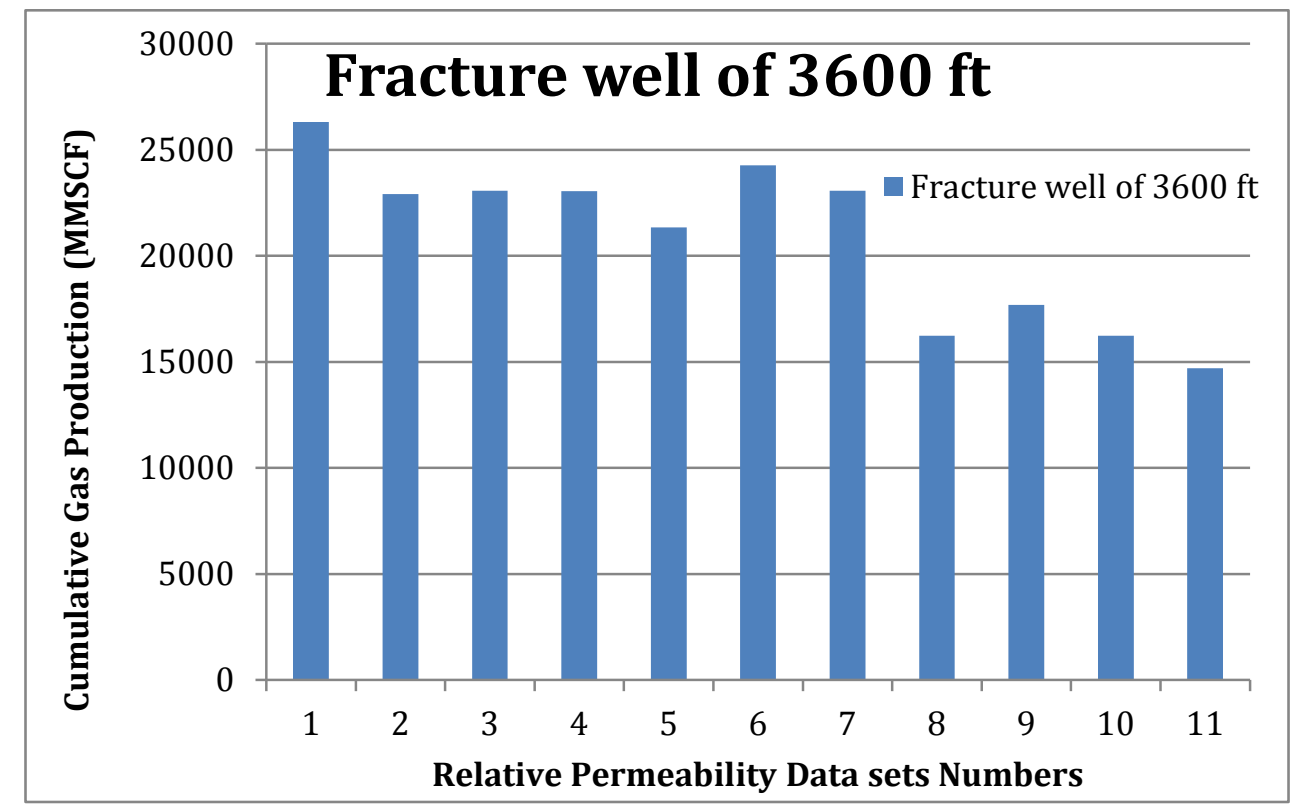

Figure 15: Gas produced from horizontal fracture treated well of $3600 \mathrm{ft}$

\subsection{Cumulative gas production from horizontal well of length $2000 f t$}

Table 6 summarizes the results obtained from the simulation runs of 11 sets of relative permeability data. The cumulative gas produced range from an approximate value of 14,242 (MMSCF) for the first data set to 8,291 (MMSCF) for the eleventh data set. This represents a change of $41.78 \%$. Results are also projected in Figure (17). It can be concluded that the relative permeability data used has an effect on the cumulative gas produced. 
Table 6: Cumulative gas produced from horizontal well of $2000 \mathrm{ft}$

\begin{tabular}{|c|c|}
\hline \multirow{2}{*}{ RUNS } & Cumulative Gas Production (MMSCF) \\
\hline 1 & 14242 \\
\hline 2 & 14242 \\
\hline 3 & 14243 \\
\hline 4 & 14364 \\
\hline 5 & 12693 \\
\hline 6 & 12692 \\
\hline 7 & 14244 \\
\hline 8 & 8291.4 \\
\hline 9 & 9601 \\
\hline 10 & 8291.4 \\
\hline 11 & 8291.4 \\
\hline
\end{tabular}

The analysis of the graph of the cumulative gas production of horizontal well of length $2000 \mathrm{ft}$. from 11 different set of relative permeability show that there is no considerable change for the first 4 data set and the cumulative gas production remained constant and was equal to $14242 \mathrm{MMSCF}$.There is a significant decrease in value for the fifth and sixth run and the gas produced passed to 8291MMSCF with a new increase for the seventh run. From the $8^{\text {th }}$ data set to 11 data the influence of the relative permeability can be well seen with the alternate variation of the gas production value. Overall the relative permeability affects the gas production based on the data used for the simulation. 


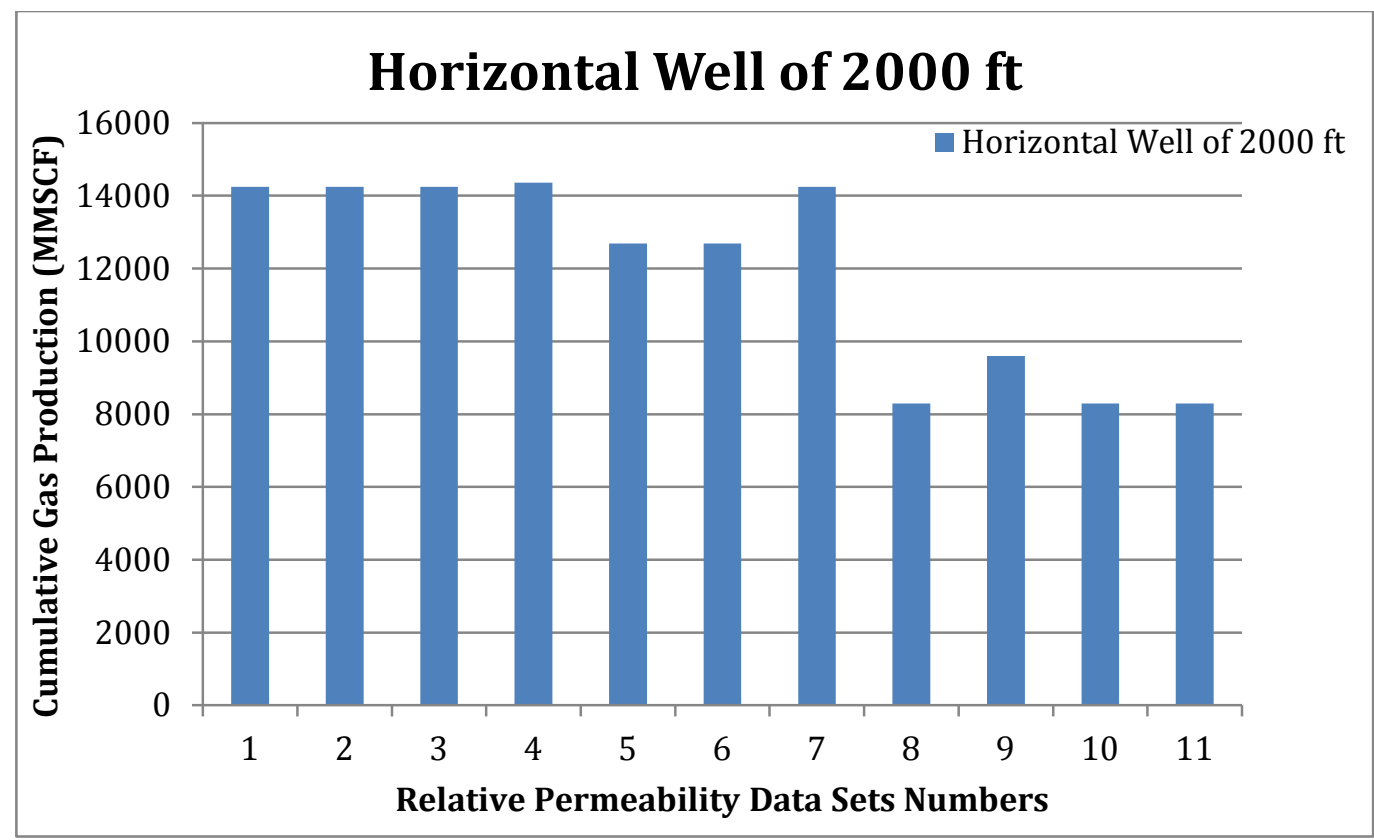

Figure 16: Cumulative gas produced from horizontal well of $2000 \mathrm{ft}$

\subsection{Horizontal well fracture treatment with $2000 \mathrm{ft}$ lateral}

Table 7 summarizes the results obtained from the simulation runs of 11 sets of relative permeability data. The cumulative gas produced range from an approximate value of 17,637 (MMSCF) for the first data set to 10,296 (MMSCF) for the eleventh data set. This represents a change of $41.62 \%$. Results are also projected in Figure (18). 
Table 7: Cumulative gas produced from horizontal fracture well of $2000 \mathbf{f t}$

\begin{tabular}{|c|c|}
\hline \multirow{2}{*}{ RUNS } & Cumulative Gas Production (MMSCF) \\
\hline 1 & 17637 \\
\hline 2 & 24538 \\
\hline 3 & 17708 \\
\hline 4 & 14790 \\
\hline 5 & 13562 \\
\hline 6 & 22328 \\
\hline 7 & 17709 \\
\hline 8 & 9990.1 \\
\hline 10 & 17816 \\
\hline 11 & 9990 \\
\hline
\end{tabular}

Figure-18 shows the results for runs with fractured horizontal well of $2,000 \mathrm{ft}$ lateral. Here the relative permeability impact can be better appreciated since the cumulative gas production is proportional to the relative permeability data used. For example, the highest gas production has been obtained during the second simulation run and is approximately equal to 24,538 MMSCF while the lowest value is 9,990 MMSCF.

Comparing these values to well without fracture treatment, it can be said that the effect of the relative permeability on the fractured well generates more gas production. Four fractures treatments are considered for this well with fracture spacing of $500 \mathrm{ft}$. The gas production repartition also differs from the well without fracture. The relative permeability effects on fracture well can be observed as the factor that allows the well to produce more gas. 
In summary we can say that, by keeping the entire reservoirs parameters constant and by varying only the relative permeability data, the cumulative gas production results with the well of long lateral length are higher than the one with short lateral length. With the introduction of fracture the same observation are made but the longer well produce more gas in presence of fracture also. The relative permeability has a significant impact on both the gas production obtained from the fracture well with an important lateral length as well as the horizontal well of the same lateral length without fracture.

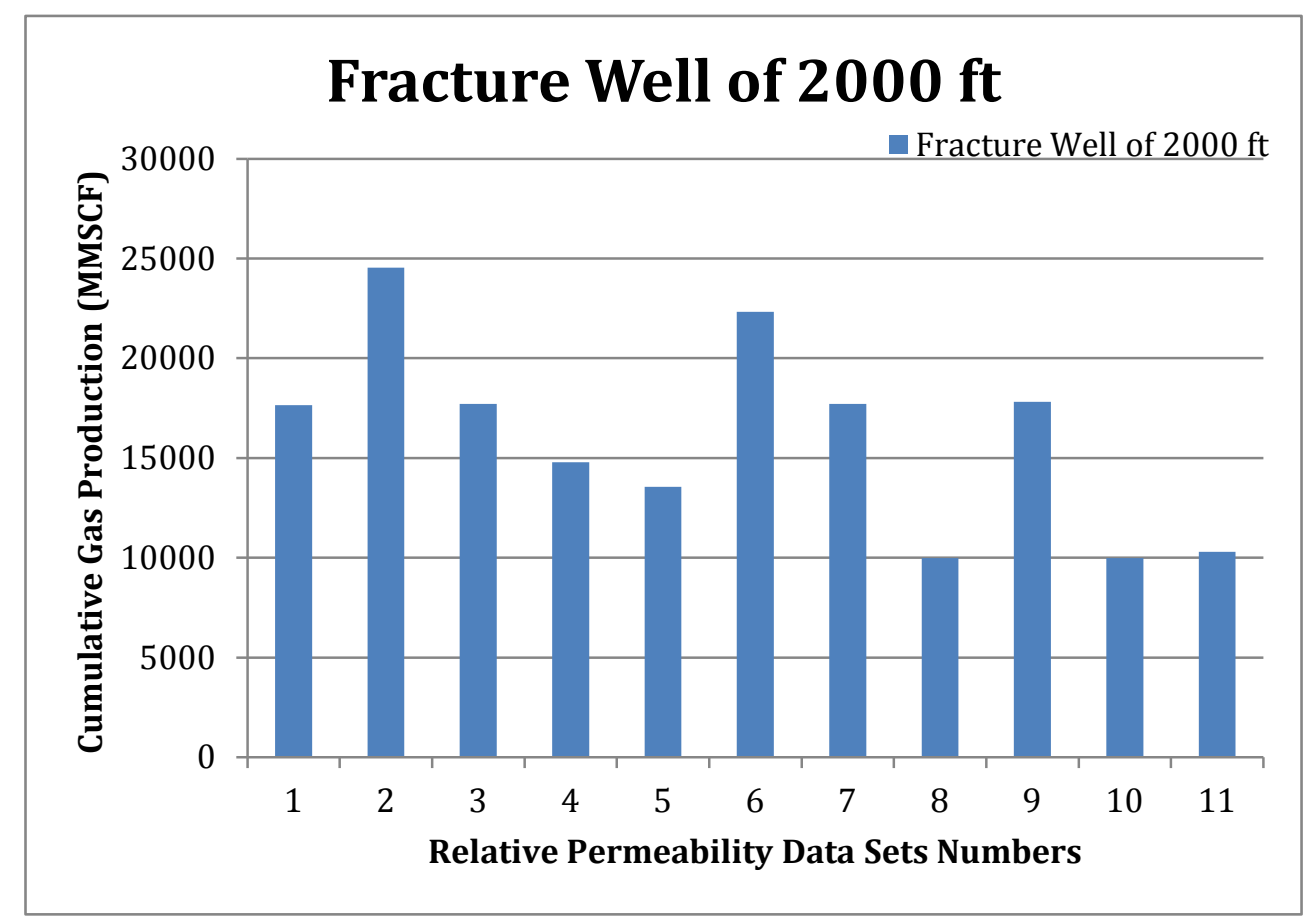

Figure 17: Cumulative gas produced from horizontal treated fracture well of $2000 \mathbf{f t}$

\subsection{Cumulative gas production from Vertical well:}

Table- 8 summarizes the results obtained from the simulations runs of 11 different sets of relative permeability data. The values in the table range from 3024.2 (MMSCF) 
for the first data set to 1,568 (MMSCF) for the eleventh data set. This represents a change of $48.15 \%$. Results are also projected in Figure (19).

Table 8: Cumulative gas produced from Vertical well

\begin{tabular}{|c|c|}
\hline \multirow{2}{*}{ RUNS } & Cumulative Gas Production (MMSCF) \\
\hline 1 & 3002 \\
\hline 2 & 3002 \\
\hline 3 & 3003 \\
\hline 4 & 3024.2 \\
\hline 5 & 2613 \\
\hline 6 & 2612 \\
\hline 7 & 3003.3 \\
\hline 8 & 1568.3 \\
\hline 9 & 1867.1 \\
\hline 10 & 1568.3 \\
\hline 11 & 1568.2 \\
\hline
\end{tabular}

For the vertical well, the change in cumulative gas production is not as important as for the horizontal well. It is also important to mention that for the vertical well there is an insignificant variation on gas produced values for the first 4 simulation data runs while a slightly decrease can be observed for the fifth and sixth run. The simulation runs $8^{\text {th }}$ to $11^{\text {th }}$ show an important decrease in the gas production results.

Based on our observation, it is not easy to say how the relative permeability could affect the gas production from vertical well but it does have some considerable impacts on the cumulative gas production. 
By comparing simultaneously the bare diagram from the vertical well and the one from horizontal well with different lateral length with or without fracture treatment we can notice that they have almost the same trends, and since the same types of relative permeability data have been used to conduct this study, we can conclude that the relative permeability affects more the gas production from the horizontal well.

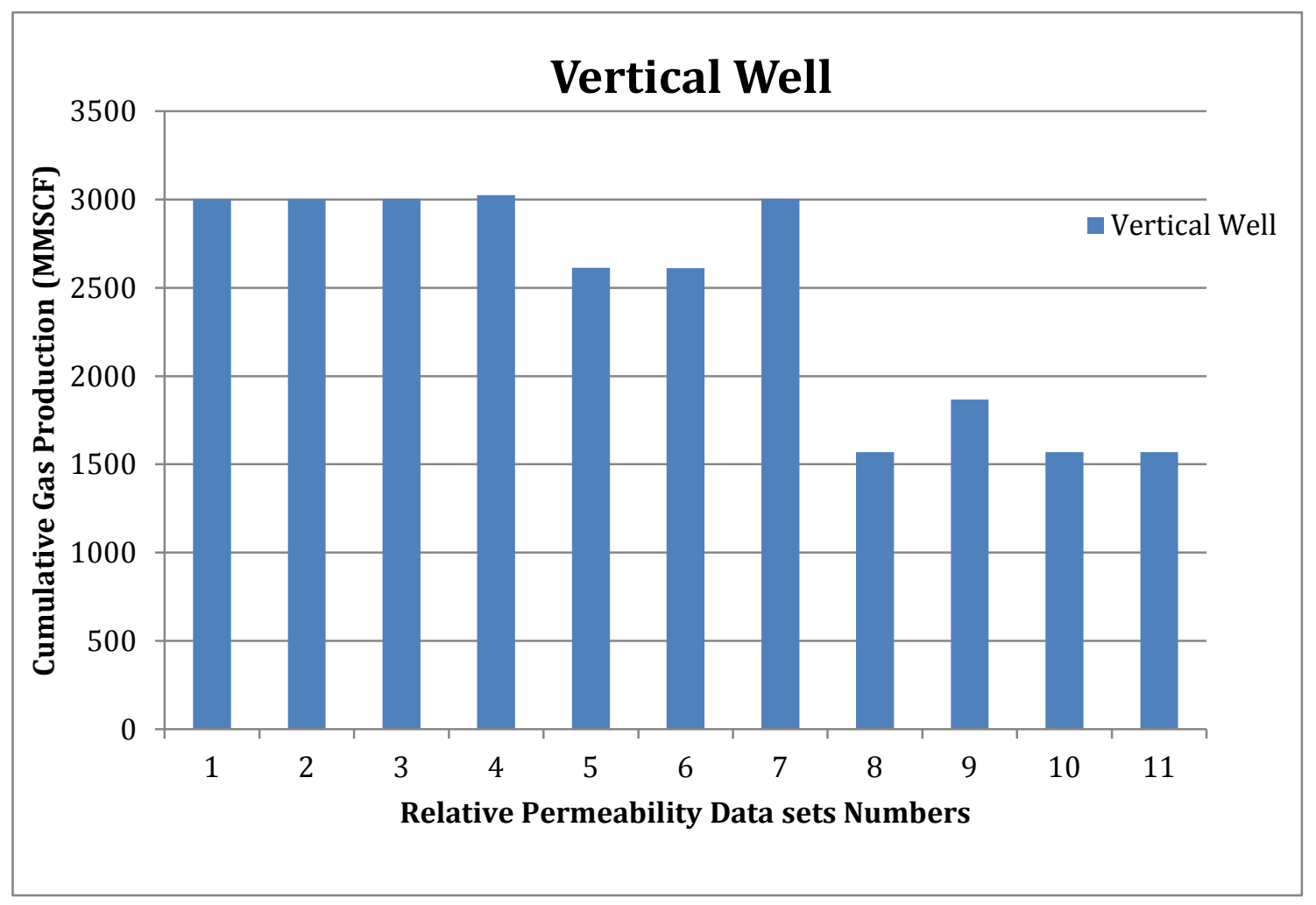

Figure 18: Cumulative gas produced from vertical well 
Figure 20 shows cumulative gas production results from horizontal well of lateral length of $3600 \mathrm{ft}$ without fracture treatment and with fracture treatment using 11 different sets of relative permeability curves.

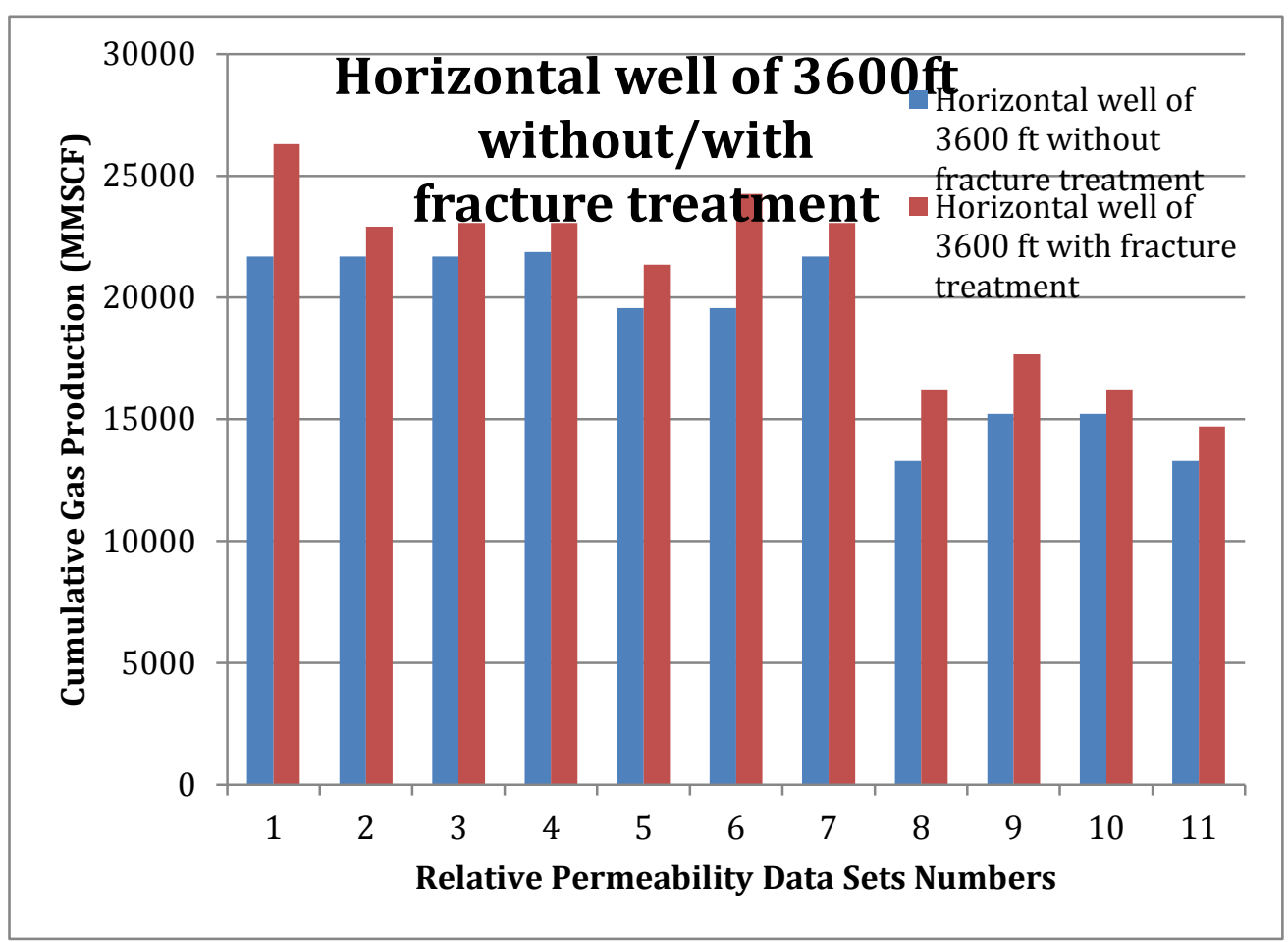

Figure 20: Horizontal well of $3600 \mathrm{ft}$ without/with fracture treatment 
The same observation is made for figure 21 except for some rare cases where the cumulative gas production for the fractured treated well of $2000 \mathrm{ft}$ double the one obtained from the well without fracture.

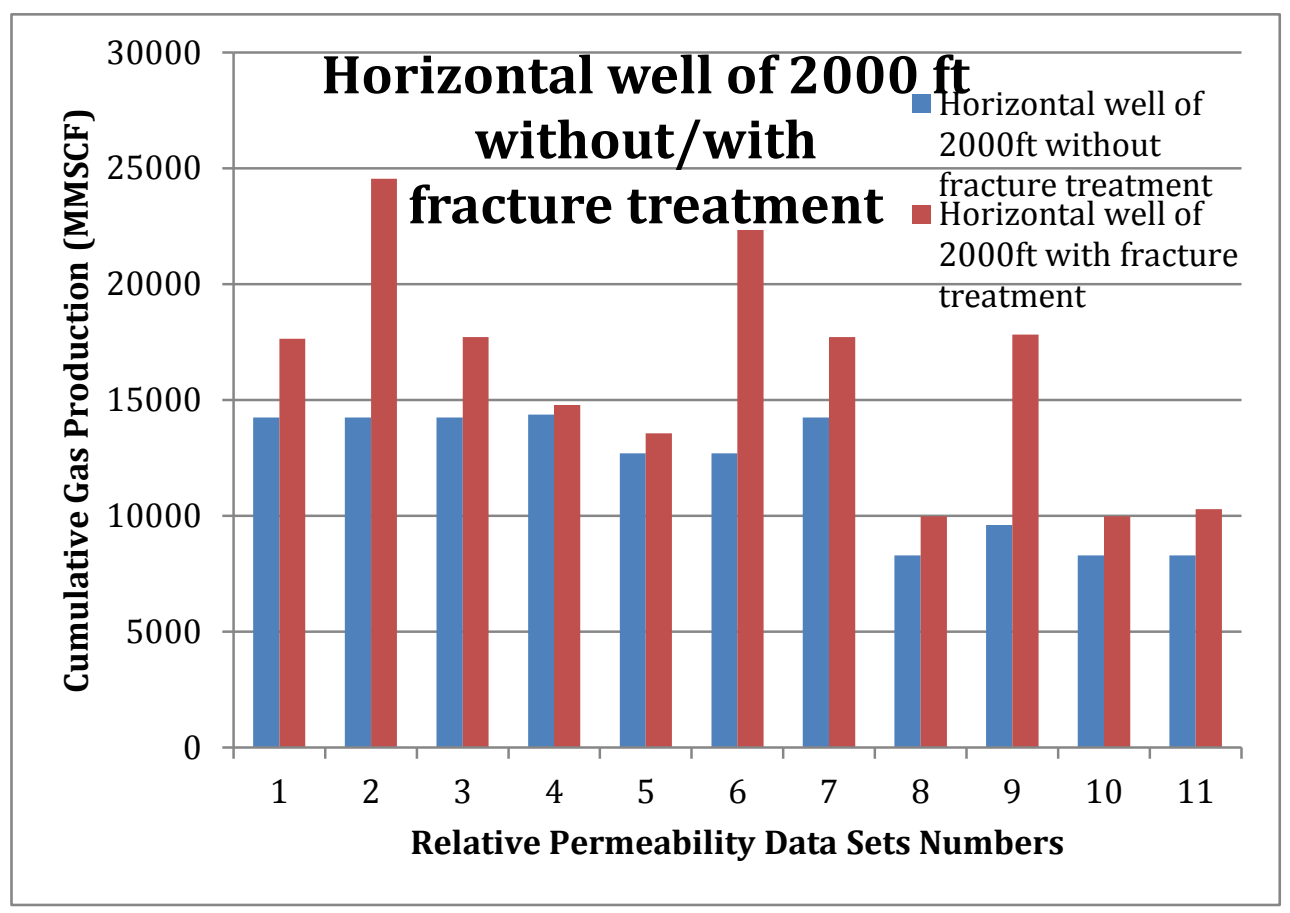

Figure 21: Horizontal well of $2000 \mathrm{ft}$ without and with fracture treatment. 
Figure 22 shows two horizontal wells of different lateral lengths without fracture treatment. It can be inferred that the cumulative gas production from the horizontal well of lateral length $3600 \mathrm{ft}$ is higher than the one from the horizontal well of lateral length of $2000 \mathrm{ft}$.

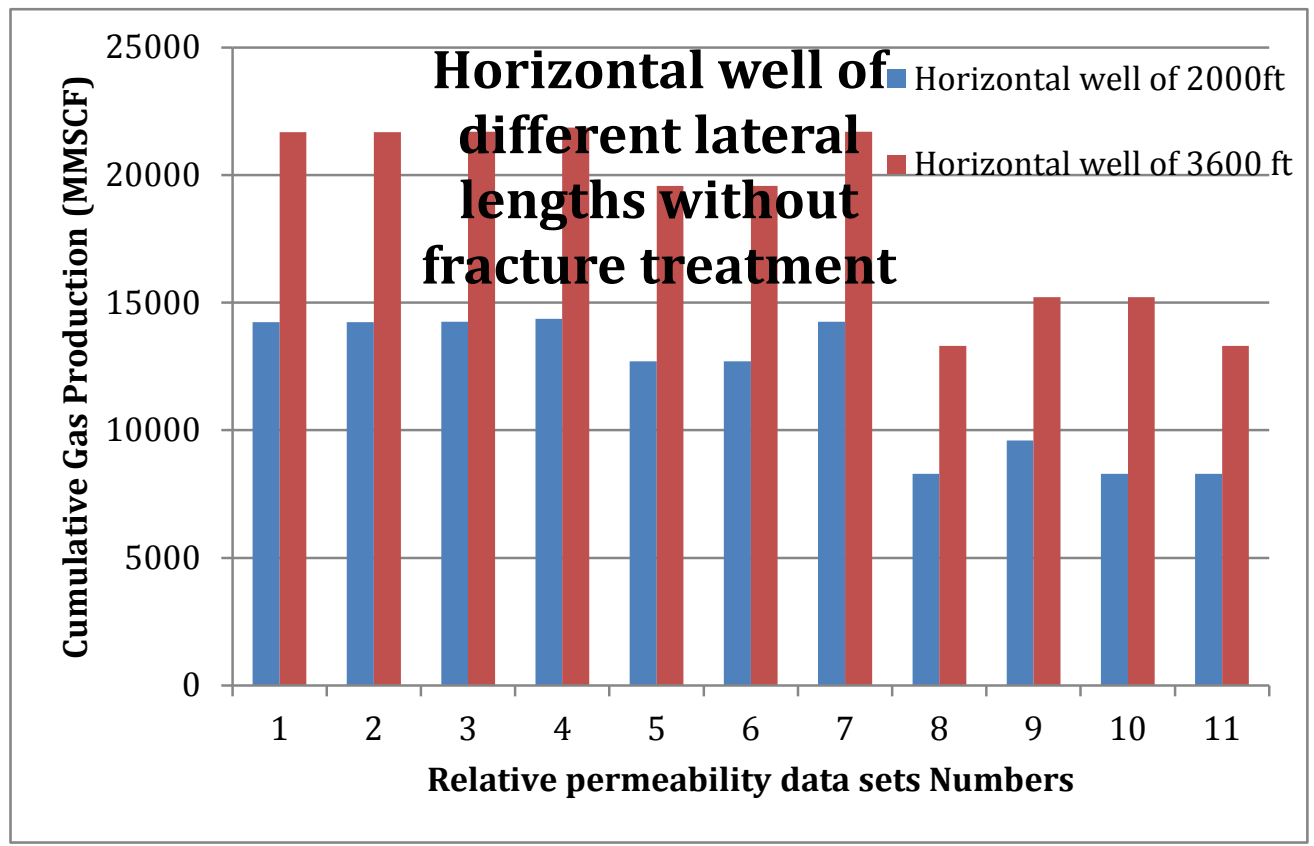

Figure 22: Comparison of 2 different lateral length of horizontal well without fracture (2000ft and 3600ft) 
Figure 23 shows two horizontal wells of different lateral lengths. It can be inferred from this figure that the cumulative gas production from the long lateral horizontal well is higher than the one from the short horizontal lateral length except some rare cases.

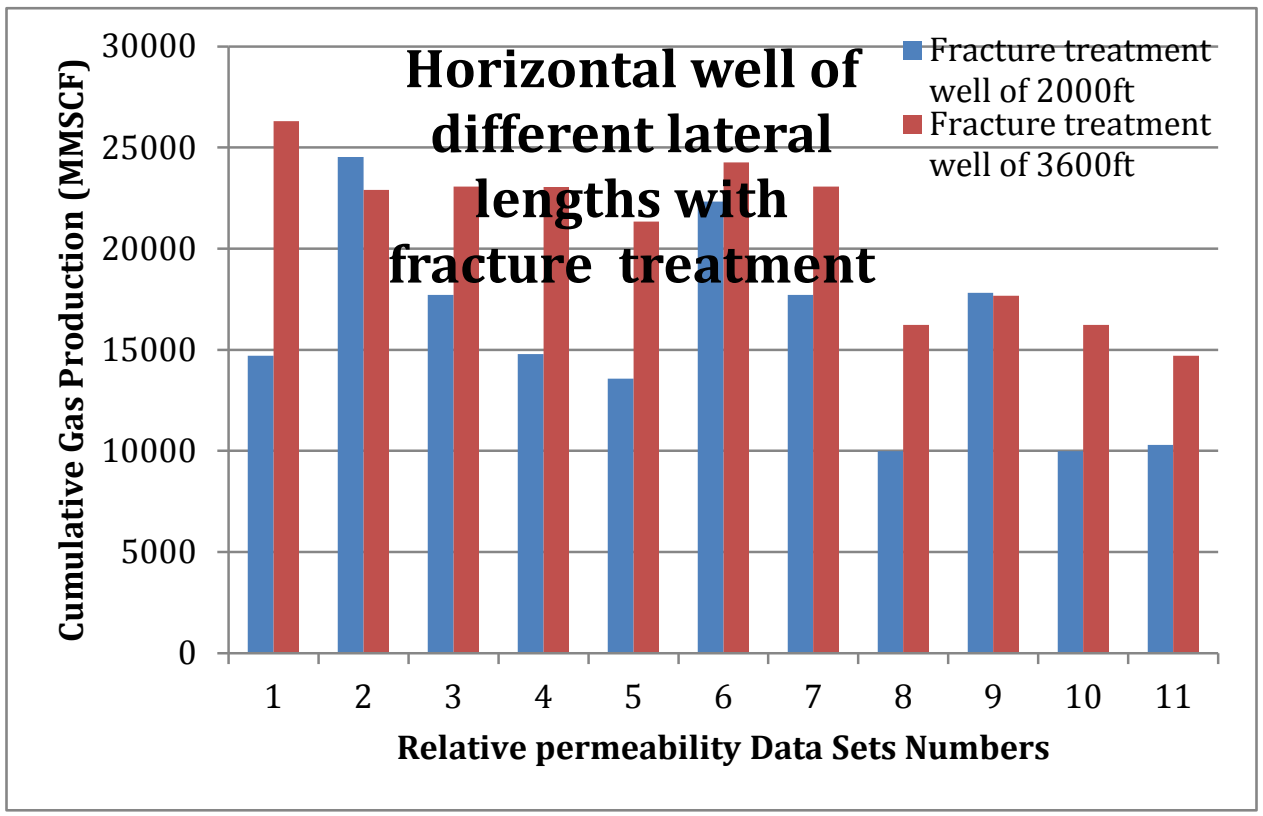

Figure 23: Comparison of 2 different lateral length of horizontal well with fracture treatment (2000ft and $3600 \mathrm{ft}$ ) 


\section{CONCLUSION}

This study shows that cumulative gas production from horizontal fractured treated well under the influence of relative permeability is more than the one from the same lateral length of horizontal well without fracture. The same observation has also been made for the horizontal well of $2000 \mathrm{ft}$. but comparison of the results show that the cumulative gas production for the fractured treated well is significantly higher than the one without fracture. It can be concluded that the relative permeability affects more the fractured short lateral length horizontal well than the longer lateral horizontal well. In addition the gas production from the well of long lateral length of $3600 \mathrm{ft}$. without fracture is more than the one from the well of $2000 \mathrm{ft}$. lateral length. The relative permeability have different degrees of impact on the cumulative gas production.

Results show also a variation in the cumulative gas production as follows: $38.67 \%$ for the horizontal well with $3600 \mathrm{ft}$ lateral; $44.12 \%$ for the horizontal well with $3600 \mathrm{ft}$ lateral fracture treatment; $41.78 \%$ for the horizontal well with $2000 \mathrm{ft}$ lateral; $41.62 \%$ for the horizontal well with $2000 \mathrm{ft}$. lateral and $48.14 \%$ for the vertical well. From these results, it can be seen that the gas production in horizontal well with longer lateral with fracture treatment is influenced more by relative permeability. Comparing the gas production from the different horizontal well of different lateral length, we can say that the impact of relative permeability is more pronounced for the longer horizontal wellbore. The impacts of the relative permeability are quietly insignificant for the vertical well since it doesn't allow the well to produce more gas. The relative permeability affects then more the horizontal fracture well cumulative gas production than the other types of scenarios namely the horizontal well without fracture and the vertical well. It has also 
been noticed that the longer is the well and higher the influence of relative permeability on gas production. The relative permeability associates with fracture stimulate the well and generate more uncertainty for gas production. Furthermore, this study has allowed us to have better understanding of how the influence of relative permeability in gas production history should be taken into account.

The relative permeability is an important factor to consider in cumulative gas production prediction since its effect is not negligible and then has to be considered. 


\section{REFERENCES}

Alzate, Guillermo A., Chen, Her-Yuan, and Teufel, Lawrence W., "Drainage Shape and Size of a Vertically Fractured Tight Gas Well", SPE 71070-MS SPE Rocky Mountain Petroleum Technology Conference, Keystone, Colorado, 21-23 May 2001.

Barree, R.D. and Conway, M.W., "Beyond Beta Factors: A complete Model for Darcy, Forchheimer, and Trans-Forchheimer Flow in Porous Media," Paper SPE 89325 presented at the SPE Annual Technical Conference and Exhibition, Houston, Texas , U.S.A., 26-29 September 2004.

Barree, R.D., and Conway, M.W., "Multiphase Non-Darcy Flow in Proppant Packs," SPE Production \& Operations, pp. 257-268, Vol. 24, No. 2, May 2009.

Casse, F.J. and Ramey Jr., H.J., "The effect of temperature and confining pressure on single-phase flow in consolidated rocks". SPEJ, Vol. 31, No. 8, pp. 1051-1059, August 1979.

Cox, S.A., Stoltz, R.P., and Knobloch, T., “ Determination of Effective Drainage Area for Tight Gas Wells”, SPE 98035-MS SPE Eastern Regional Meeting, Morgantown, West Virginia, 14-16 September 2005.

Craig, Jr., F.F., "The Reservoir Engineering Aspects of Waterflooding." Monograph series, Vol. No. 3, SPE, Richardson, TX. 1993. 
Dickins, Mark I., McVay, Duane A. and Schubarth, Stephen K., "The Impacts of Gravity Segregation on Multiphase Non-Darcy Flow in Hydraulically Fractured Gas Wells" SPE 116748, Denver, Colorado, 21-24 September 2008.

Edmondson, T.A., "Effects of temperature on water flooding." J. Can.Pet.Tech , p 236, Oct- Dec 1965.

Energy Information Administration (EIA), Natural Gas liquids Reserves, U.S Crude Oil, Annual Report, 2002.

Gawish, Ahmed and Al-Homadhi, Emad, "Relative Permeability Curves for High Pressures, High Temperature Reservoir Conditions" Oil and Gas Business, 2008.

Holditch, S.A., "Tight Gas Sands.” JPT, pp. 84-90, June 2006.

Honarpour, M., Koederitz, L., and Harvey, A.H., "Relative Permeability of Petroleum Reservoirs,” CRC Press, Boca Raton, FL., 1986.

Honarpour, M. and Mahmood, S.M., "Relative-Permeability Measurements: An Overview.” JPT, Vol. 40, No. 8, August 1988.

Khan, Waqar Ali, Rehman, Shar Abdur, Akram, Agha Hasan and Ahmad, Ammar, "Factor affecting Production Behavior in Tight Gas Reservoirs," paper SPE 149045 presented at SPE/DGS Saudi Arabia Section Technical Symposium and Exhibition, Al-Khobar, Sauid Arabia, 15-18 May 2011. 
Koch, D.L. and Ladd, A.J.C., "Moderate Reynolds Number Flows through Periodic and Random Arrays of Aligned Cylinders," J. Fluid Mech, 349, 31-66, 1977.

Kumar, Anil, "Drainage Areas for wells in Edge Water-Drive Reservoirs", Journal of Petroleum Technology, pp 1673-1682 Vol. 29, No 12, December 1977.

Miller, M.A. and Ramey Jr., H.J. "Effect of temperature on oil/water relative permeability of unconsolidated and consolidated sands," SPE paper 12116, December 1985.

Olson, K.E., Haidar, S., Milton-Taylor, D., Olsen, E., “ Multiphase Non-Darcy Pressure Drop in Hydraulic Fracturing", Paper SPE 90406 presented at the Annual Technical Conference and Exhibition, Houston, Texas, 26-29 September 2004.

Pankaj, P. and Kumar, V., "Well Testing in Tight Gas Reservoir: Today's Challenge and Future's Opportunity," SPE paper 129032 presented at the SPE Oil and Gas India Conference and Exhibition, Mumbai, India, 20-22 January 2010.

Ramey, H,J., Kumar, Anil, and Gulatie, M.S., “ Gas Well Test Analysis Under Water-Drive Conditions.” Monograph on Project 61-51, AGA, Arlington, VA, 1973.

Rushing, J.A., Newsham, K.E. and Van Fraassen, K.C., " Measurement of the Two-Phase Gas Slippage Phenomenon and Its Effect on Gas Relative Permeability in Tight Gas Sands," Paper SPE 84297 presented at the 2003 SPE Annual Technical Conference and Exhibition, Denver CO, Oct 5-8, 2003 
Rushing, J.A and Sullivan, R.B. " Evaluation of a Hybrid Water- Frac Stimulation Technology in the Bossier Tight Gas Sand Play," paper SPE 84394 presented at the SPE Annual Technical Conference and Exhibition, Denver, CO, Oct.5-8, 2003.

Schembre, J.M., Tang, G-Q. and Kovscek, A.R., "Effect of temperature on relative permeability for heavy-oil diatomite reservoirs". SPE paper 93831 presented at the Western Regional Meeting, Irvine, CA, March 30 - April 1, 2005.

Sullivan, R.B., Rushing, J.A., Bachman, R.C., Settari, A., Conway, M.W., and Barree, R.D., "Evaluation of Nonlinear Relative Permeabilities and Their Impact on Waterfrac Performance in Tight Gas Sands,” paper SPE 98329 presented at International Symposium and Exhibition on Formation Damage Control, Lafayette, Louisiana, 15-17 February 2006.

Torabzaden, S.J. and Handy, L.L., "The effect of temperature and interfacial tension on water/oil relative permeabilities of consolidated sands." SPE paper 12689, Symposium on EOR, Tulsa, OK, April 1984.

Van Spronsen, E., Three-Phase Relative Permeability Measurement Using the Centrifuge Method," paper SPE 10688 presented at Enhanced Oil Recovery Symposium, Tulsa, Okla., 4-7 April 1982.

Vasconcelos, H.H.M, Costa, U.M.S., and Almeida, M.P., “Turbulent Effects on Fluid Flow Through Disordered Porous Media,” Phisica A, 299, 371-377, 2001. 
Yost II, A.B., Overbey Jr., W.K., "Production and Stimulation Analysis of Multiple Hydraulic Fracturing of a 2,000 ft Horizontal Well,” paper SPE 19090 presented at Gas Technology Symposium, Dallas, TX, 7-9 June 1989. 


\section{Appendices A}

This document shows the entire relative permeability data table that has been used with their respective curves for all the 11 sets of relative permeability data.

Table A 1: Relative permeability data for Run\#0

\begin{tabular}{|l|l|l|l|}
\hline Sw & Krw & \multicolumn{1}{|r|}{ SI } & Krg \\
\hline 0.2 & 0 & 0.2 & 0.5 \\
\hline 0.25 & 0 & 0.228125 & 0.411987 \\
\hline 0.3 & & 0.25625 & 0.334961 \\
\hline 0.34375 & $4.88 \mathrm{E}-05$ & 0.284375 & 0.268188 \\
\hline 0.3875 & 0.000391 & 0.3125 & 0.210937 \\
\hline 0.43125 & 0.001318 & 0.340625 & 0.162476 \\
\hline 0.475 & 0.003125 & 0.36875 & 0.12207 \\
\hline 0.51875 & 0.006104 & 0.396875 & 0.088989 \\
\hline 0.5625 & 0.010547 & 0.425 & 0.0625 \\
\hline 0.60625 & 0.016748 & 0.453125 & 0.04187 \\
\hline 0.65 & 0.025 & 0.48125 & 0.026367 \\
\hline 0.69375 & 0.035596 & 0.509375 & 0.015259 \\
\hline 0.7375 & 0.048828 & 0.5375 & 0.007813 \\
\hline 0.78125 & 0.6499 & 0.565625 & 0.003296 \\
\hline
\end{tabular}




\begin{tabular}{|r|l|l|r|}
\hline 0.825 & 0.084375 & 0.59375 & 0.000977 \\
\hline 0.86875 & 0.107275 & 0.621875 & 0.000122 \\
\hline 0.9125 & 0.133984 & 0.65 & 0 \\
\hline 0.95625 & 0.164795 & 0.725 & 0 \\
\hline 1 & 0.2 & 0.8 & 0 \\
\hline
\end{tabular}

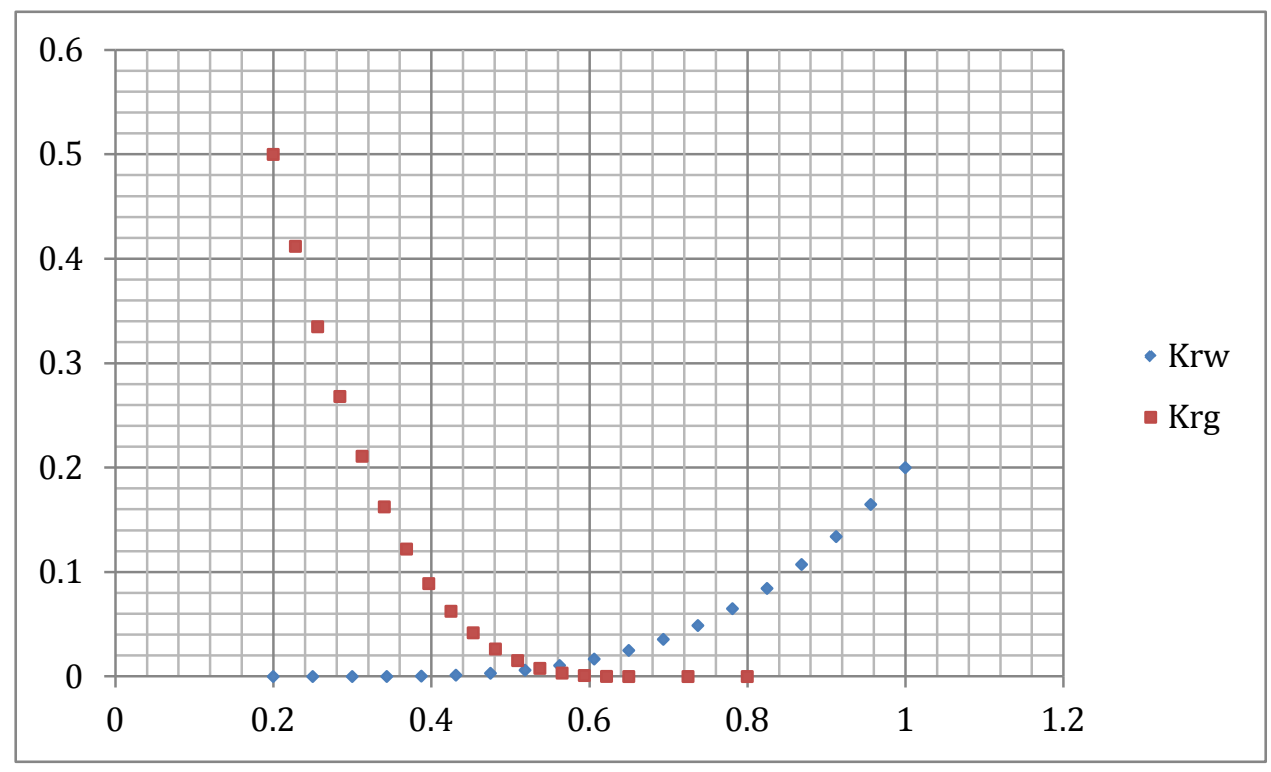

Figure A-1: Gas-water Relative Permeability curve for Run\#0 
Table A-2: Relative permeability data for Run\#1

\begin{tabular}{|c|c|c|c|}
\hline Sw & Krw & SI & $\mathrm{Krg}$ \\
\hline 0.2 & 0 & 0.2 & 0.5 \\
\hline 0.25 & 0 & 0.228125 & 0.411987 \\
\hline 0.3 & 0 & 0.25625 & 0.334961 \\
\hline 0.34375 & $3.88 \mathrm{E}-05$ & 0.284375 & 0.268188 \\
\hline 0.3875 & 0.000411 & 0.3125 & 0.210937 \\
\hline 0.43125 & 0.002184 & 0.340625 & 0.162476 \\
\hline 0.475 & 0.004125 & 0.36875 & 0.12207 \\
\hline 0.51875 & 0.007104 & 0.396875 & 0.088989 \\
\hline 0.5625 & 0.015 & 0.425 & 0.0625 \\
\hline 0.60625 & 0.02 & 0.453125 & 0.04187 \\
\hline 0.65 & 0.03 & 0.48125 & 0.026367 \\
\hline 0.69375 & 0.04 & 0.509375 & 0.015259 \\
\hline 0.7375 & 0.05 & 0.5375 & 0.007813 \\
\hline 0.78125 & 0.06 & 0.565625 & 0.003296 \\
\hline 0.825 & 0.07 & 0.59375 & 0.000977 \\
\hline 0.86875 & 0.1 & 0.621875 & 0.000122 \\
\hline 0.9125 & 0.12 & 0.65 & 0 \\
\hline 0.95625 & 0.16 & 0.725 & 0 \\
\hline 1 & 0.2 & 0.8 & 0 \\
\hline
\end{tabular}




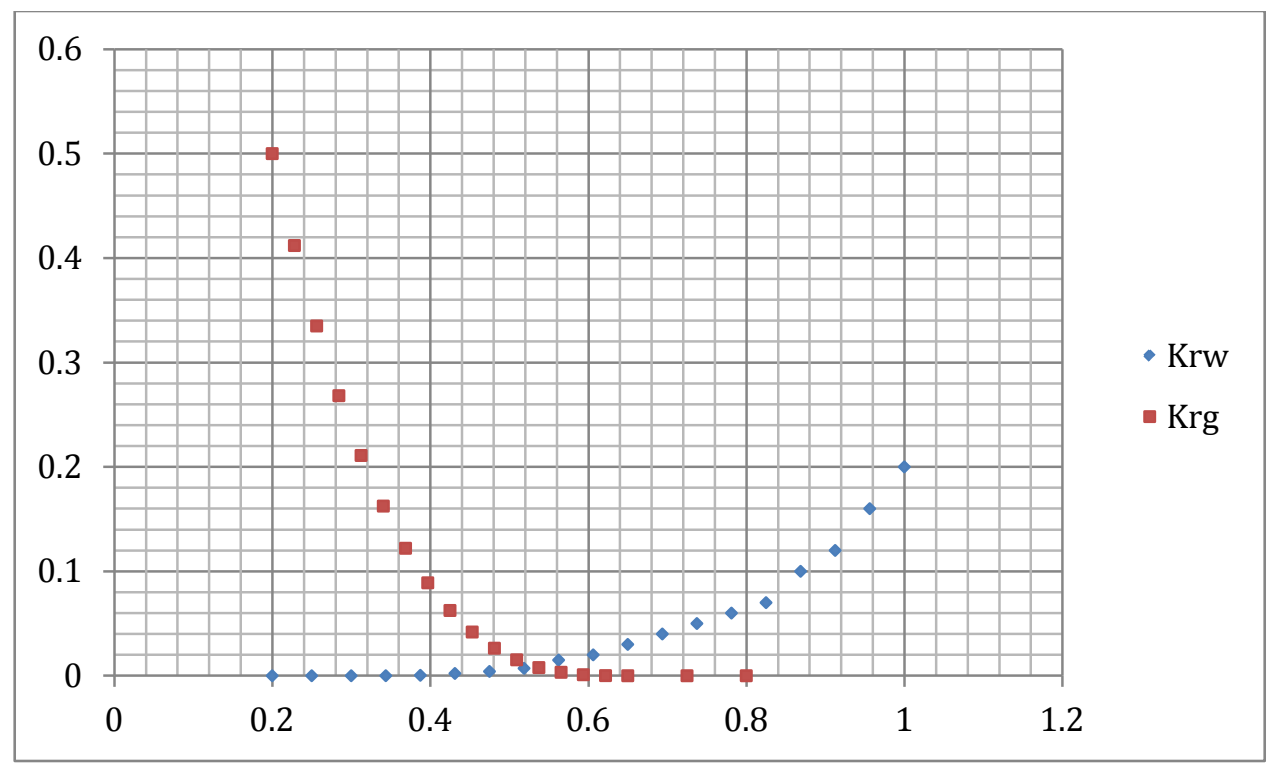

Figure A-2: Gas-water relative permeability curve for Run\#1

Table A-3: Relative permeability data for Run\#2

\begin{tabular}{|l|l|l|l|}
\hline Sw & Krw & \multicolumn{1}{|c|}{ SI } & Krg \\
\hline 0.2 & & 0.2 & 0.5 \\
\hline 0.25 & 0.004 & 0.228125 & 0.411987 \\
\hline 0.3 & 0.018 & 0.25625 & 0.334961 \\
\hline 0.34375 & 0.03 & 0.284375 & 0.268188 \\
\hline 0.3875 & 0.05 & 0.3125 & 0.210937 \\
\hline 0.43125 & 0.07 & 0.340625 & 0.162476 \\
\hline 0.475 & 0.09 & 0.36875 & 0.12207 \\
\hline 0.51875 & 0.11 & 0.396875 & 0.088989 \\
\hline 0.5625 & 0.13 & 0.425 & 0.0625 \\
\hline
\end{tabular}




\begin{tabular}{|l|l|l|l|}
\hline 0.60625 & 0.15 & 0.453125 & 0.04187 \\
\hline 0.65 & 0.17 & 0.48125 & 0.026367 \\
\hline 0.69375 & 0.21 & 0.509375 & 0.015259 \\
\hline 0.7375 & 0.23 & 0.5375 & 0.007813 \\
\hline 0.78125 & 0.26 & 0.565625 & 0.003296 \\
\hline 0.825 & 0.29 & 0.59375 & 0.000977 \\
\hline 0.86875 & 0.32 & 0.621875 & 0.000122 \\
\hline 0.9125 & 0.35 & 0.65 & 0 \\
\hline 0.95625 & 0.37 & 0.725 & 0 \\
\hline & 0.39 & 0.8 & 0 \\
\hline
\end{tabular}

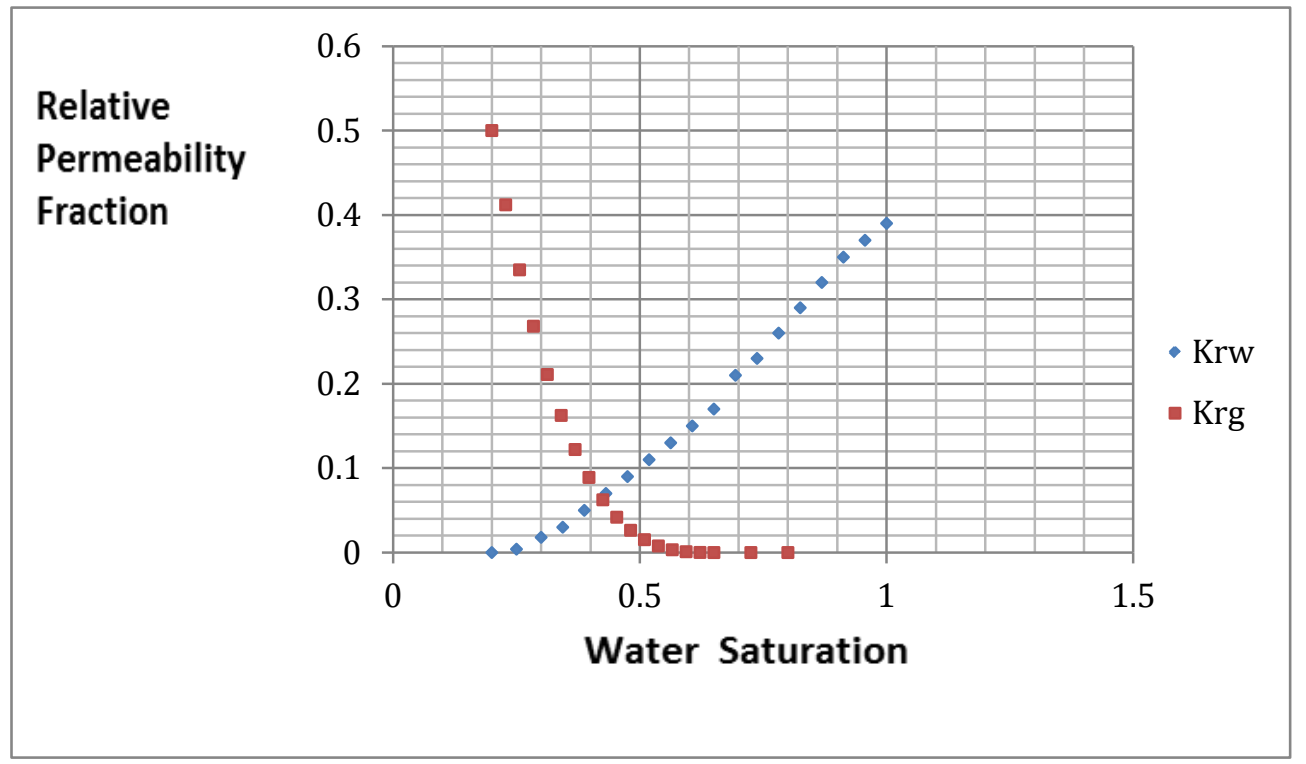

Figure A 3: Gas- water Relative Permeability Curve for Run\#2 
Table A-4: Relative permeability data for Run\#3

\begin{tabular}{|c|c|c|c|}
\hline Sw & Krw & SI & $\mathrm{Krg}$ \\
\hline 0.2 & 0 & 0.2 & 0.5 \\
\hline 0.25 & 0 & 0.275 & 0.453987 \\
\hline 0.3 & 0 & 0.35 & 0.37561 \\
\hline 0.34375 & $4.88 \mathrm{E}-05$ & 0.378125 & 0.328188 \\
\hline 0.3875 & 0.000391 & 0.40625 & 0.260537 \\
\hline 0.43125 & 0.001518 & 0.434375 & 0.222476 \\
\hline 0.475 & 0.004125 & 0.4625 & 0.18207 \\
\hline 0.51875 & 0.007104 & 0.490625 & 0.098989 \\
\hline 0.5625 & 0.015547 & 0.51875 & 0.0625 \\
\hline 0.60625 & 0.018748 & 0.546875 & 0.05287 \\
\hline 0.65 & 0.035 & 0.575 & 0.046367 \\
\hline 0.69375 & 0.045596 & 0.603125 & 0.035259 \\
\hline 0.7375 & 0.058828 & 0.63125 & 0.009813 \\
\hline 0.78125 & 0.06499 & 0.659375 & 0.007296 \\
\hline 0.825 & 0.084375 & 0.6875 & 0.000886 \\
\hline 0.86875 & 0.127275 & 0.715625 & 0.000622 \\
\hline 0.9125 & 0.145984 & 0.74375 & 0 \\
\hline 0.95625 & 0.164795 & 0.771875 & 0 \\
\hline 1 & 0.2 & 0.8 & 0 \\
\hline
\end{tabular}




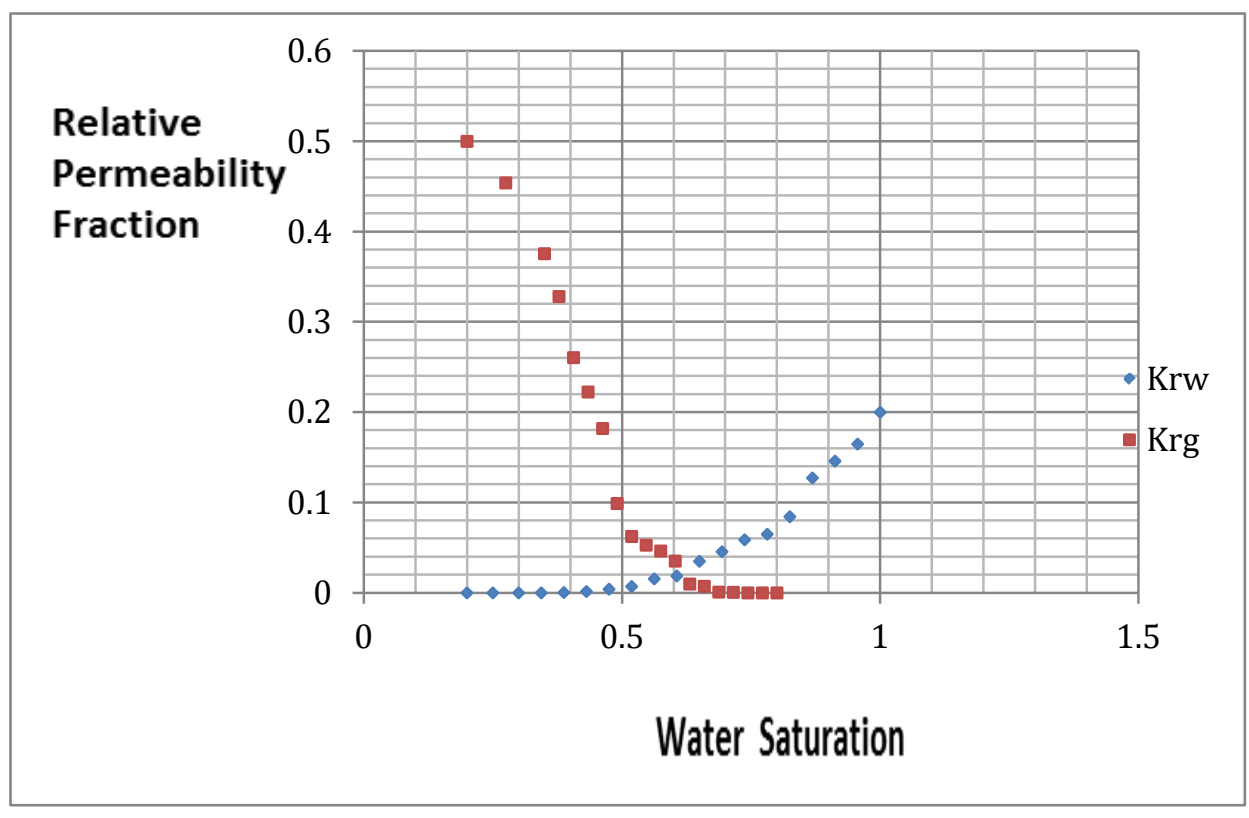

Figure A-4: Gas-water relative permeability curve for Run\#3 
Table A 5: Relative permeability data for Run\#4

\begin{tabular}{|l|l|l|l|}
\hline Sw & Krw & \multicolumn{1}{|r|}{ SI } & Krg \\
\hline 0.2 & & 0.2 & 0.43 \\
\hline 0.25 & 0.005 & 0.228125 & 0.37098 \\
\hline 0.3 & 0.015 & 0.25625 & 0.34246 \\
\hline 0.34375 & 0.02 & 0.284375 & 0.316168 \\
\hline 0.3875 & 0.04 & 0.3125 & 0.27053 \\
\hline 0.43125 & 0.05 & 0.340625 & 0.25217 \\
\hline 0.475 & 0.07 & 0.36875 & 0.20107 \\
\hline 0.51875 & 0.09 & 0.396875 & 0.16898 \\
\hline 0.5625 & 0.1 & 0.425 & 0.1285 \\
\hline 0.60625 & 0.11 & 0.453125 & 0.082 \\
\hline 0.65 & 0.13 & 0.48125 & 0.075355 \\
\hline 0.69375 & 0.15 & 0.509375 & 0.066219 \\
\hline 0.7375 & 0.17 & 0.5375 & 0.04681 \\
\hline 0.78125 & 0.2 & 0.565625 & 0.03986 \\
\hline 0.825 & 0.22 & 0.59375 & 0.0347 \\
\hline 0.86875 & 0.24 & 0.621875 & 0.02119 \\
\hline 0.9125 & 0.26 & 0.65 & 0.015 \\
\hline 0.95625 & 0.28 & 0.725 & \\
\hline & 0.3 & 0.8 & \\
\hline & & & \\
\hline & & & \\
\hline & & & \\
\hline
\end{tabular}




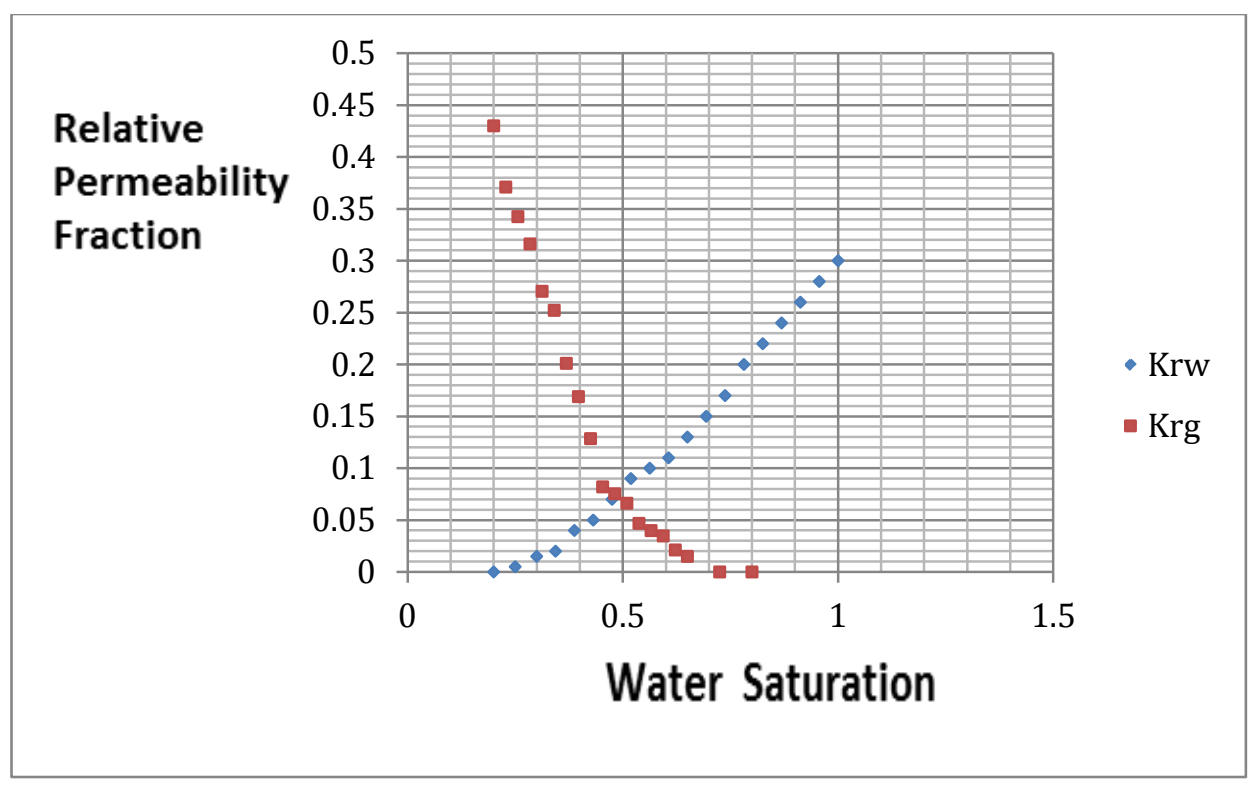

Figure A-5: Gas water Relative permeability curve for Run\#4 
Table A-6: Relative permeability data for Run\#5

\begin{tabular}{|c|c|c|c|}
\hline Sw & Krw & SI & $\mathrm{Krg}$ \\
\hline 0.2 & 0 & 0.2 & 0.43 \\
\hline 0.25 & 0 & 0.228125 & 0.37098 \\
\hline 0.3 & 0 & 0.25625 & 0.34246 \\
\hline 0.34375 & $4.88 \mathrm{E}-05$ & 0.284375 & 0.316168 \\
\hline 0.3875 & 0.000391 & 0.3125 & 0.27053 \\
\hline 0.43125 & 0.001318 & 0.340625 & 0.25217 \\
\hline 0.475 & 0.003125 & 0.36875 & 0.20107 \\
\hline 0.51875 & 0.006104 & 0.396875 & 0.16898 \\
\hline 0.5625 & 0.010547 & 0.425 & 0.1285 \\
\hline 0.60625 & 0.016748 & 0.453125 & 0.082 \\
\hline 0.65 & 0.025 & 0.48125 & 0.075355 \\
\hline 0.69375 & 0.035596 & 0.509375 & 0.066219 \\
\hline 0.7375 & 0.048828 & 0.5375 & 0.04681 \\
\hline 0.78125 & 0.06499 & 0.565625 & 0.03986 \\
\hline 0.825 & 0.084375 & 0.59375 & 0.0347 \\
\hline 0.86875 & 0.107275 & 0.621875 & 0.02119 \\
\hline 0.9125 & 0.133984 & 0.65 & 0.015 \\
\hline 0.95625 & 0.164795 & 0.725 & 0 \\
\hline 1 & 0.2 & 0.8 & 0 \\
\hline
\end{tabular}




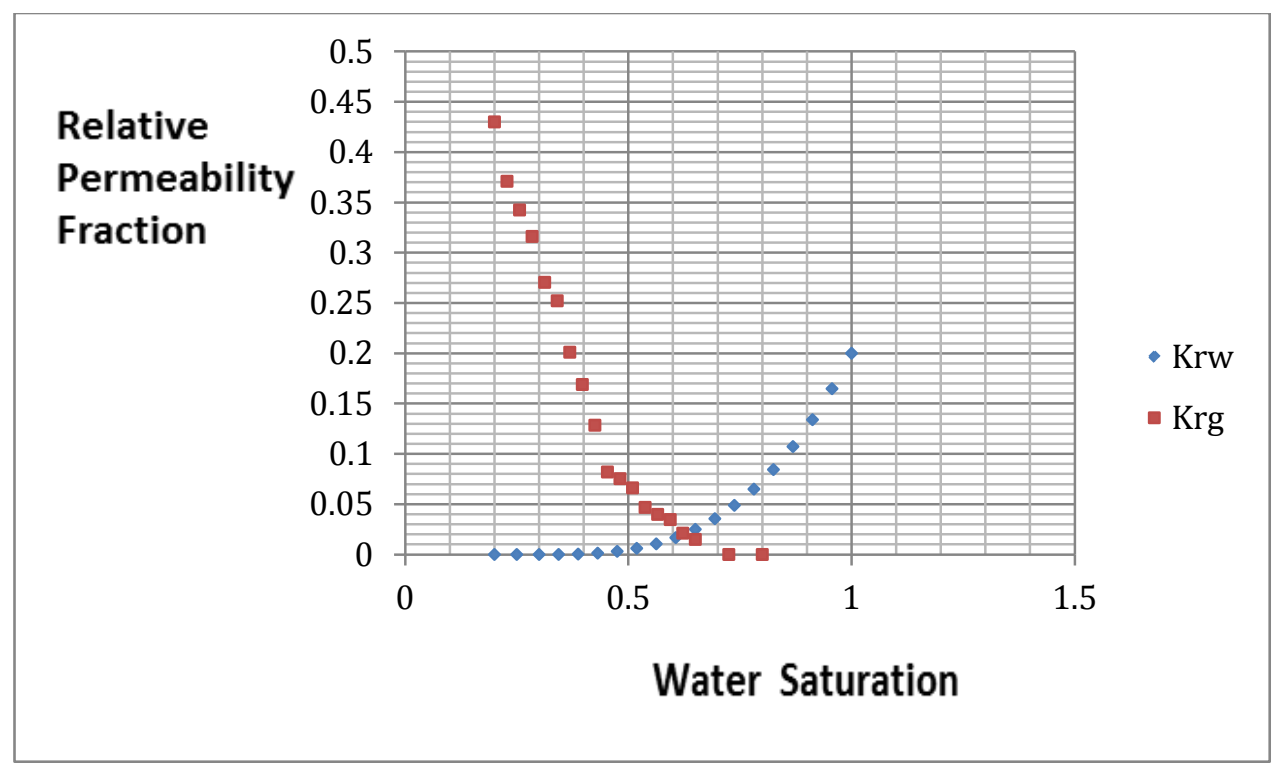

Figure A-6: Gas water Relative permeability curve for Run\#5 
Table A-7: Relative permeability data for Run\#6

\begin{tabular}{|c|c|c|c|}
\hline Sw & Krw & SI & $\mathrm{Krg}$ \\
\hline 0.2 & 0 & 0.2 & 0.5 \\
\hline 0.25 & 0.005 & 0.228125 & 0.411987 \\
\hline 0.3 & 0.015 & 0.25625 & 0.334961 \\
\hline 0.34375 & 0.02 & 0.284375 & 0.268188 \\
\hline 0.3875 & 0.04 & 0.3125 & 0.210937 \\
\hline 0.43125 & 0.05 & 0.340625 & 0.162476 \\
\hline 0.475 & 0.07 & 0.36875 & 0.12207 \\
\hline 0.51875 & 0.09 & 0.396875 & 0.088989 \\
\hline 0.5625 & 0.1 & 0.425 & 0.0625 \\
\hline 0.60625 & 0.11 & 0.453125 & 0.04187 \\
\hline 0.65 & 0.13 & 0.48125 & 0.026367 \\
\hline 0.69375 & 0.15 & 0.509375 & 0.015259 \\
\hline 0.7375 & 0.17 & 0.5375 & 0.007813 \\
\hline 0.78125 & 0.2 & 0.565625 & 0.003296 \\
\hline 0.825 & 0.22 & 0.59375 & 0.000977 \\
\hline 0.86875 & 0.24 & 0.621875 & 0.000122 \\
\hline 0.9125 & 0.26 & 0.65 & 0 \\
\hline 0.95625 & 0.28 & 0.725 & 0 \\
\hline 1 & 0.3 & 0.8 & 0 \\
\hline
\end{tabular}




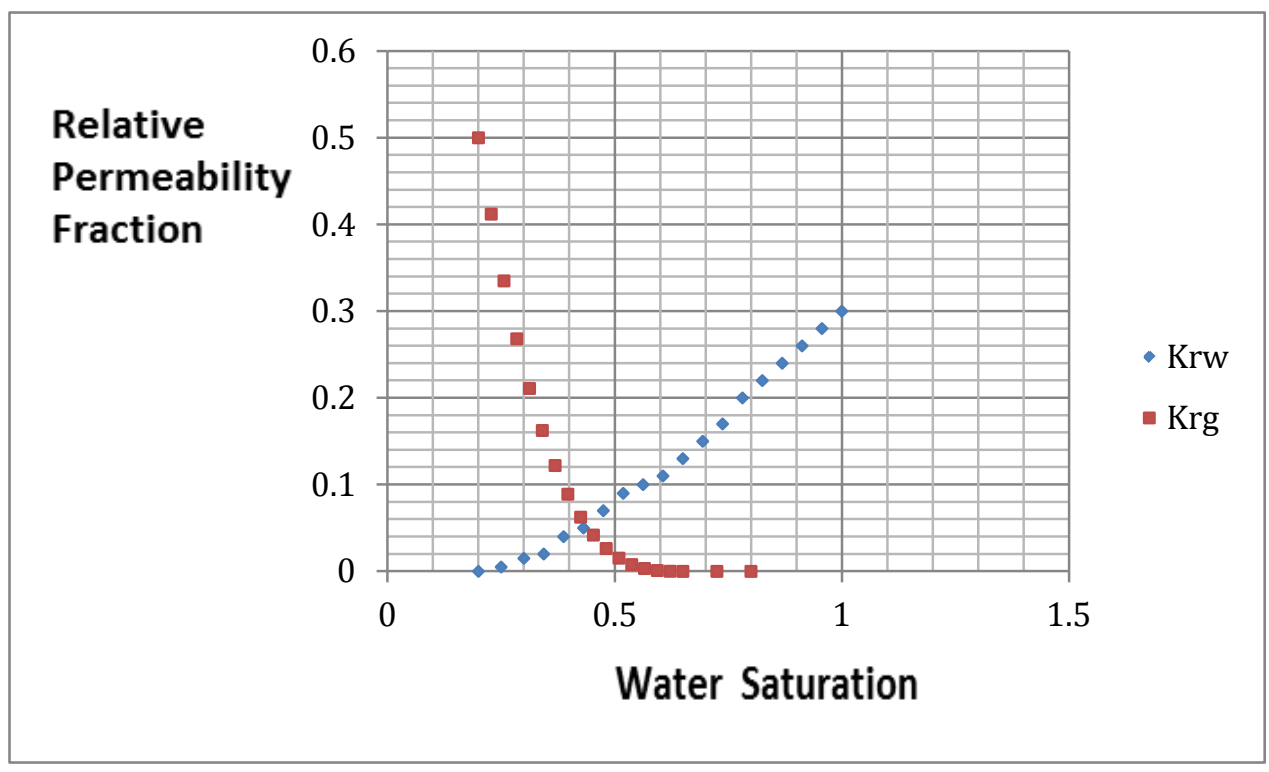

Figure A-7: Gas water Relative permeability curve for Run\#6 
Table A-8: Relative permeability data for Run\#7

\begin{tabular}{|c|c|c|c|}
\hline Sw & Krw & SI & $\mathrm{Krg}$ \\
\hline 0.2 & 0 & 0.2 & 0.25 \\
\hline 0.25 & 0.005 & 0.228125 & 0.22008 \\
\hline 0.3 & 0.015 & 0.25625 & 0.19005 \\
\hline 0.34375 & 0.02 & 0.284375 & 0.176168 \\
\hline 0.3875 & 0.04 & 0.3125 & 0.15053 \\
\hline 0.43125 & 0.05 & 0.340625 & 0.11217 \\
\hline 0.475 & 0.07 & 0.36875 & 0.10057 \\
\hline 0.51875 & 0.09 & 0.396875 & 0.06898 \\
\hline 0.5625 & 0.1 & 0.425 & 0.0325 \\
\hline 0.60625 & 0.11 & 0.453125 & 0.03 \\
\hline 0.65 & 0.13 & 0.48125 & 0.020155 \\
\hline 0.69375 & 0.15 & 0.509375 & 0.011219 \\
\hline 0.7375 & 0.17 & 0.5375 & 0.00581 \\
\hline 0.78125 & 0.2 & 0.565625 & 0.002586 \\
\hline 0.825 & 0.22 & 0.59375 & 0.00065 \\
\hline 0.86875 & 0.24 & 0.621875 & 0.000505 \\
\hline 0.9125 & 0.26 & 0.65 & 0 \\
\hline 0.95625 & 0.28 & 0.725 & 0 \\
\hline 1 & 0.3 & 0.8 & 0 \\
\hline
\end{tabular}




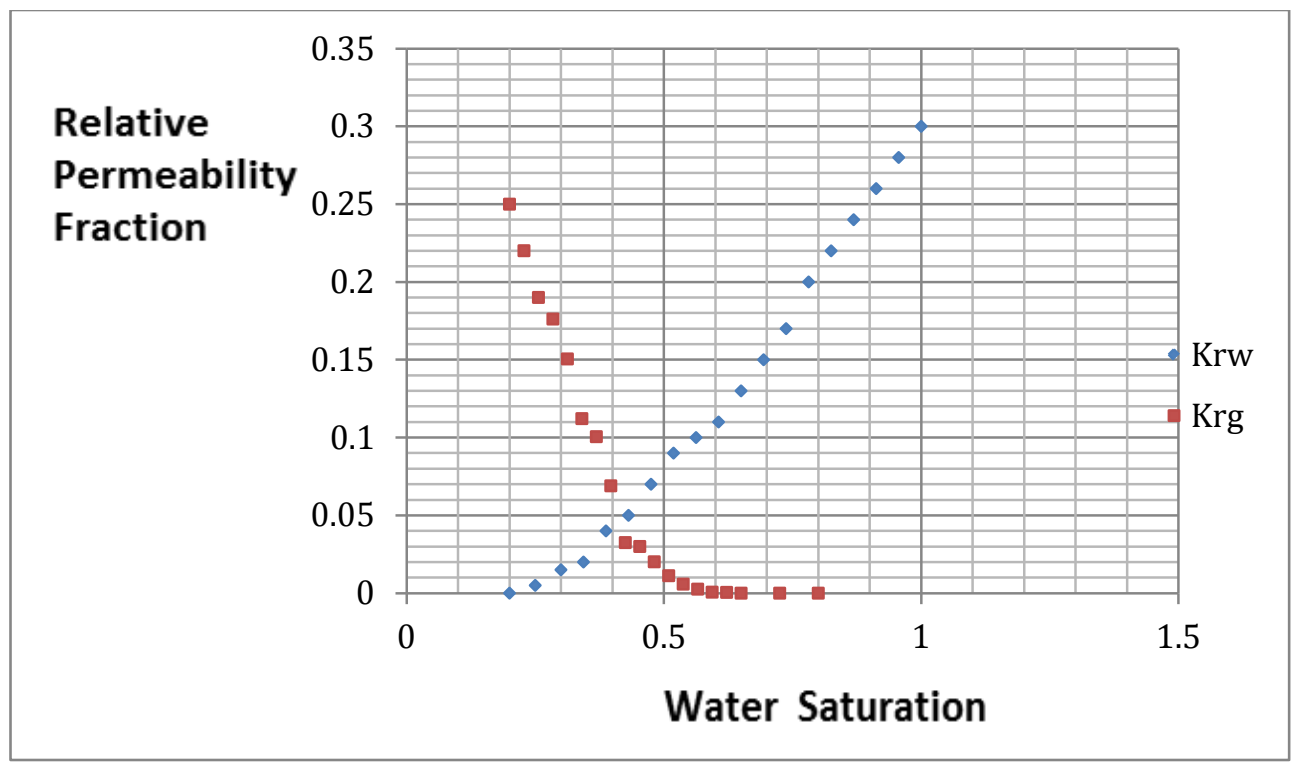

Figure A-8: Gas water Relative permeability curve for Run\#7 
Table A-9: Relative permeability data for Run\#8

\begin{tabular}{|l|l|l|l|}
\hline Sw & \multicolumn{1}{|c|}{ Krw } & Krg \\
\hline 0.2 & 0 & 0.2 & 0.3 \\
\hline 0.25 & 0 & 0.228125 & 0.273672 \\
\hline 0.3 & & 0.25625 & 0.261949 \\
\hline 0.34375 & 0.004688 & 0.284375 & 0.228047 \\
\hline 0.3875 & 0.010547 & 0.3125 & 0.204992 \\
\hline 0.43125 & 0.01875 & 0.340625 & 0.171797 \\
\hline 0.475 & 0.029297 & 0.36875 & 0.127188 \\
\hline 0.51875 & 0.064931 & 0.396875 & 0.114135 \\
\hline 0.5625 & 0.071057 & 0.425 & 0.098208 \\
\hline 0.60625 & 0.077182 & 0.453125 & 0.066156 \\
\hline 0.65 & 0.094922 & 0.48125 & 0.045329 \\
\hline 0.69375 & 0.132312 & 0.509375 & 0.040429 \\
\hline 0.7375 & 0.138438 & 0.5375 & 0.030628 \\
\hline 0.78125 & 0.187443 & 0.565625 & 0.023277 \\
\hline 0.825 & 0.194793 & 0.59375 & 0.004688 \\
\hline 0.86875 & 0.256049 & 0.621875 & 0.001172 \\
\hline 0.9125 & 0.263672 & 0.65 & 0 \\
\hline 0.95625 & 0.27 & 0.725 & 0 \\
\hline 1 & 0.3 & 0.8 & \\
\hline
\end{tabular}




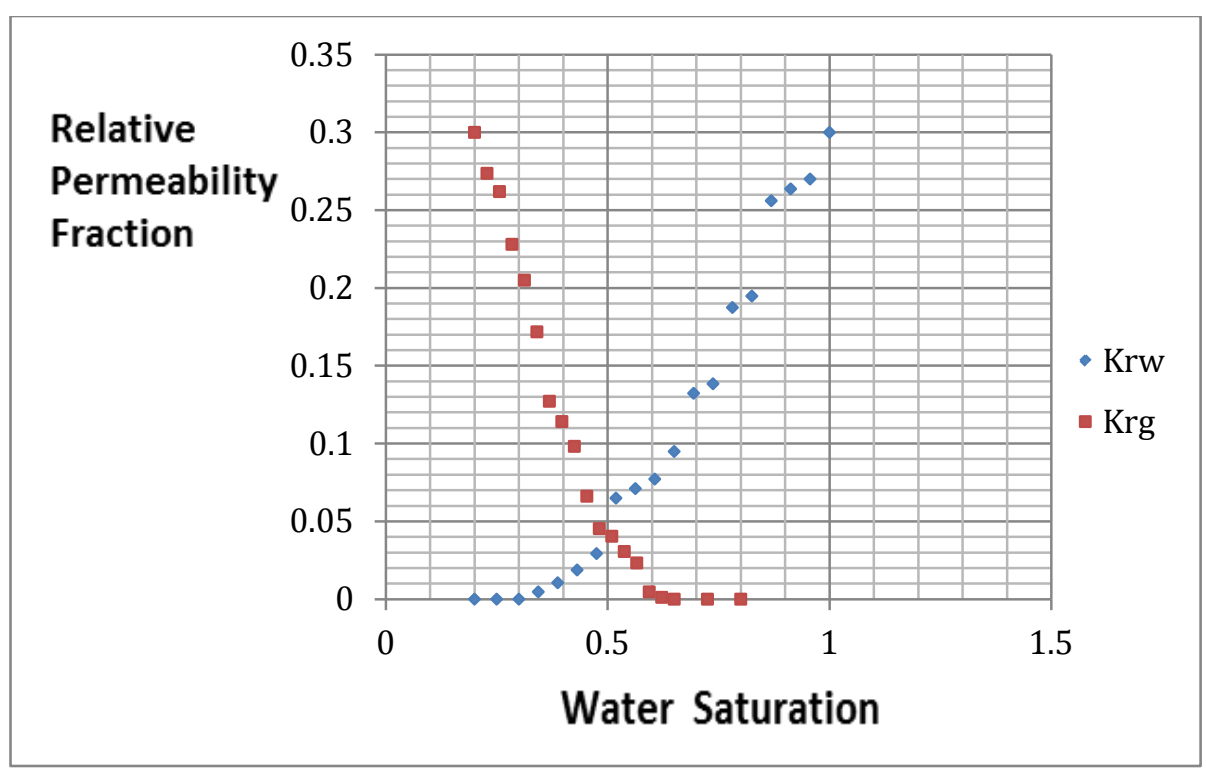

Figure A 9: Gas water Relative permeability curve for Run\#8 
Table A-10: Relative permeability data for Run\#9

\begin{tabular}{|c|c|c|c|}
\hline Sw & Krw & SI & Krg \\
\hline 0.2 & 0 & 0.2 & 0.25 \\
\hline 0.25 & 0.005 & 0.228125 & 0.22008 \\
\hline 0.3 & 0.015 & 0.25625 & 0.19005 \\
\hline 0.34375 & 0.02 & 0.284375 & 0.176168 \\
\hline 0.3875 & 0.04 & 0.3125 & 0.15053 \\
\hline 0.43125 & 0.05 & 0.340625 & 0.11217 \\
\hline 0.475 & 0.07 & 0.36875 & 0.10057 \\
\hline 0.51875 & 0.09 & 0.396875 & 0.06898 \\
\hline 0.5625 & 0.1 & 0.425 & 0.0325 \\
\hline 0.60625 & 0.11 & 0.453125 & 0.03 \\
\hline 0.65 & 0.13 & 0.48125 & 0.020155 \\
\hline 0.69375 & 0.15 & 0.509375 & 0.011219 \\
\hline 0.7375 & 0.17 & 0.5375 & 0.00581 \\
\hline 0.78125 & 0.2 & 0.565625 & 0.002586 \\
\hline 0.825 & 0.22 & 0.59375 & 0.00065 \\
\hline 0.86875 & 0.24 & 0.621875 & 0.000505 \\
\hline 0.9125 & 0.26 & 0.65 & 0 \\
\hline 0.95625 & 0.28 & 0.725 & 0 \\
\hline 1 & 0.3 & 0.8 & 0 \\
\hline
\end{tabular}




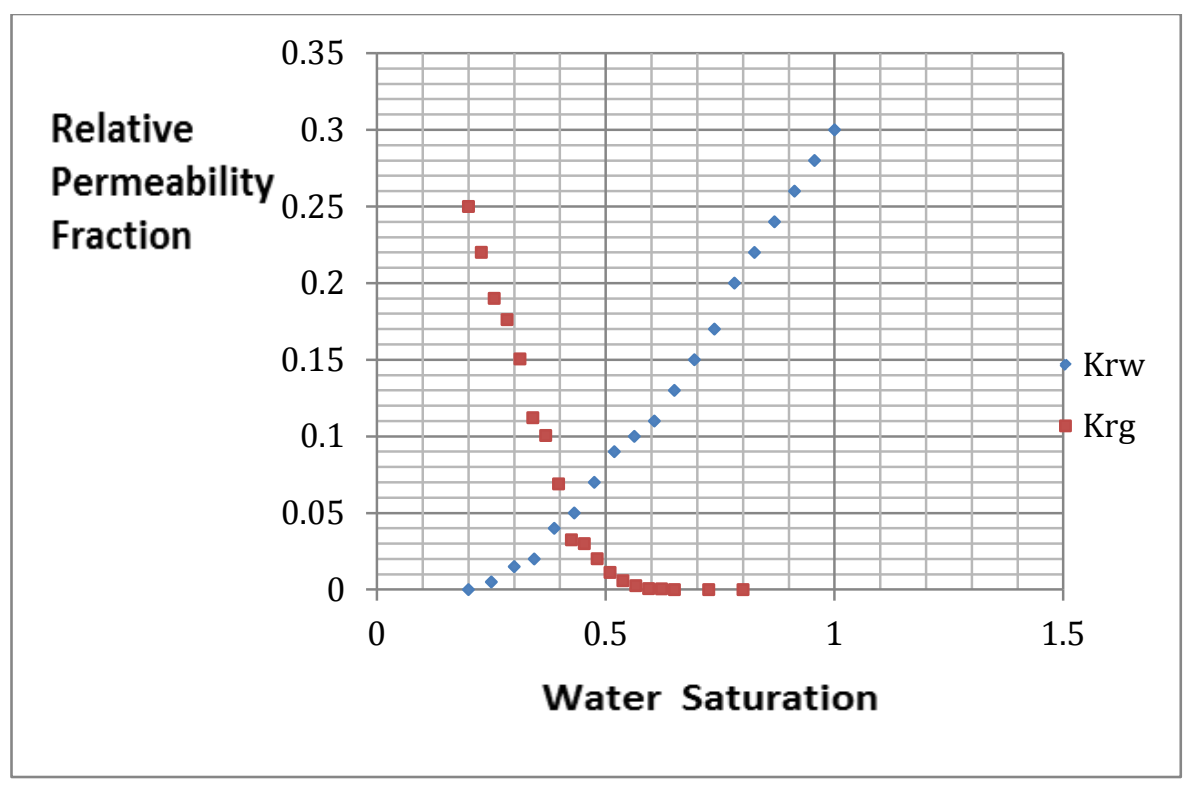

Figure A-10: Gas water Relative permeability curve for Run\#9 
Table A-11: Relative permeability data for Run\#10

\begin{tabular}{|c|c|c|c|}
\hline Sw & Krw & SI & $\mathrm{Krg}$ \\
\hline 0.2 & & 0.2 & 0.25 \\
\hline 0.25 & 0.004 & 0.228125 & 0.22008 \\
\hline 0.3 & 0.018 & 0.25625 & 0.19005 \\
\hline 0.34375 & 0.03 & 0.284375 & 0.176168 \\
\hline 0.3875 & 0.05 & 0.3125 & 0.15053 \\
\hline 0.43125 & 0.07 & 0.340625 & 0.11217 \\
\hline 0.475 & 0.09 & 0.36875 & 0.10057 \\
\hline 0.51875 & 0.11 & 0.396875 & 0.06898 \\
\hline 0.5625 & 0.13 & 0.425 & 0.0325 \\
\hline 0.60625 & 0.15 & 0.453125 & 0.03 \\
\hline 0.65 & 0.17 & 0.48125 & 0.020155 \\
\hline 0.69375 & 0.21 & 0.509375 & 0.011219 \\
\hline 0.7375 & 0.23 & 0.5375 & 0.00581 \\
\hline 0.78125 & 0.26 & 0.565625 & 0.002586 \\
\hline 0.825 & 0.29 & 0.59375 & 0.00065 \\
\hline 0.86875 & 0.32 & 0.621875 & 0.000505 \\
\hline 0.9125 & 0.35 & 0.65 & 0 \\
\hline 0.95625 & 0.37 & 0.725 & 0 \\
\hline 1 & 0.39 & 0.8 & 0 \\
\hline
\end{tabular}




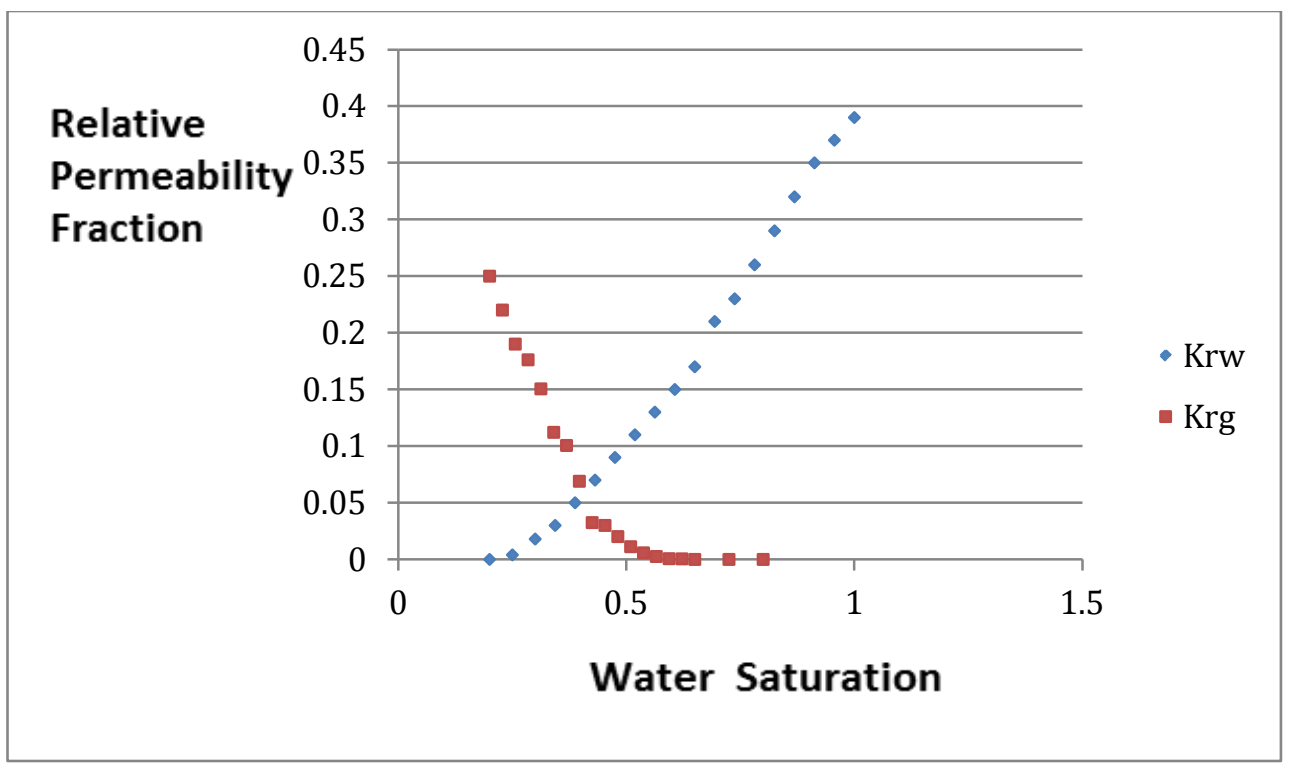

Figure A 11: Gas water Relative permeability for Run\#10 


\section{Appendices B}

This document summarizes the different graphs resulting from the 11 different set of relative permeability data for both vertical and horizontal well of $2000 \mathrm{ft}$.

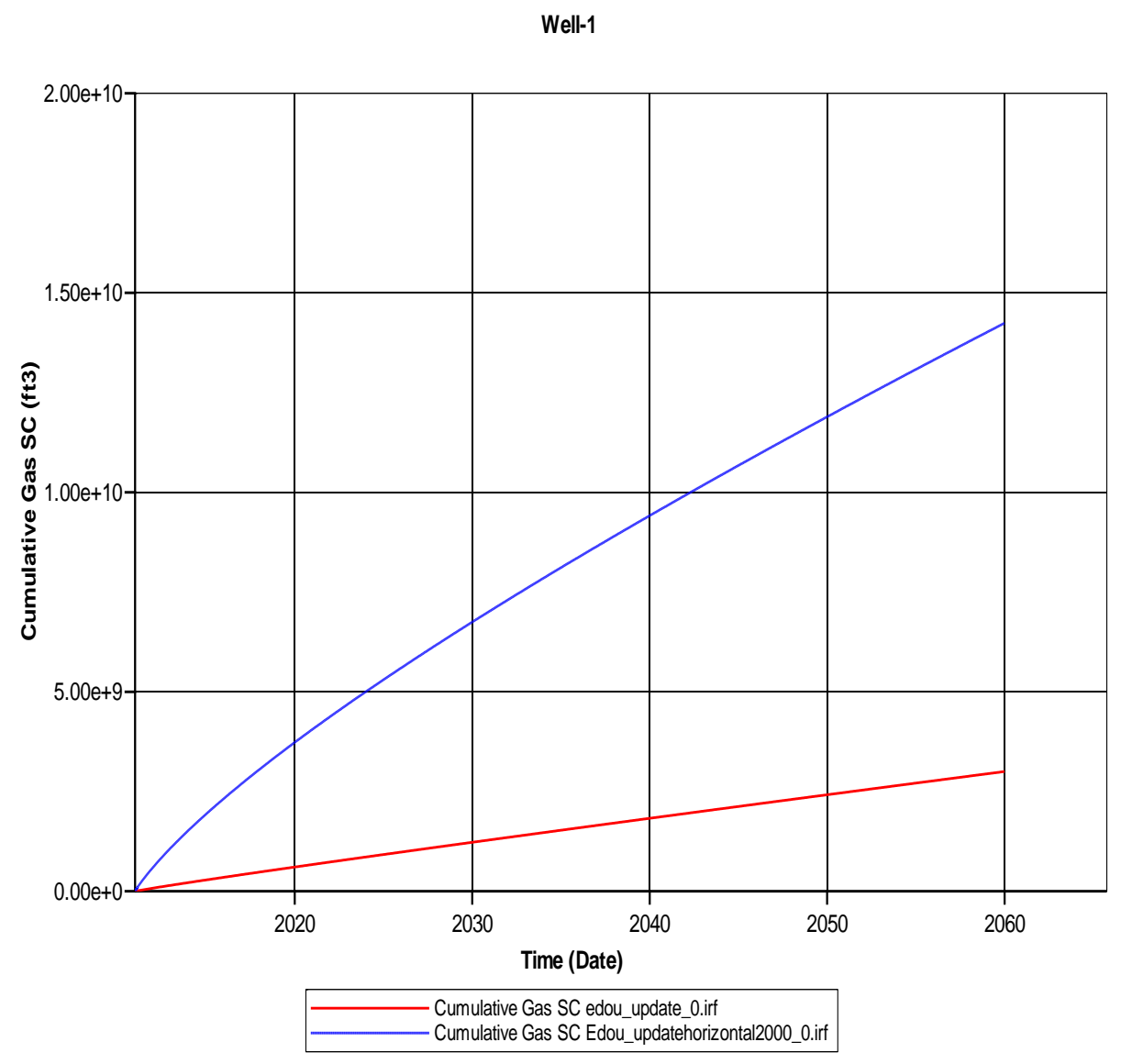

Figure B-1: Gas production from horizontal well of $2000 \mathrm{ft}$ and vertical well for Run\#0 
Well-1

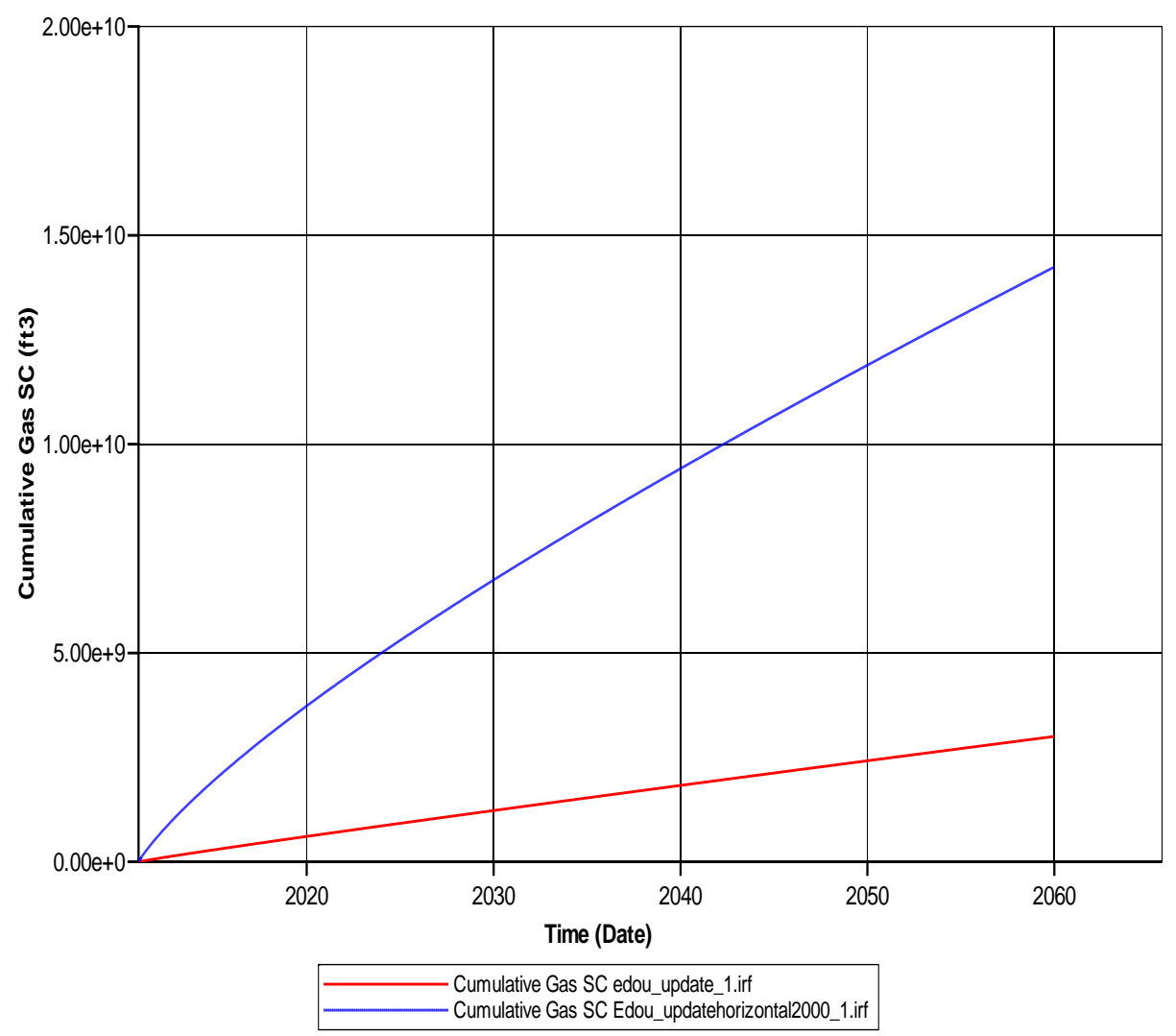

Figure B 2: Gas production from horizontal well of $2000 \mathrm{ft}$ and vertical well from Run\#1 
Well-1

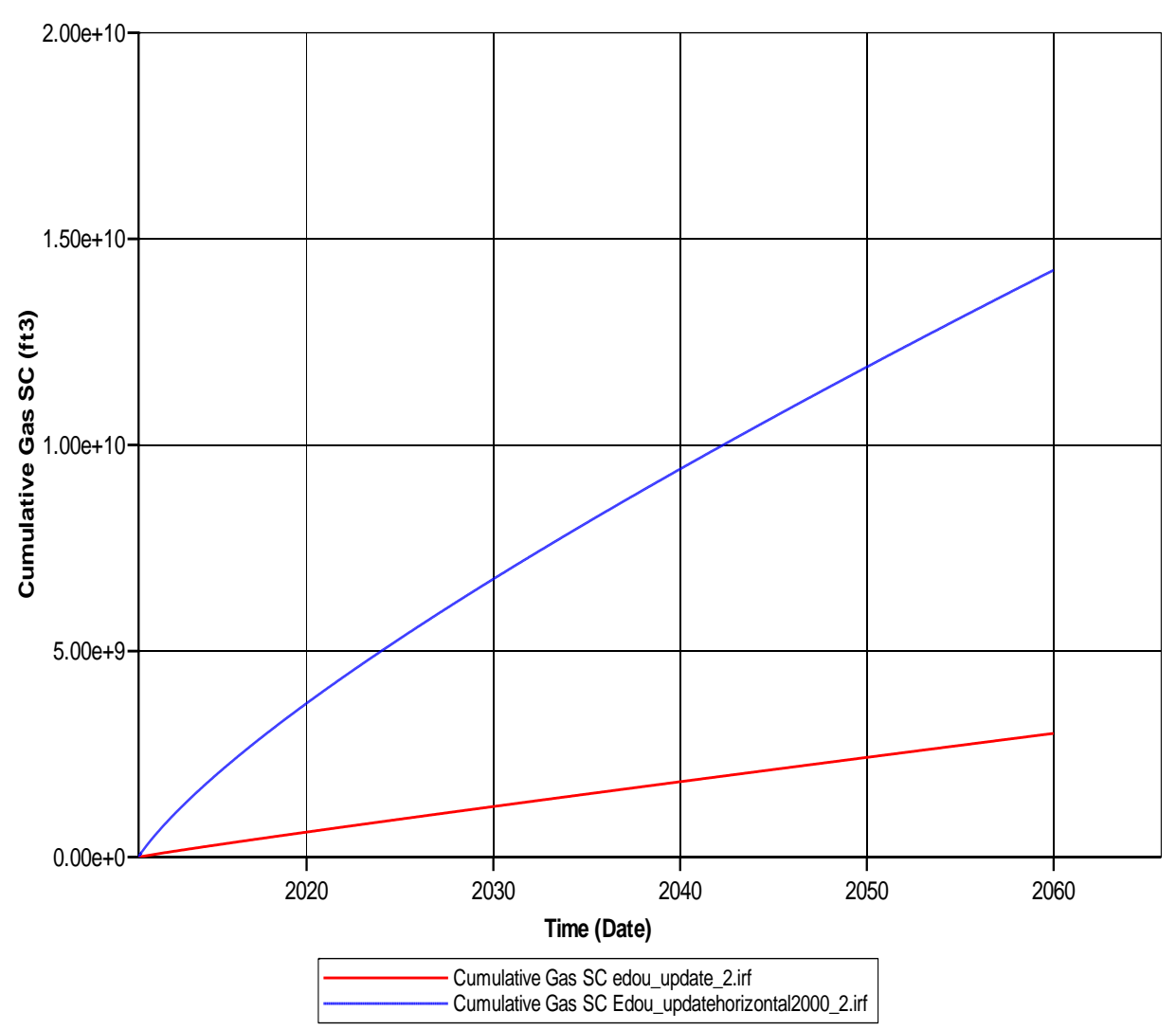

Figure B-3: Gas production from horizontal well of $2000 \mathrm{ft}$ and vertical well from Run\#2 
Well-1

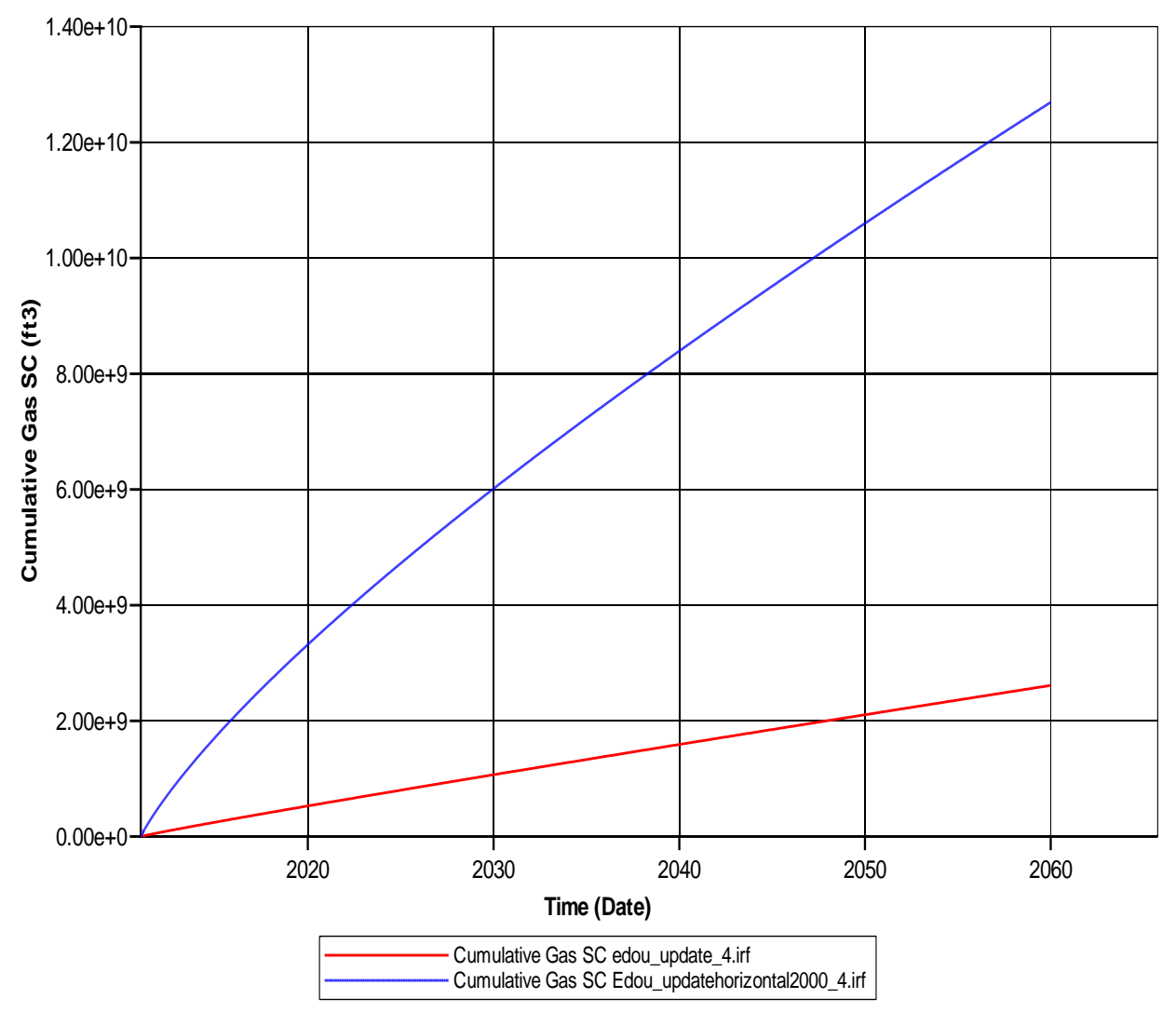

Figure B-4: Gas production from horizontal well of $2000 \mathrm{ft}$ and vertical well from Run\#4 
Well-1

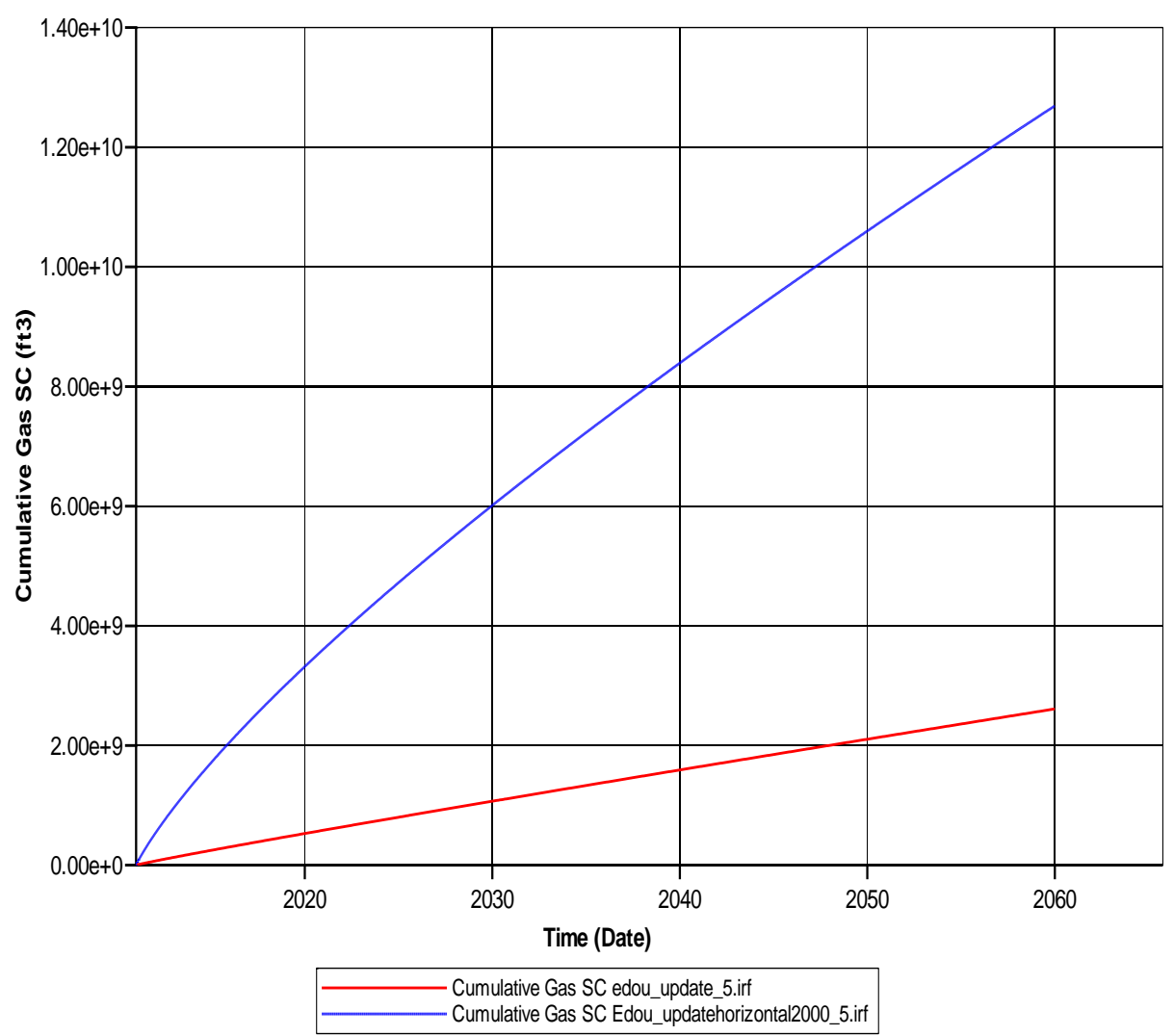

Figure B-5: Gas production from horizontal well of $2000 \mathrm{ft}$ and vertical well from Run\#5 
Well-1

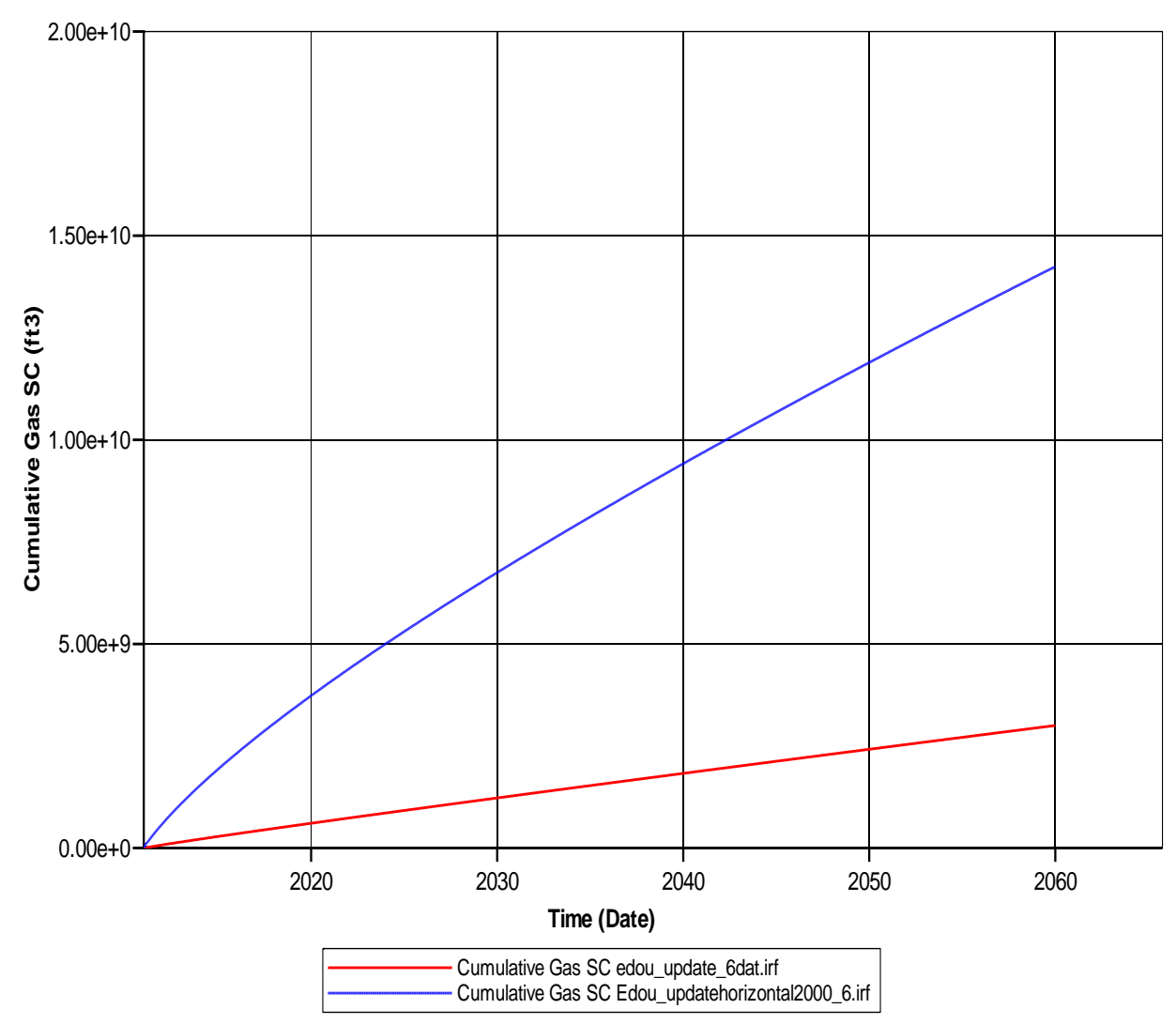

Figure B-6: Gas production from horizontal well of $2000 \mathrm{ft}$ and vertical well from Run\#6 
Well-1

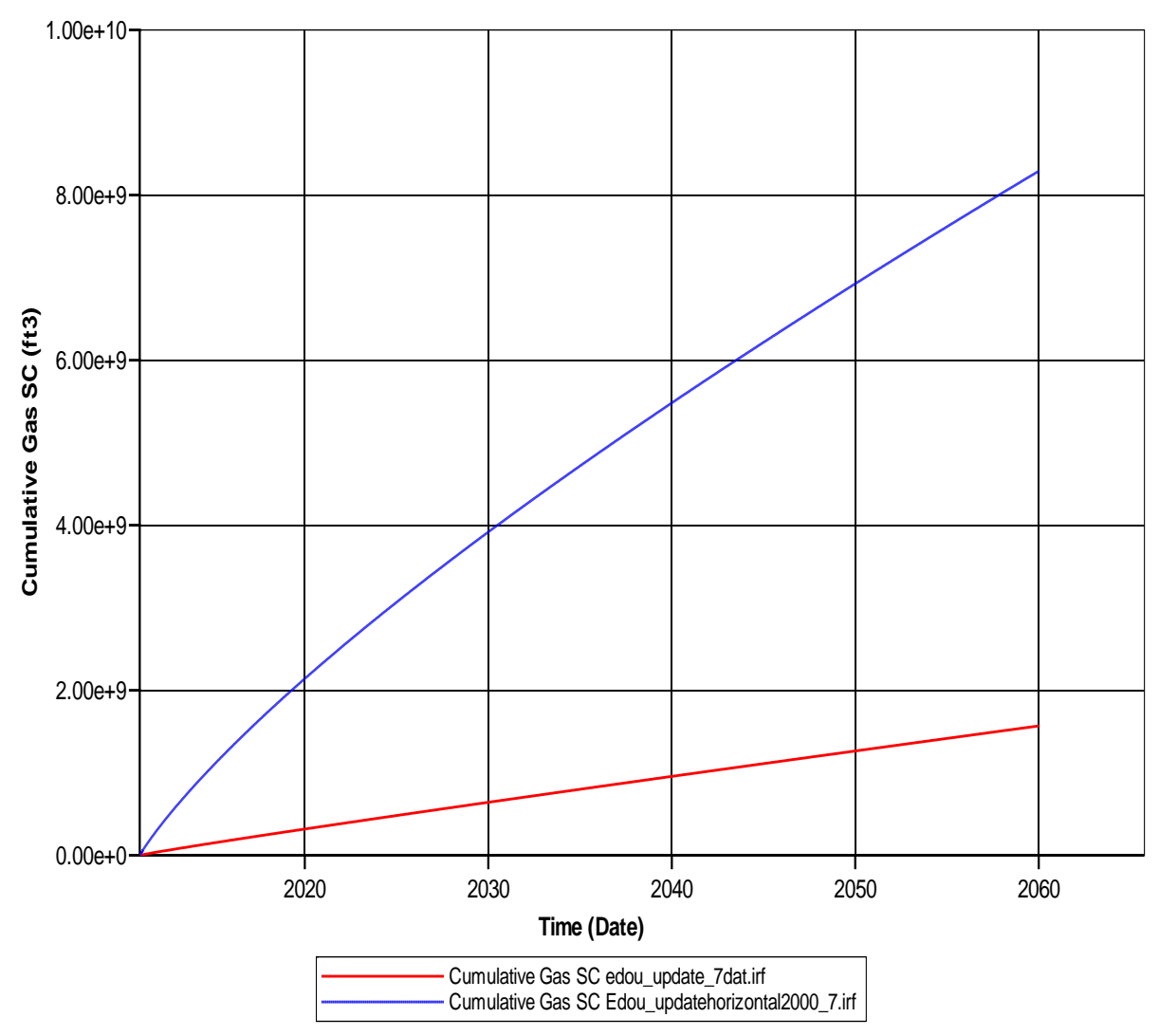

Figure B-7: Gas production from horizontal well of $2000 \mathrm{ft}$ and vertical well from Run\#7 
Well-1

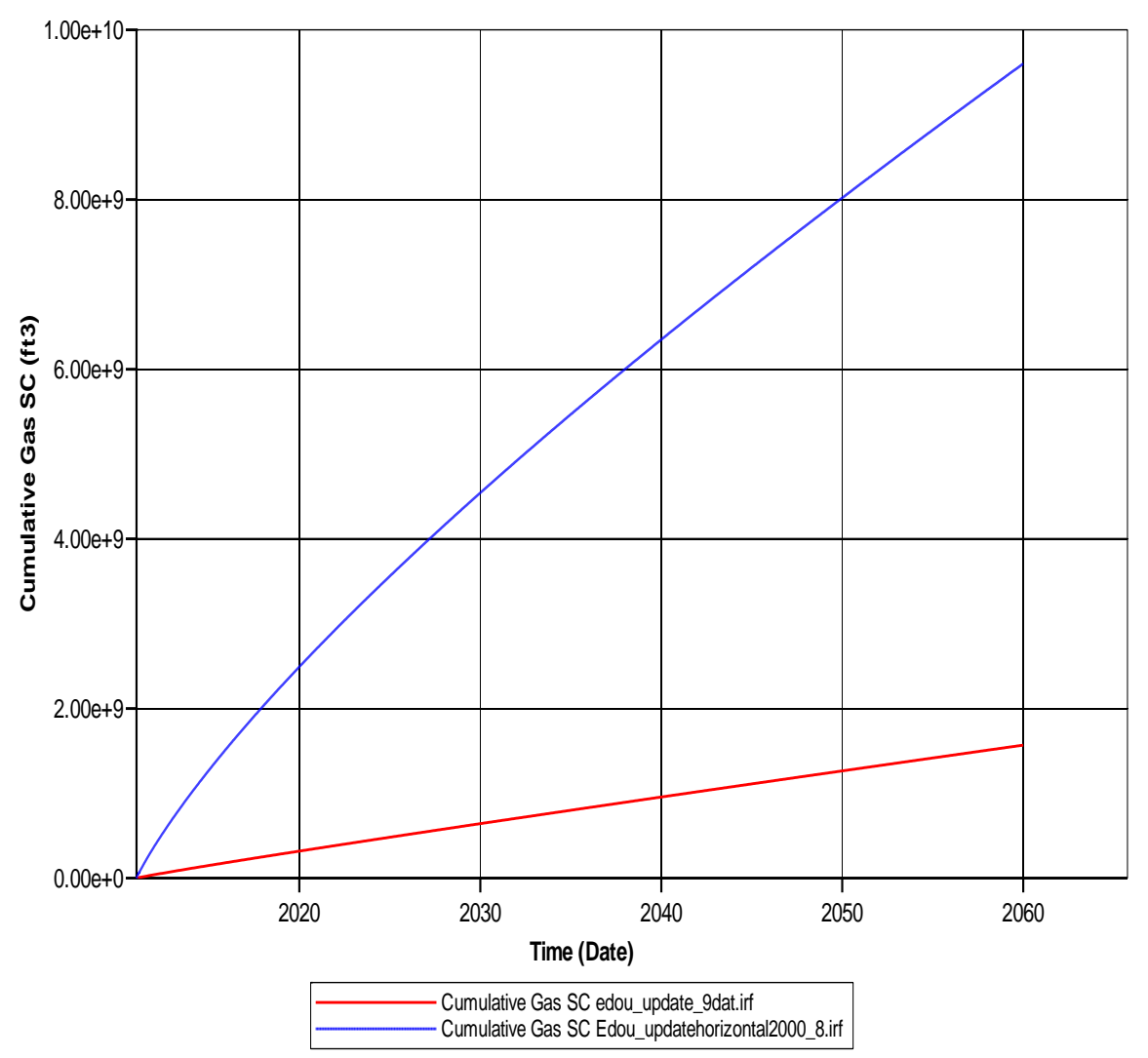

Figure B-8: Gas production from horizontal well of $2000 \mathrm{ft}$ and vertical well from Run\#8 
Well-1

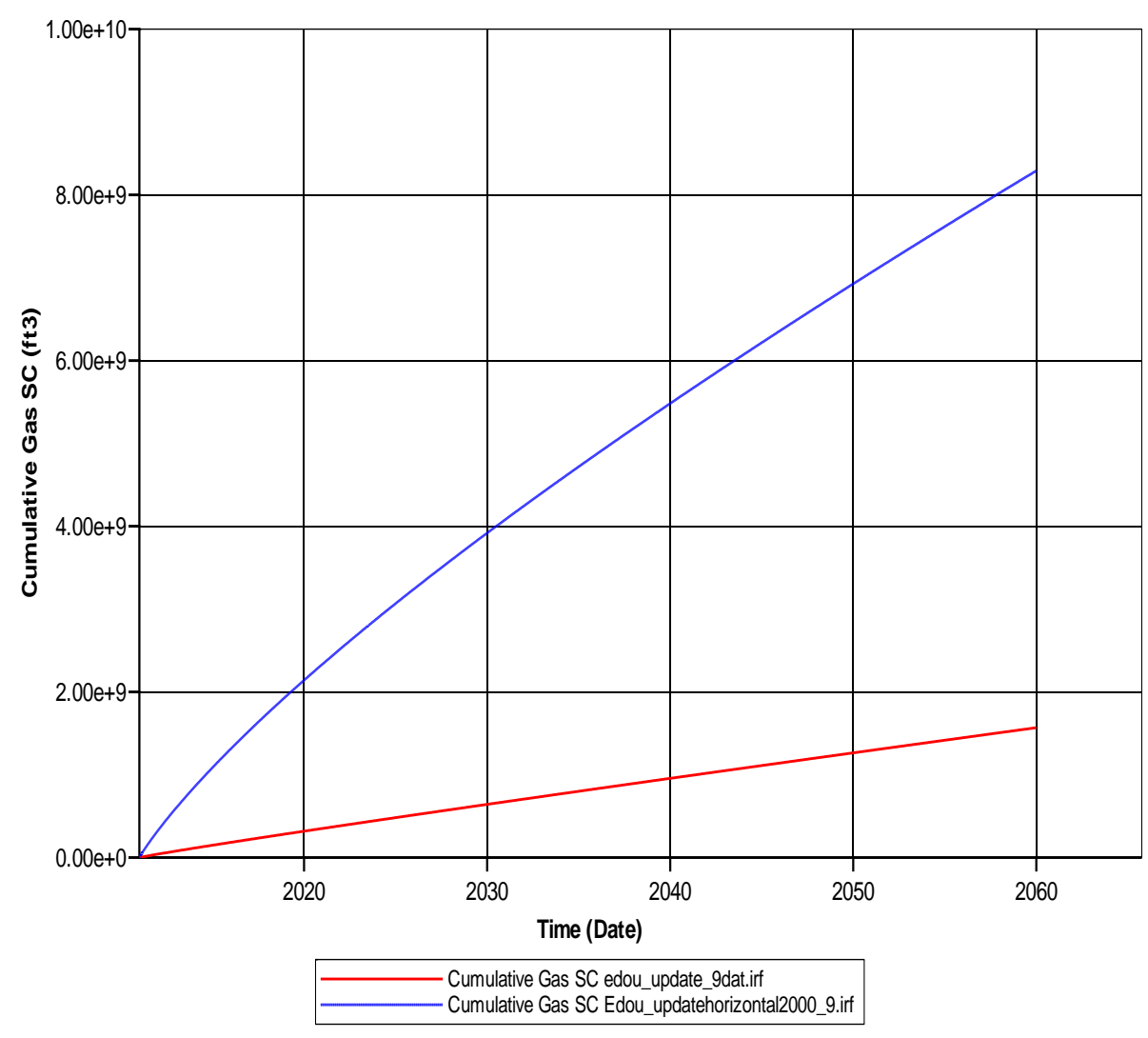

Figure B-9: Gas production from horizontal well of $2000 \mathrm{ft}$ and vertical well from Run\#9 
Well-1

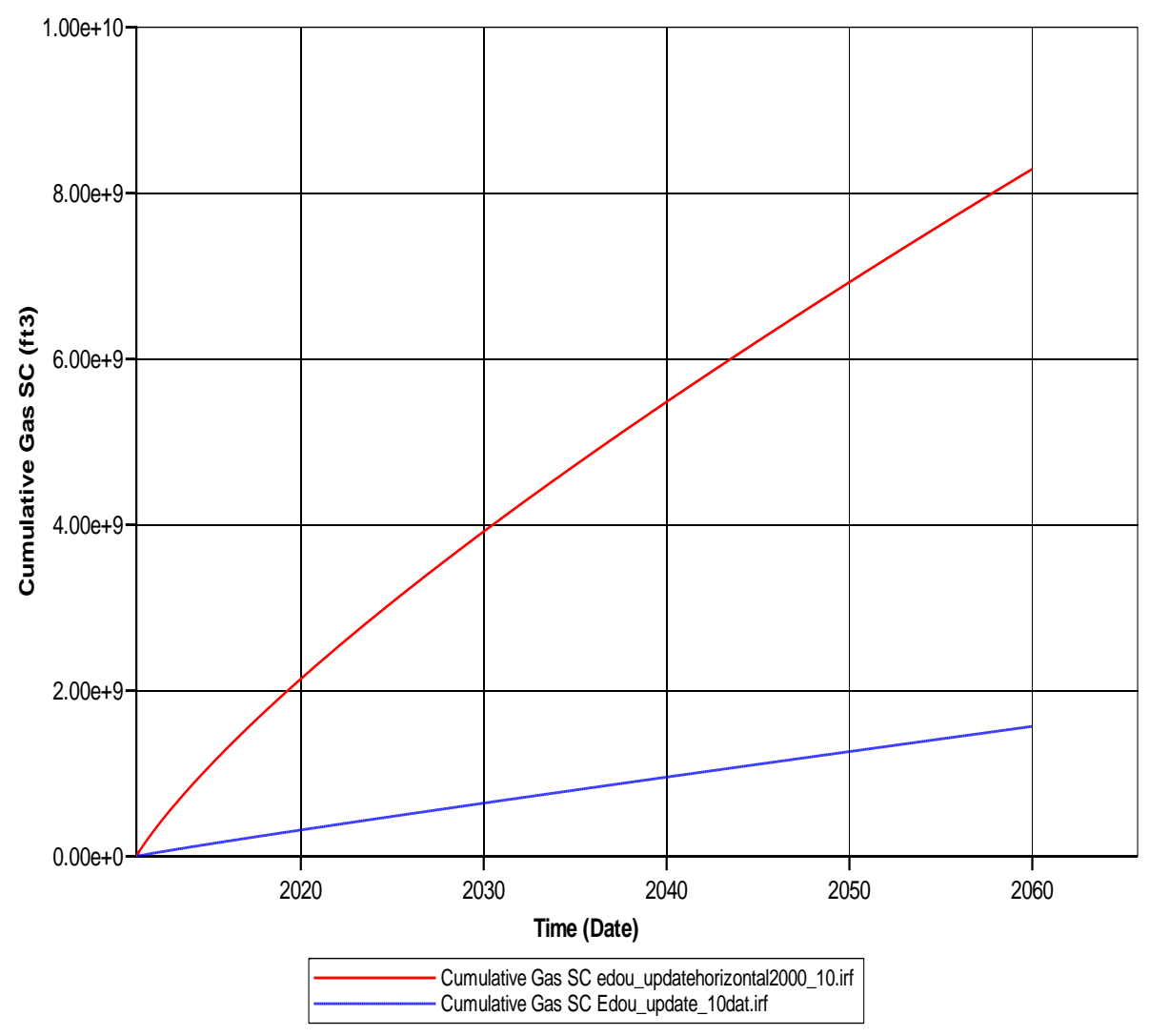

Figure B-10: Gas production from horizontal well of $2000 \mathrm{ft}$ and vertical well from Run\#10 


\section{Appendices C}

This document summarizes the different graphs resulting from the 11 different set of relative permeability data for both vertical and horizontal well of $3600 \mathrm{ft}$.

Well-1

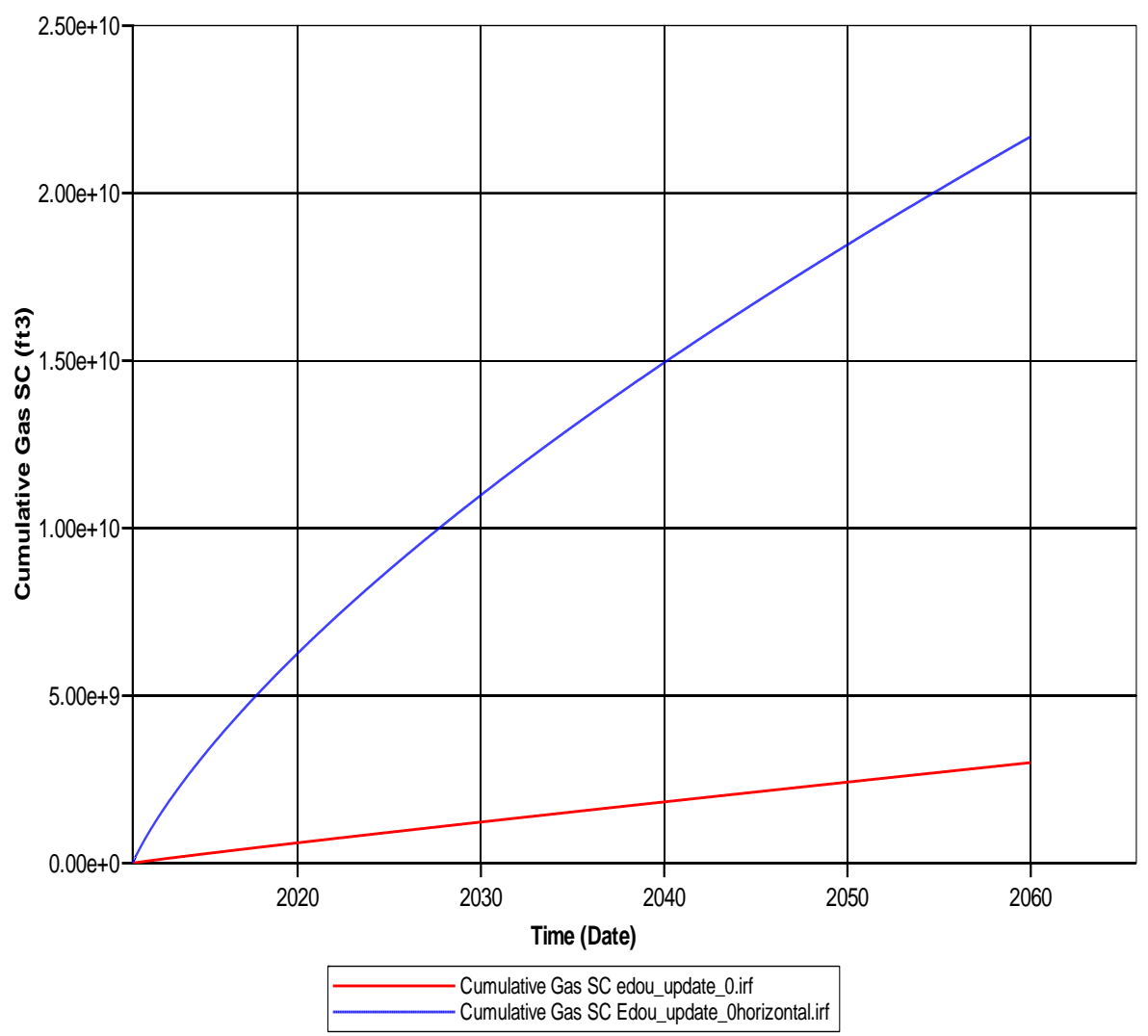

Figure C-1: Gas production from horizontal well of $3600 \mathrm{ft}$ and vertical well from Run\#0

Run\#1 
Well-1

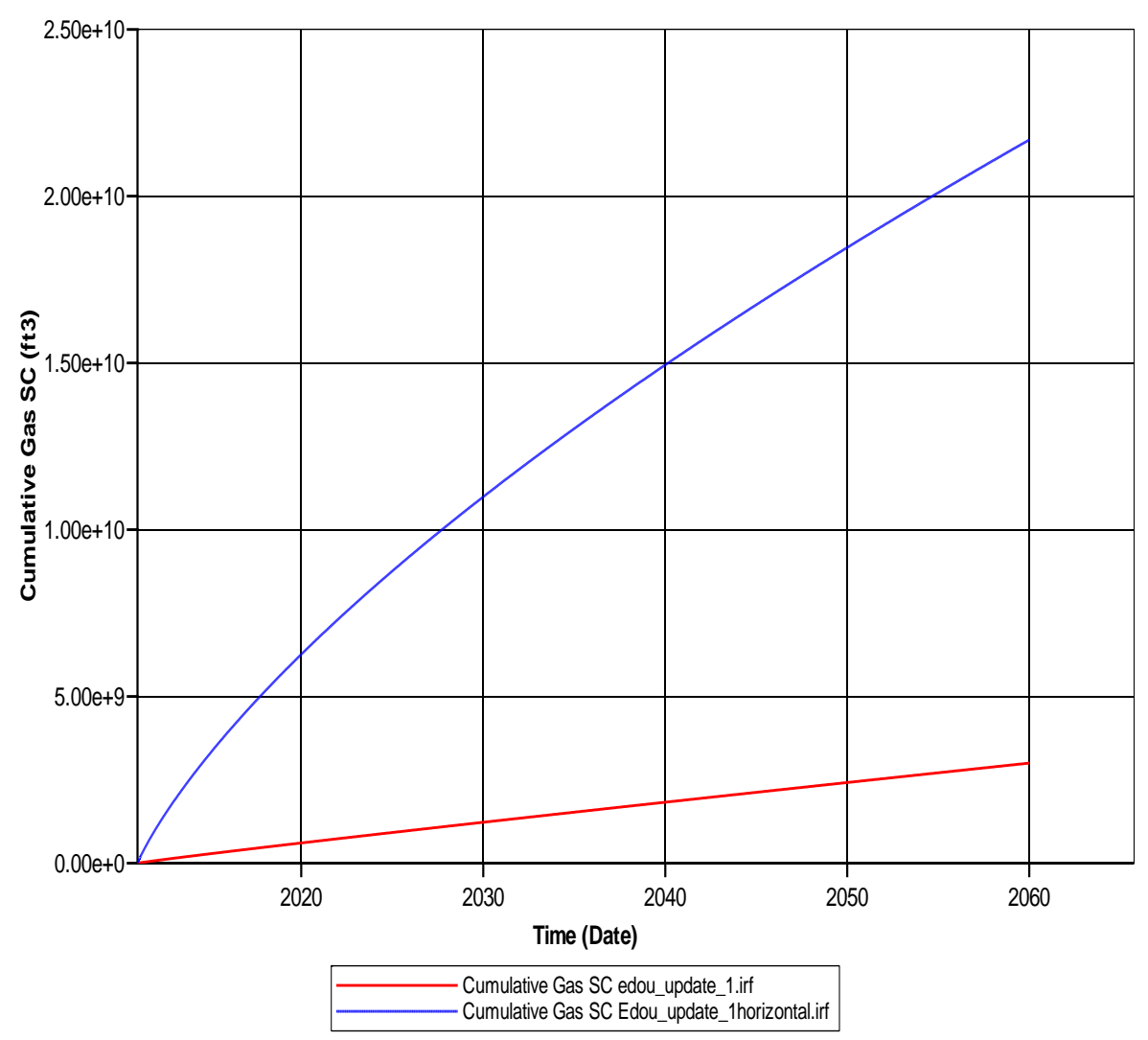

Figure C-2: Gas production from horizontal well of $3600 \mathrm{ft}$ and vertical well from Run\#1 
Well-1

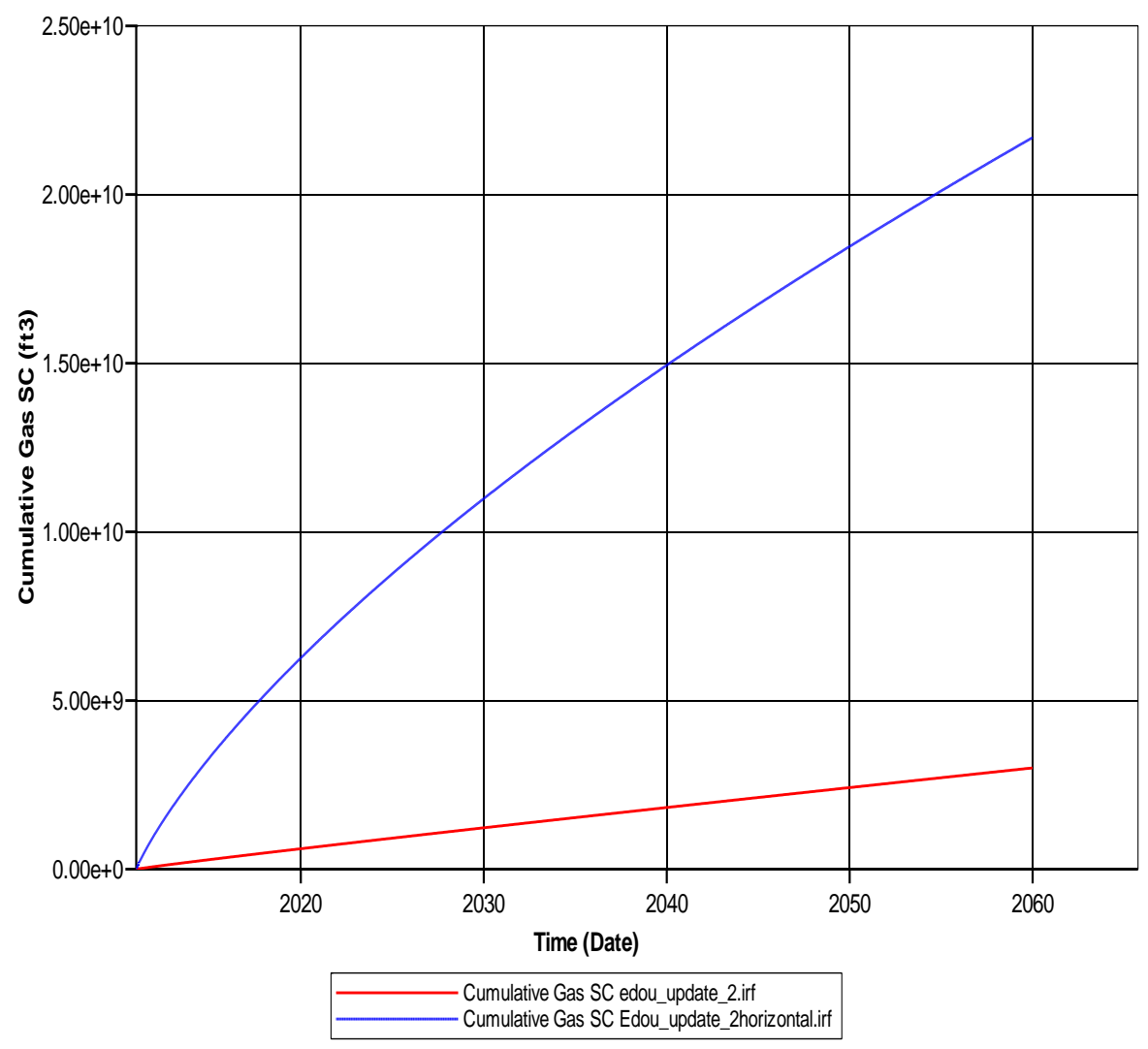

Figure C-3: Gas production from horizontal well of $3600 \mathrm{ft}$ and vertical well from Run\#2 
Well-1

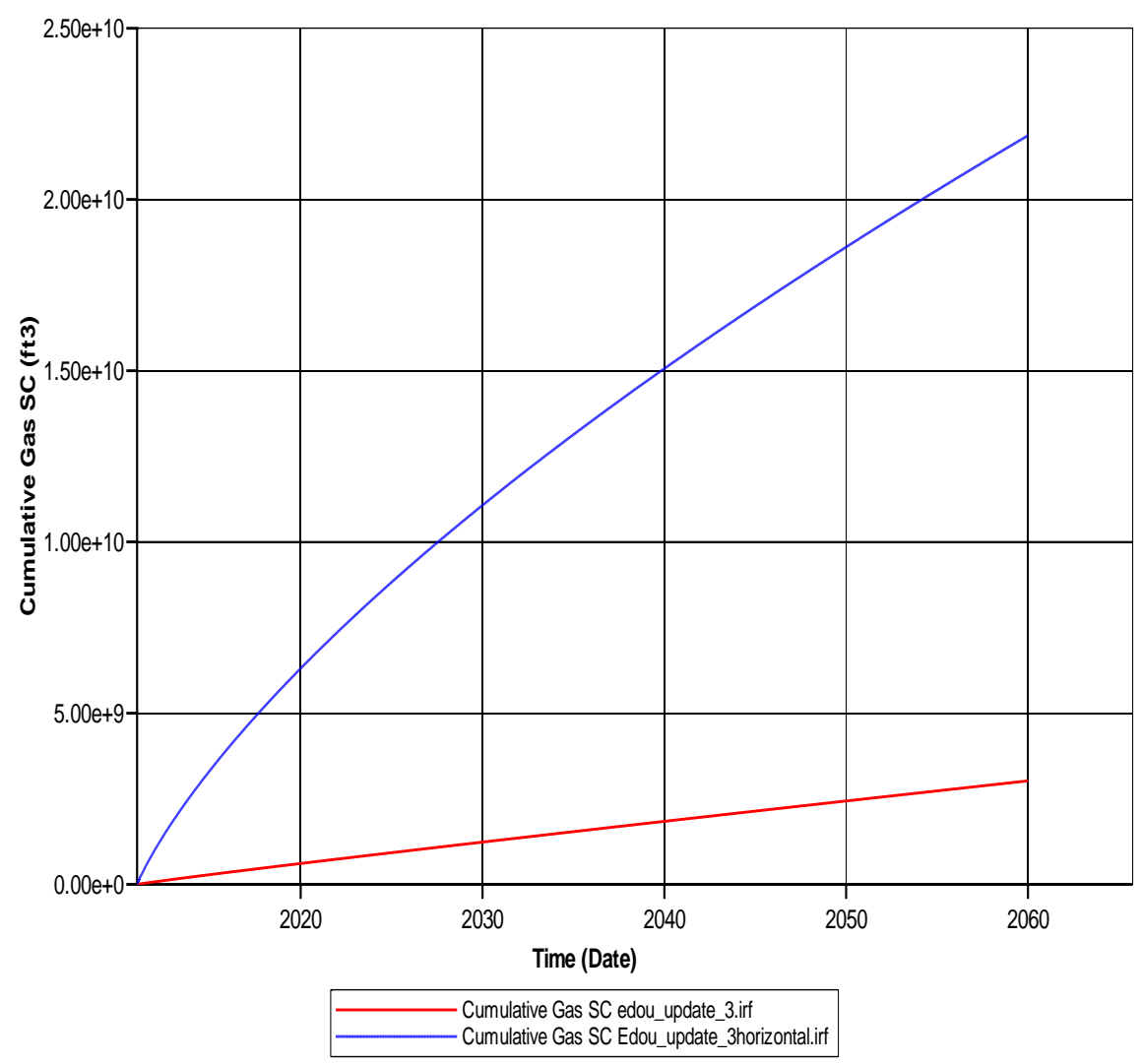

Figure C-4: Gas production from horizontal well of $3600 \mathrm{ft}$ and vertical well from Run\#3 
Well-1

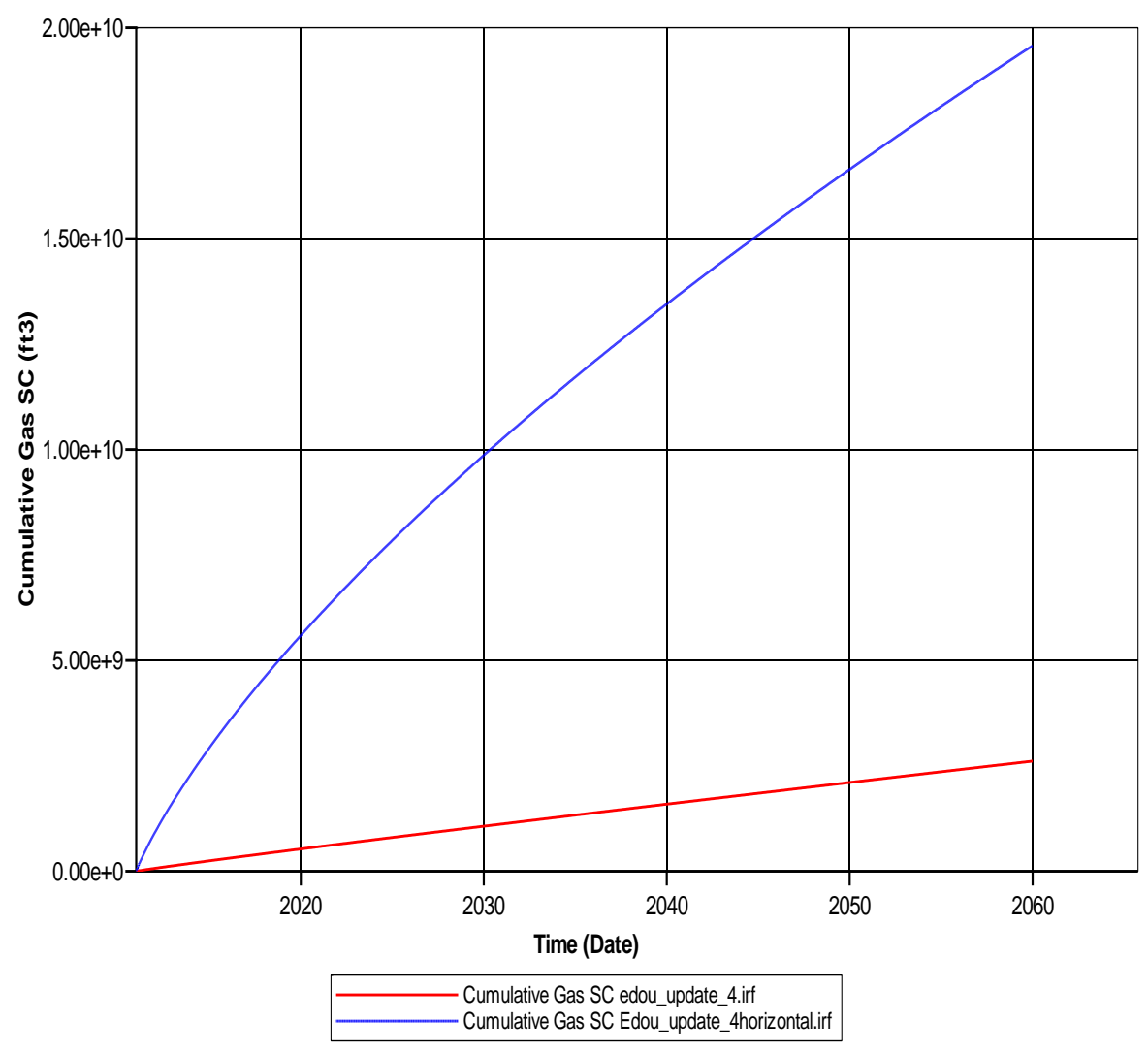

Figure C-5: Gas production from horizontal well of $3600 \mathrm{ft}$ and vertical well from Run\#4 
Well-1

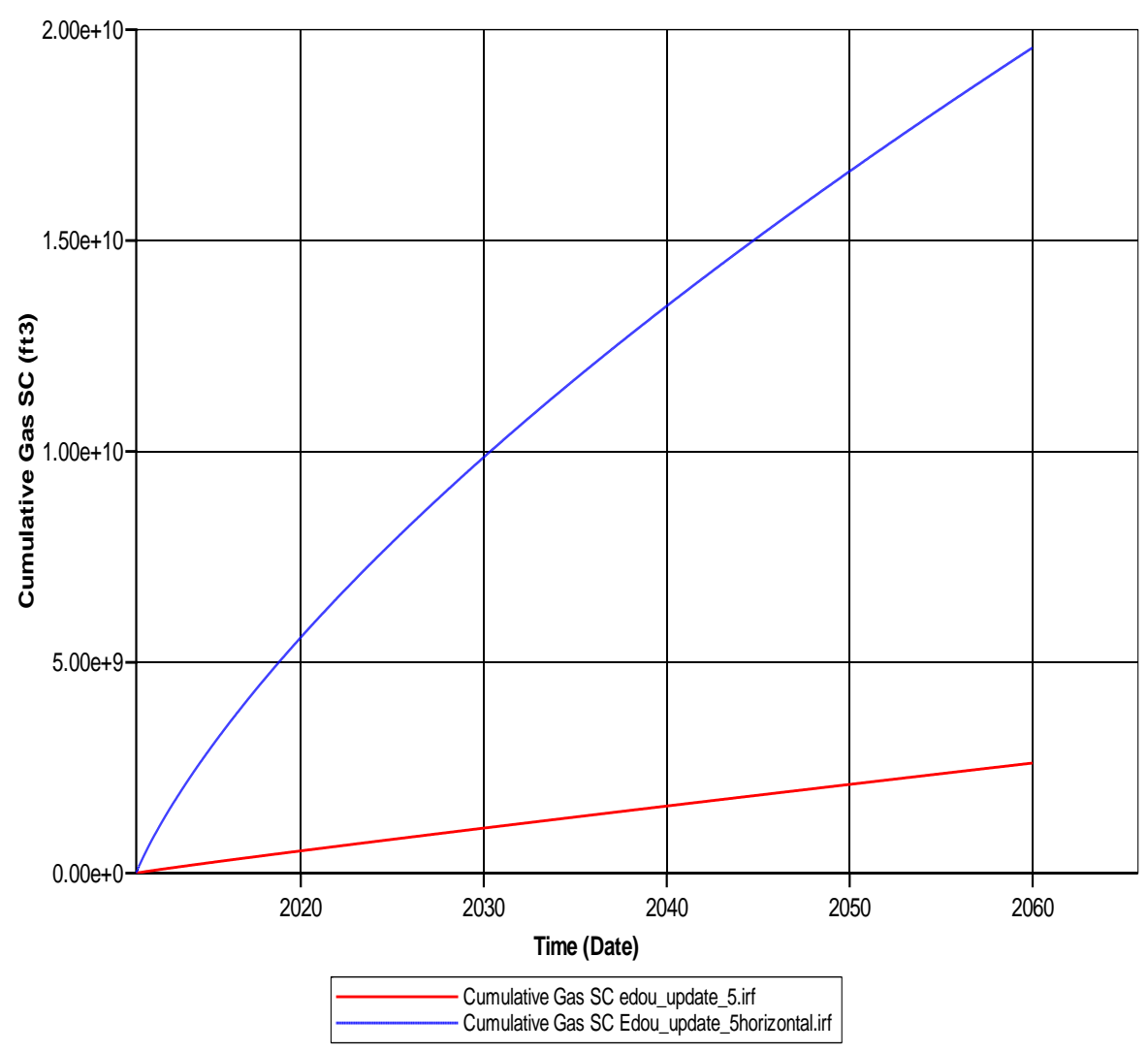

Figure C-6: Gas production from horizontal well of $3600 \mathrm{ft}$ and vertical well from Run\#5 
Well-1

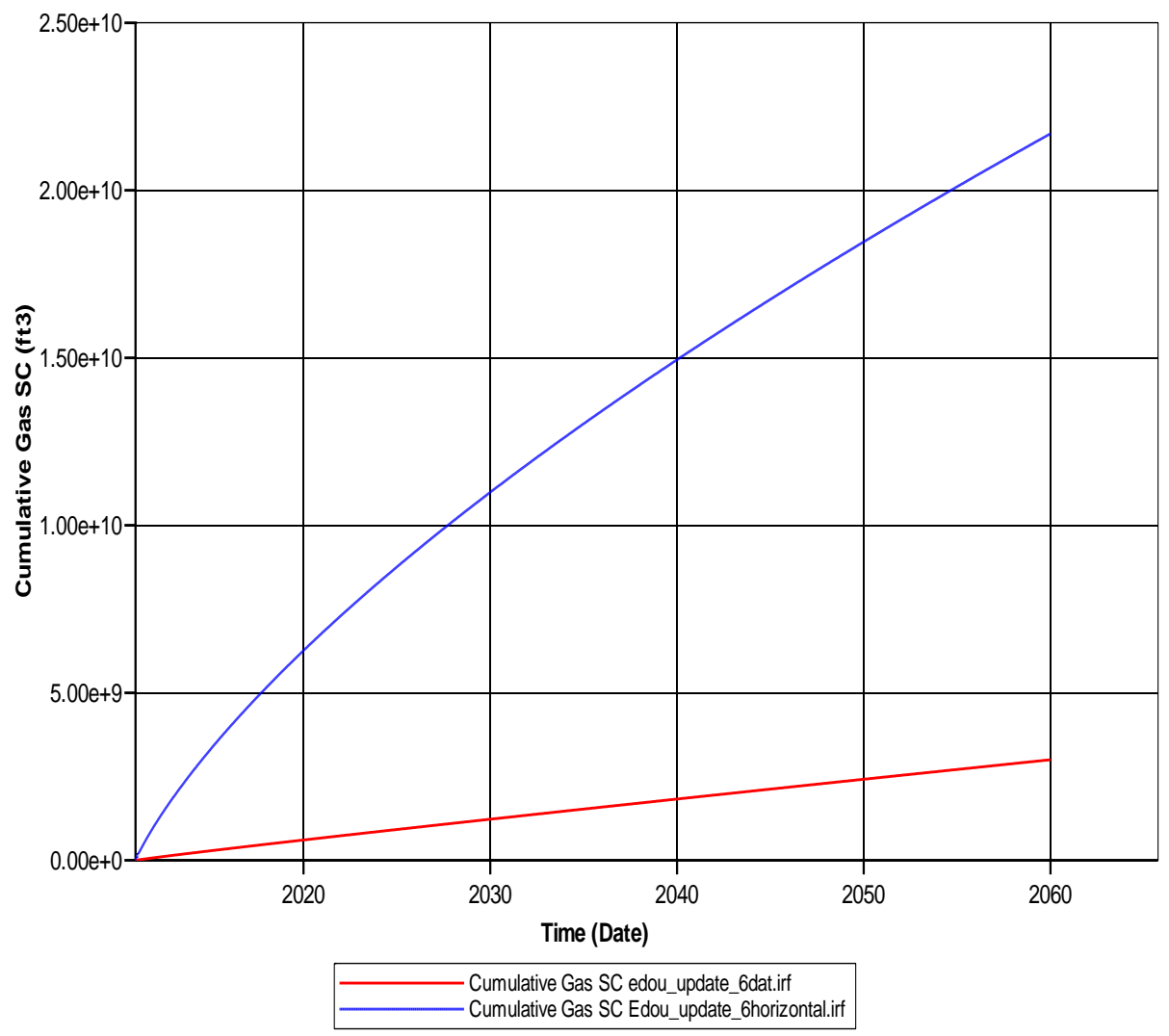

Figure C-7: Gas production from horizontal well of $3600 \mathrm{ft}$ and vertical well from Run\#6 
Well-1

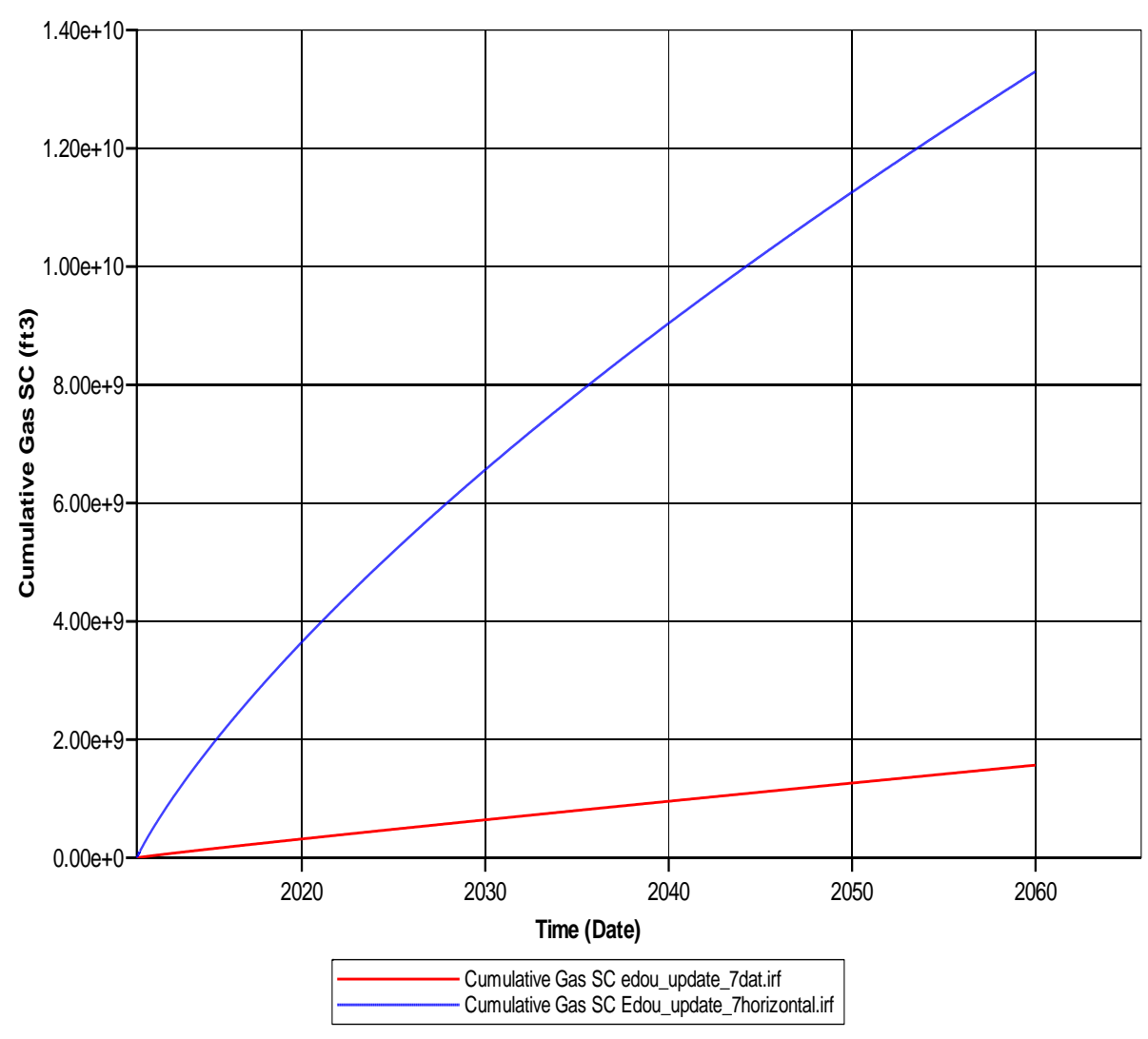

Figure C-8: Gas production from horizontal well of $3600 \mathrm{ft}$ and vertical well from Run\#7 
Well-1

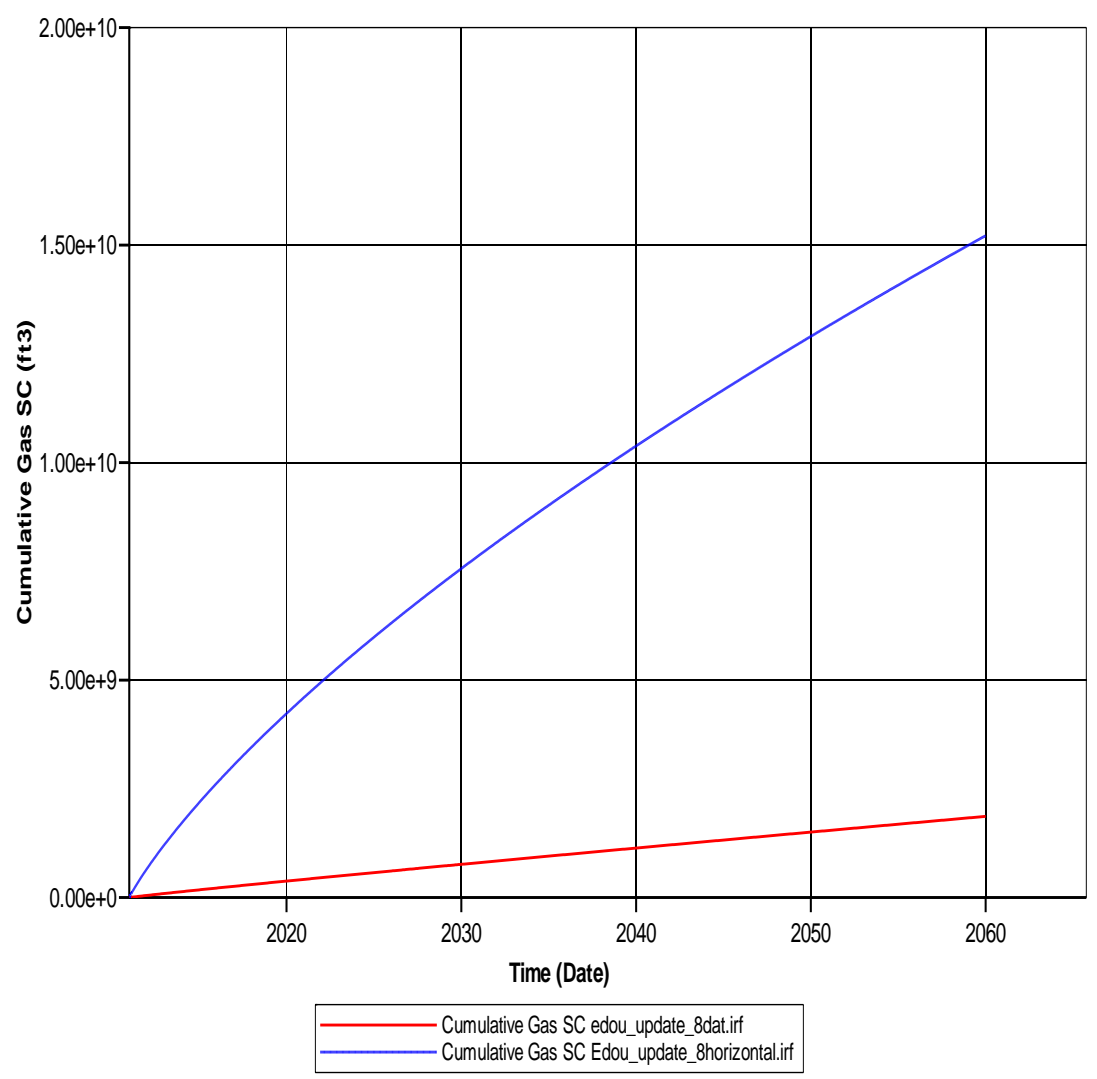

Figure C-9: Gas production from horizontal well of $3600 \mathrm{ft}$ and vertical well from Run\#8 
Well-1

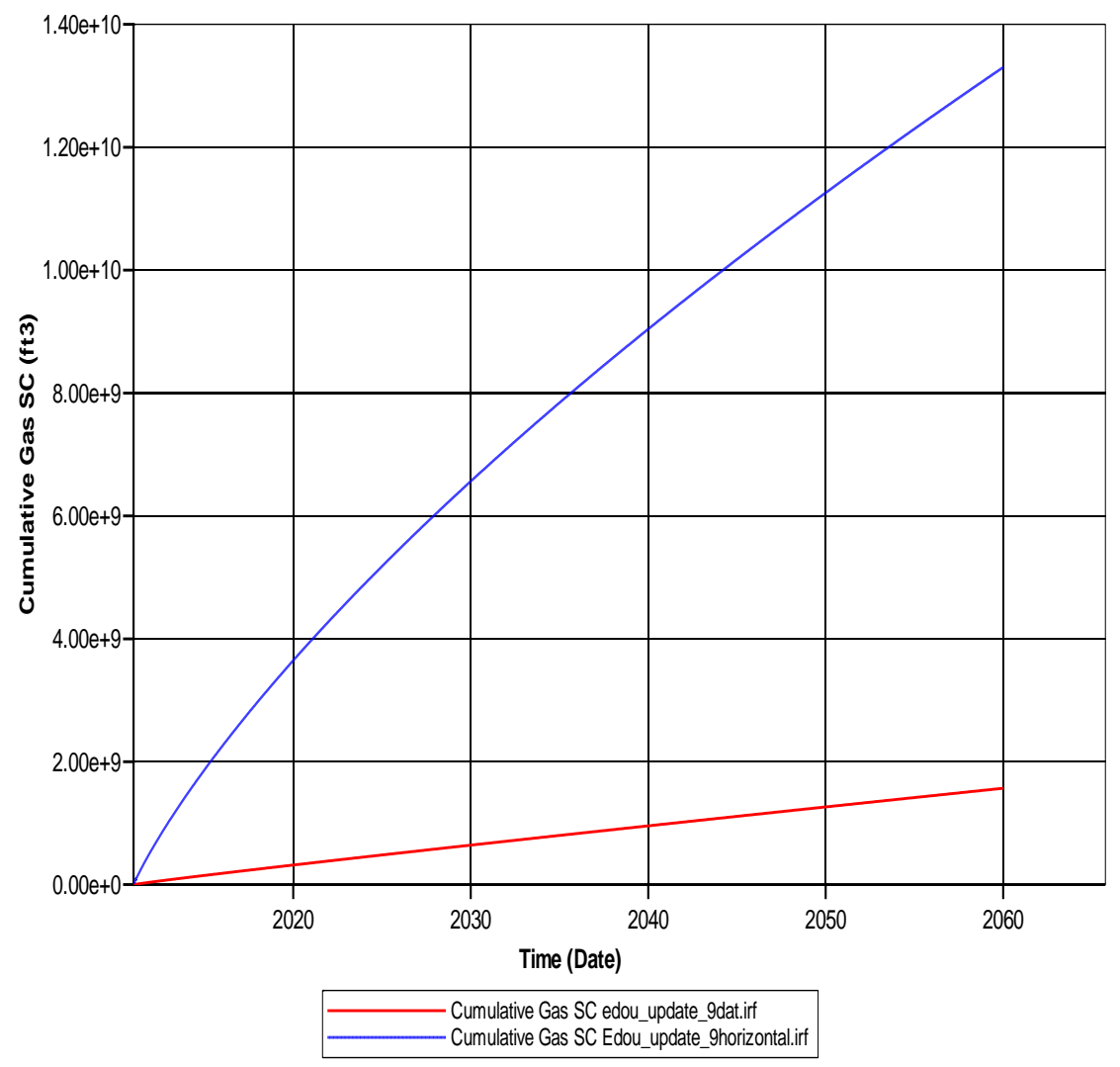

Figure C-10: Gas production from horizontal well of $3600 \mathrm{ft}$ and vertical well from Run\#9 
Well-1

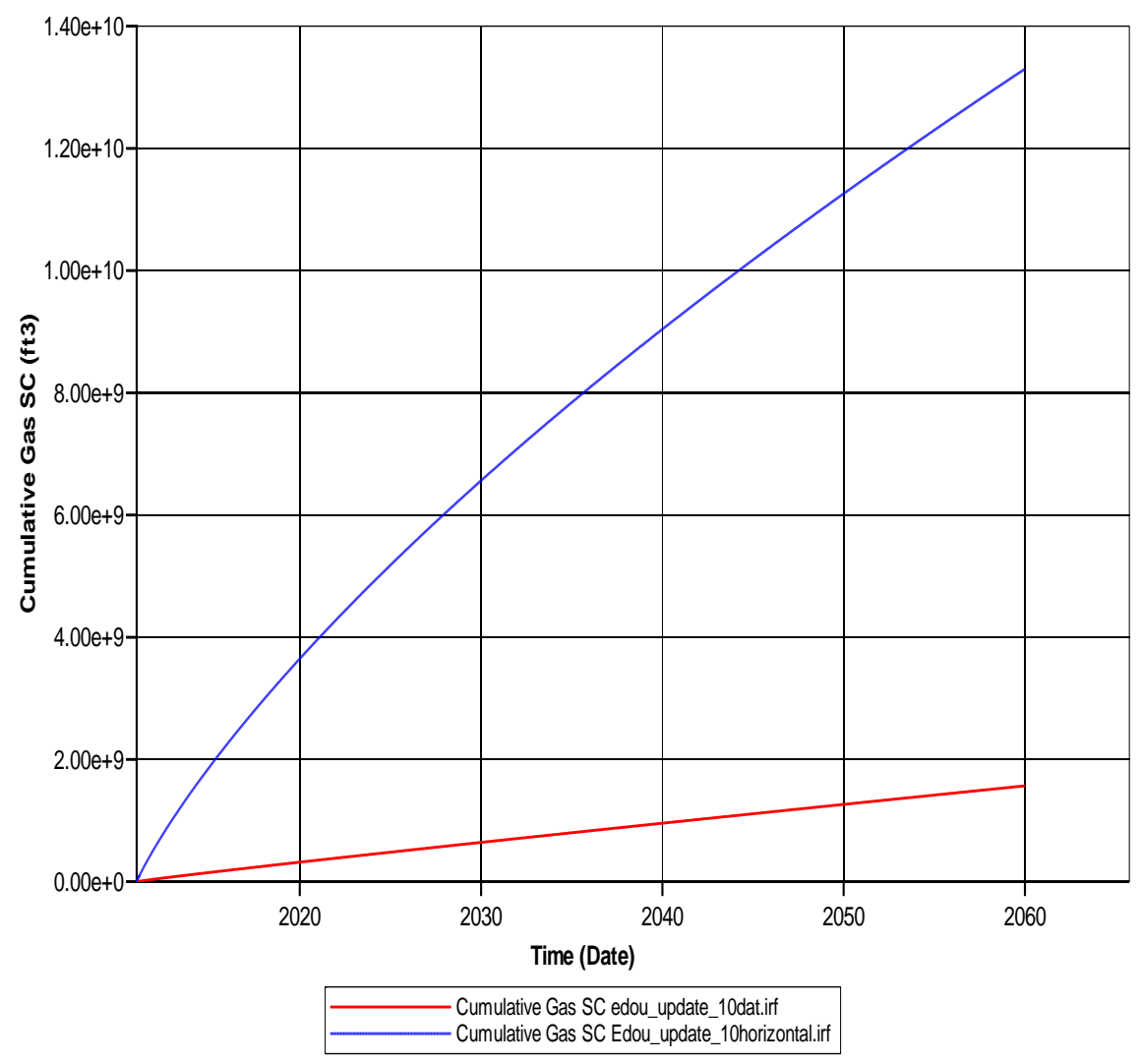

Figure C-11: Gas production from horizontal well of $3600 \mathrm{ft}$ and vertical well from Run\#10 


\section{Appendices D}

Well-1 edou update_1horizontal fracture.irf

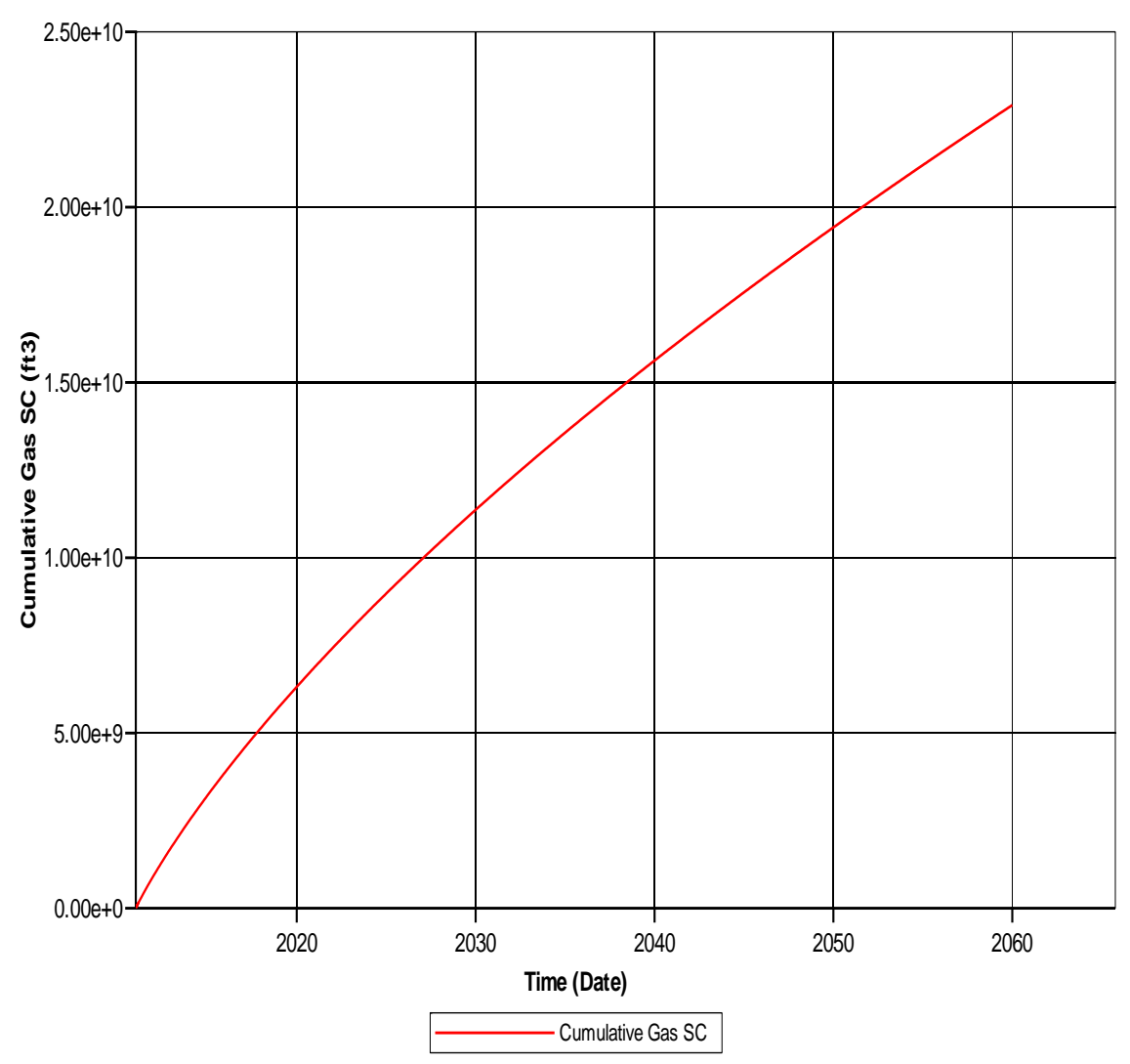

Figure D-1: Gas production from horizontal fracture well of $3600 \mathrm{ft}$ from Run\#1 
Well-1 edou_update_2horizontal fracture.irf

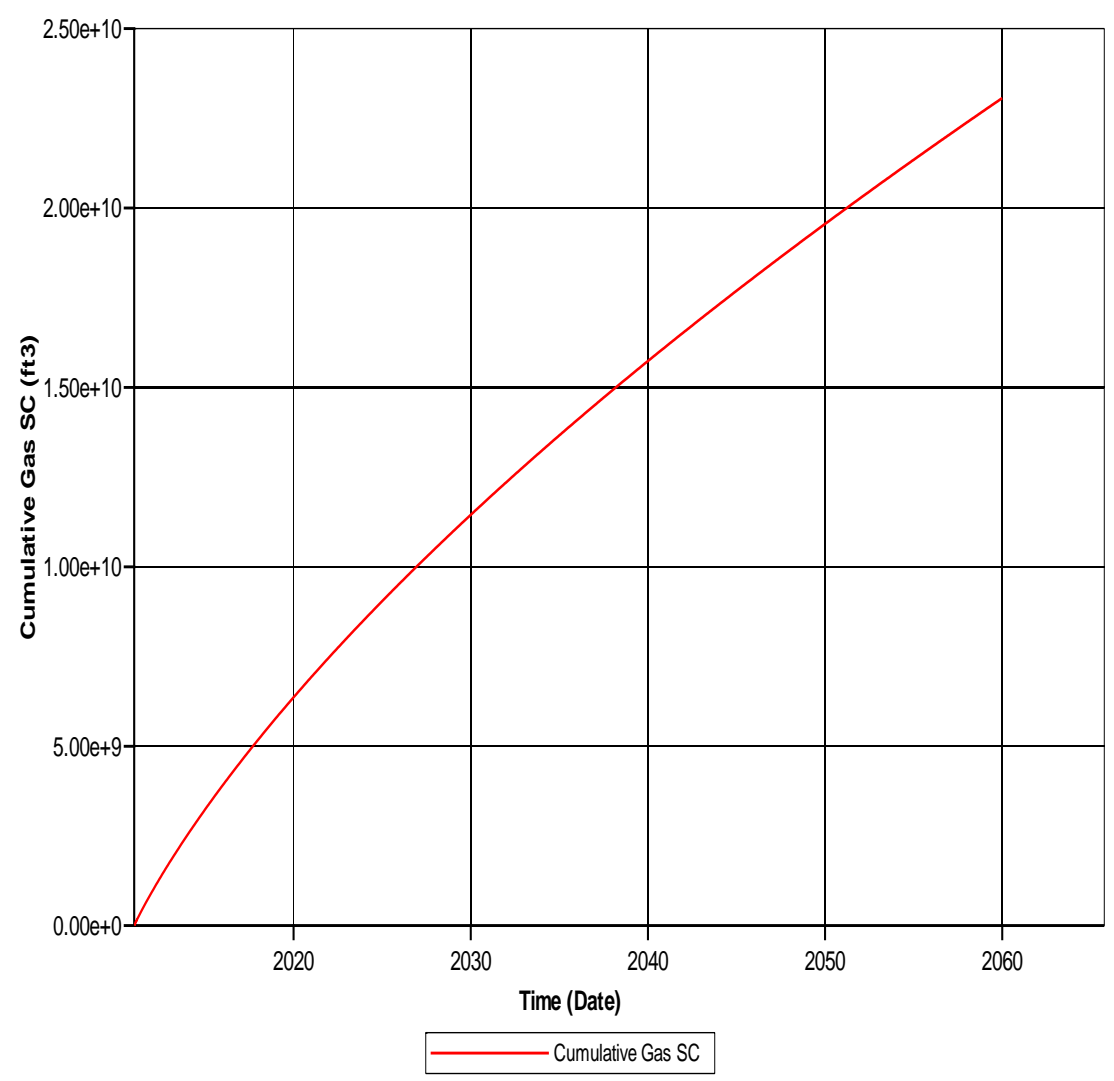

Figure D-2: Gas production from horizontal fracture well of $3600 \mathrm{ft}$ from Run\#2 
Well-1 edou_update_3horizontal.irf

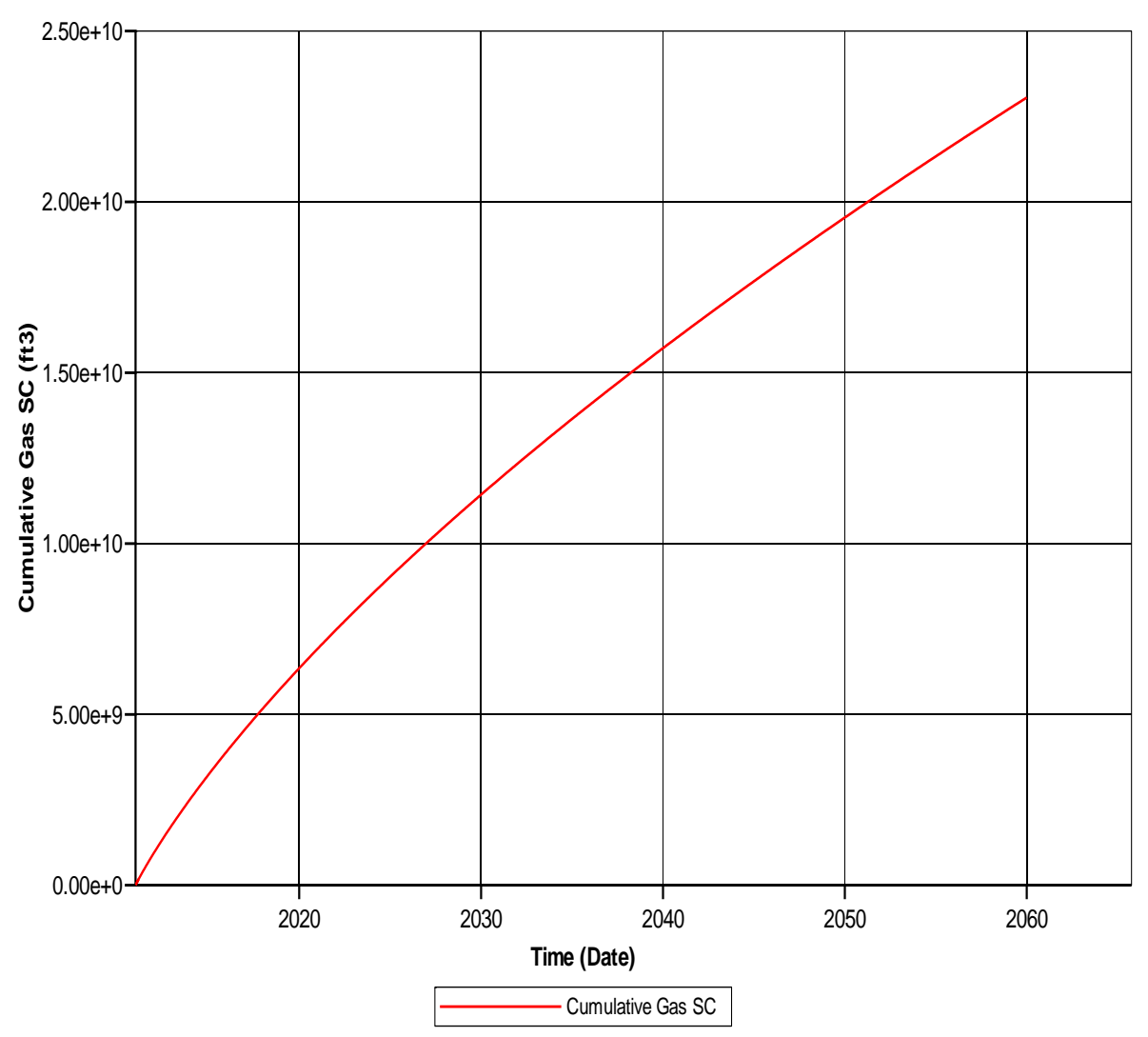

Figure D-3: Gas production from horizontal fracture well of $3600 \mathrm{ft}$ from Run\#3 
Well-1 edou_update_4horizontal.irf

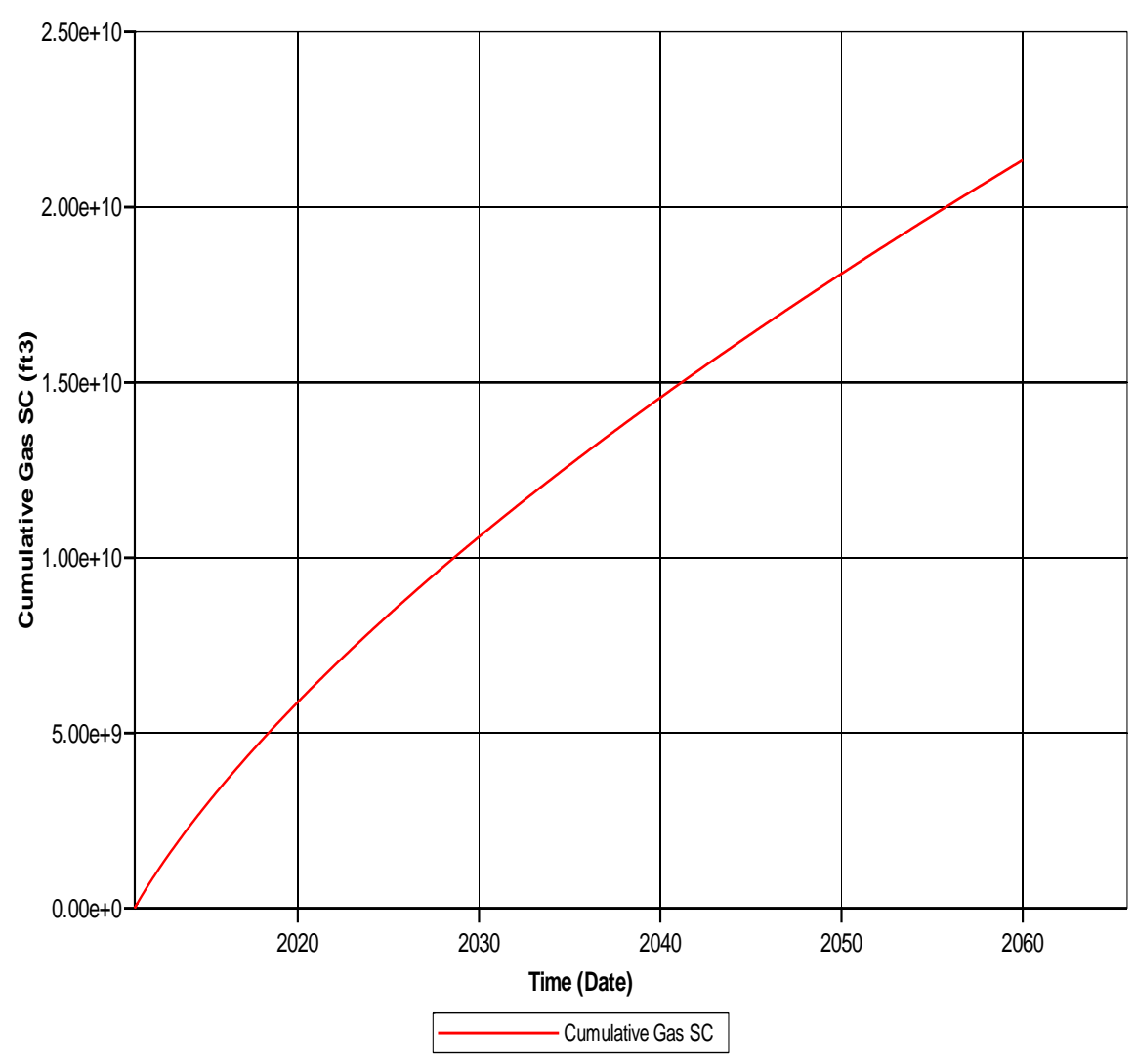

Figure D-4: Gas production from horizontal fracture well of $3600 \mathrm{ft}$ from Run\#4 
Well-1 edou_update_5horizontal.irf

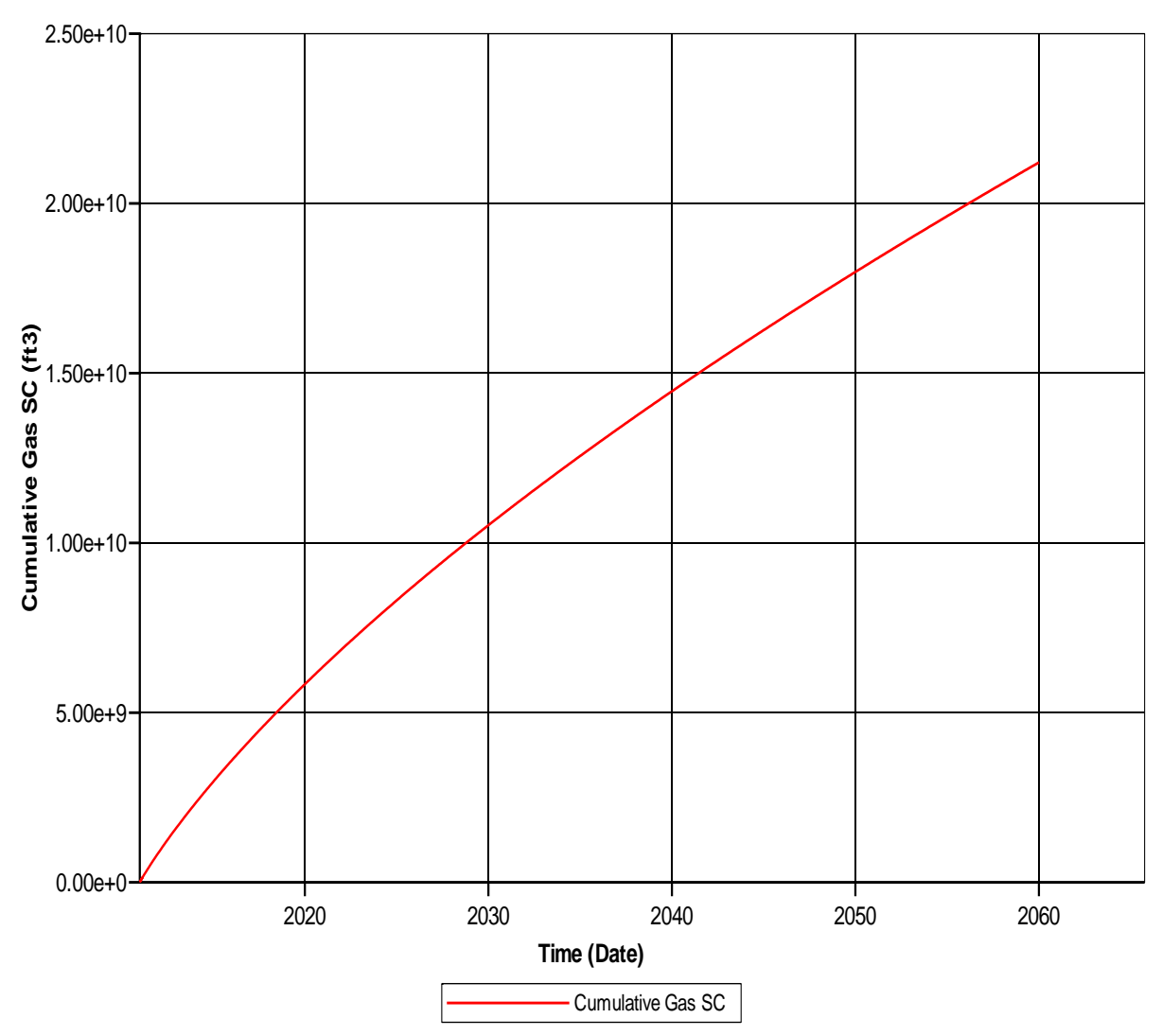

Figure D-5: Gas production from horizontal fracture well of $3600 \mathrm{ft}$ from Run\#5 
Well-1 edou_update_6dat.irf

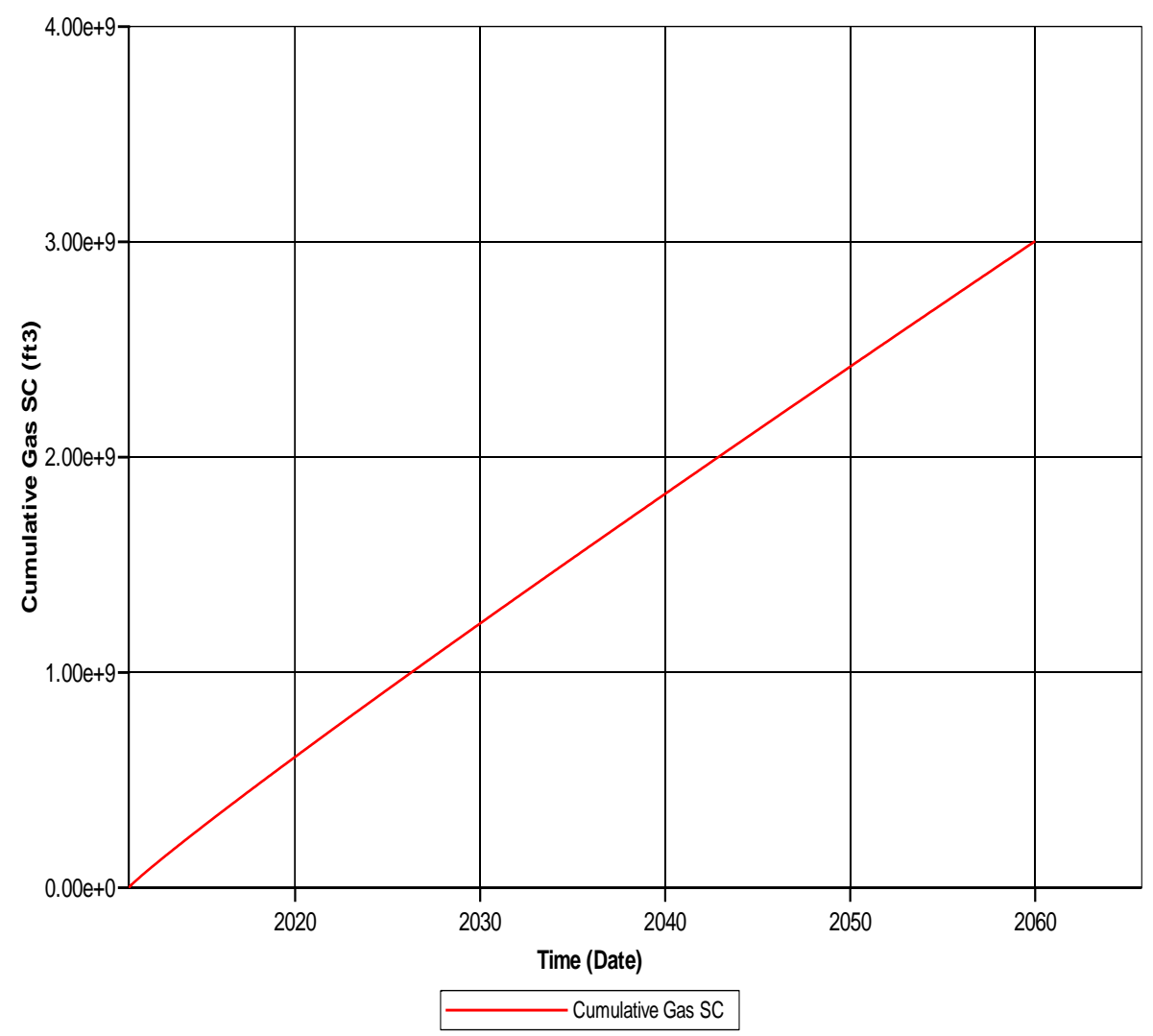

Figure D-6: Gas production from horizontal fracture well of $3600 \mathrm{ft}$ from Run\#6 
Well-1 edou_update_7horizontal fracture.irf

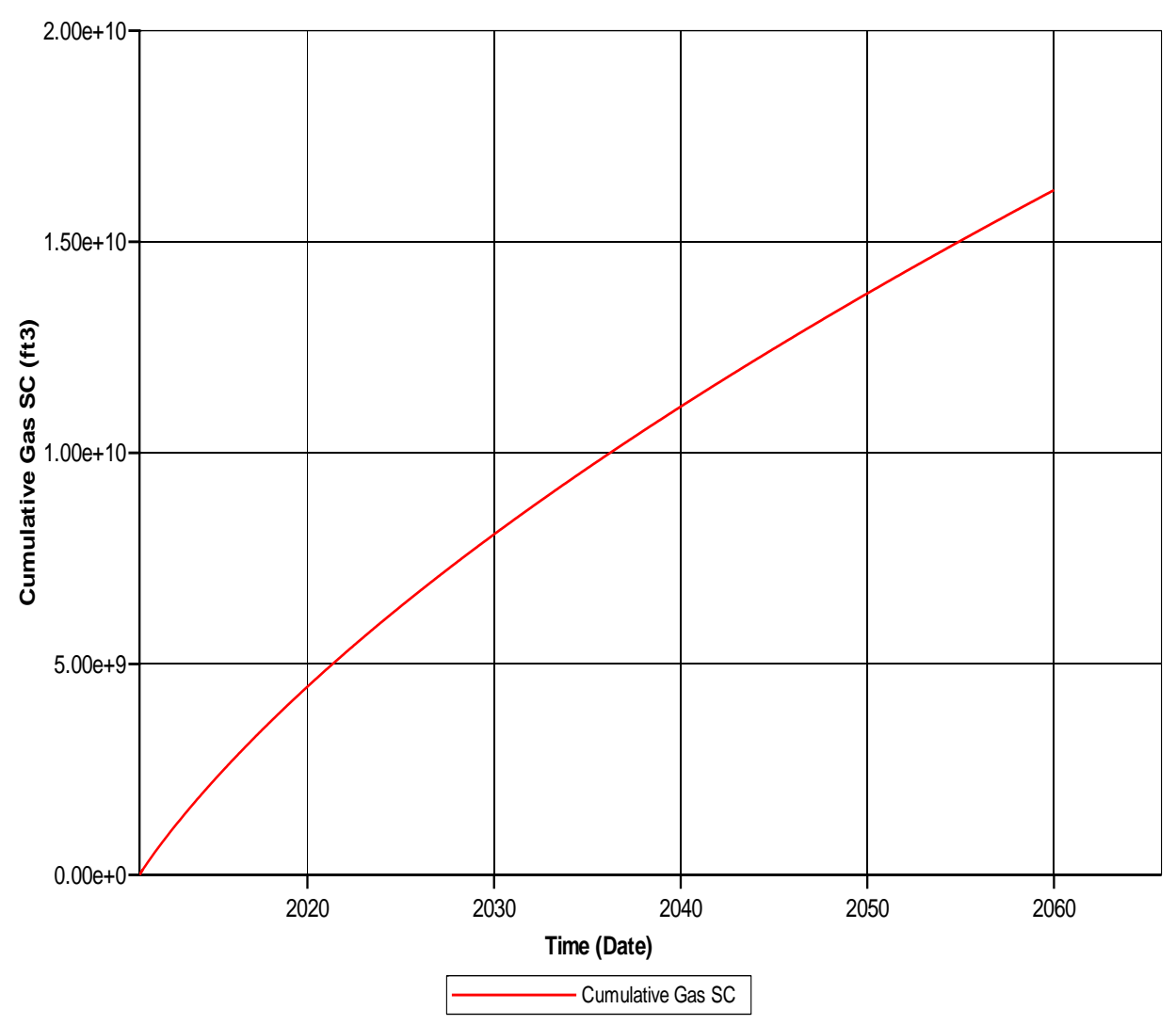

Figure D-7: Gas production from horizontal fracture well of $3600 \mathrm{ft}$ from Run\#7 
Well-1 edou_update_8horizontal fracture.irf

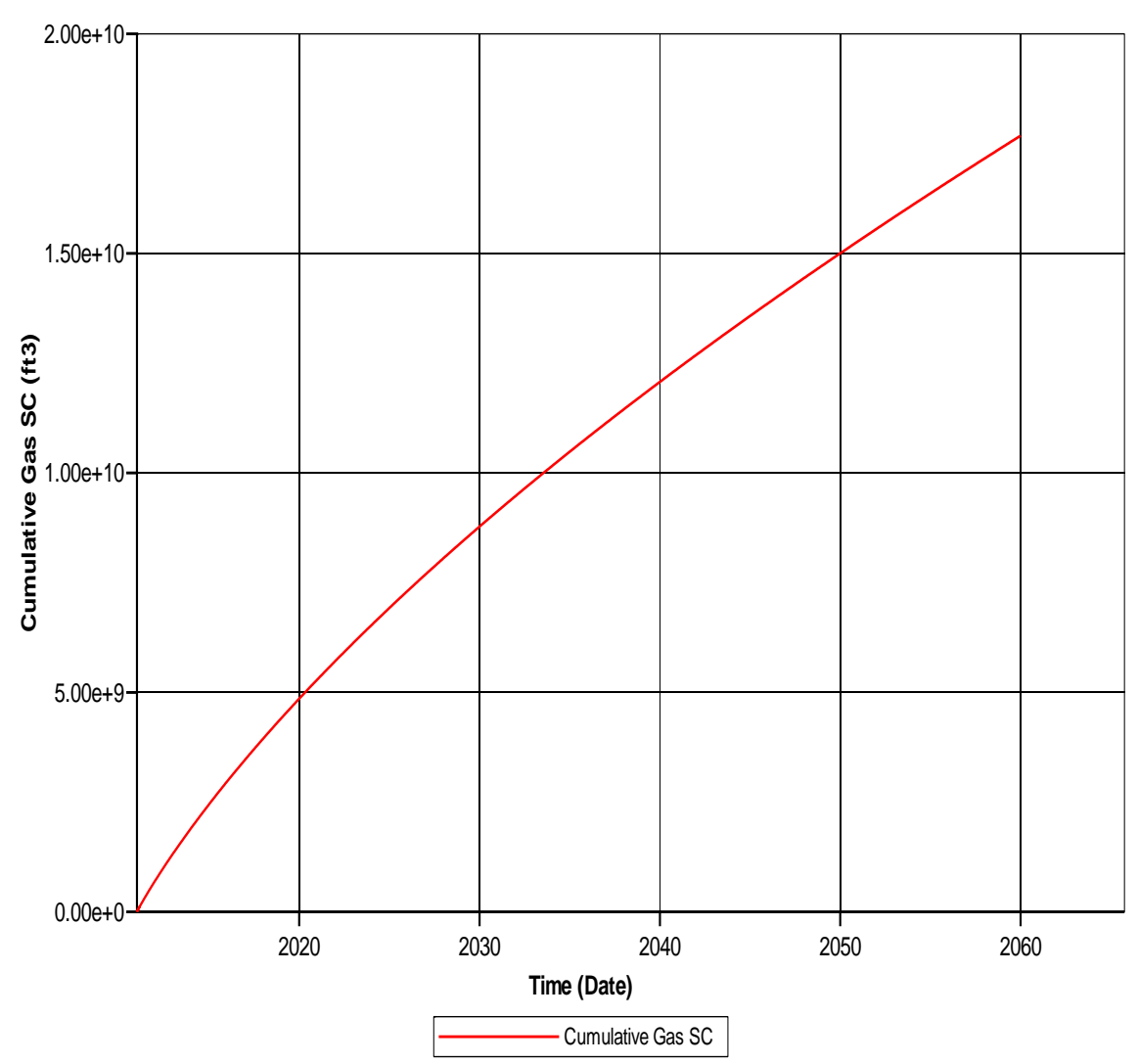

Figure D-8: Gas production from horizontal fracture well of 3600 from Run\#8 
Well-1 edou_update_9horizontal fracture.irf

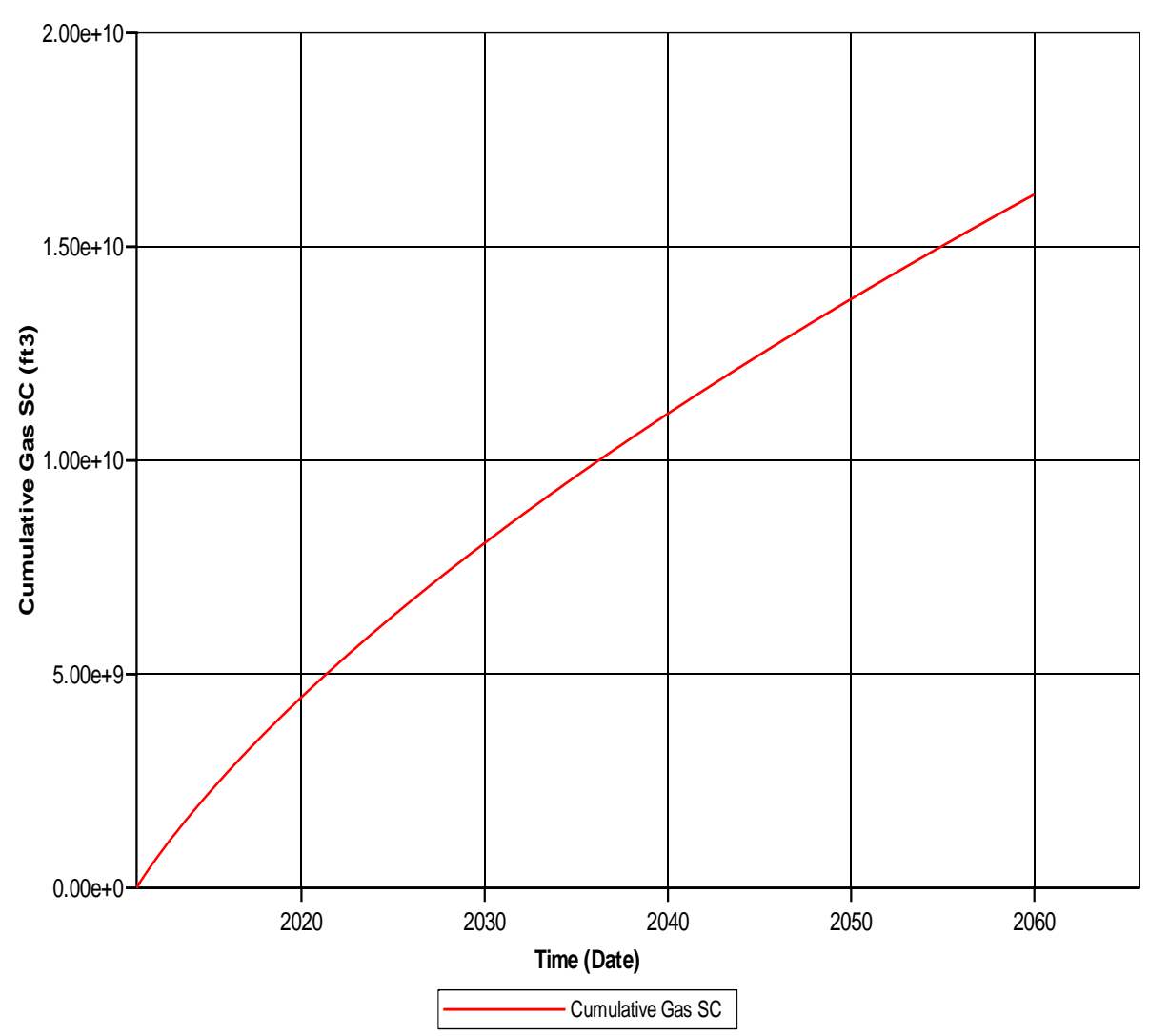

Figure D-9: Gas production from horizontal fracture well of $3600 \mathrm{ft}$ from Run\#9

\begin{tabular}{|l|l|l|l|}
\hline$\#$ & Item & Units & Value \\
\hline 1 & Tolal oil in place & STB & 0.0000 \\
\hline 2 & Tolal water in place & STB & $0.23284 \mathrm{E}+08$ \\
\hline 3 & Tolal gas in place & SCF & $0.22849 \mathrm{E}+12$ \\
\hline$\#$ & Item & Units & SECTOR -0 \\
\hline 1 & HC. Pore Volume & M RBBL & 91970 \\
\hline
\end{tabular}

Figure D-10: Summary of initial hydrocarbon in place 